Rhode Island College

Digital Commons @ RIC

Master's Theses, Dissertations, Graduate

Master's Theses, Dissertations, Graduate Research and Major Papers Overview

Research and Major Papers

2015

\title{
A Pre-Service Art Educator's Explorations of Design Education
}

Emily Woratzeck

Rhode Island College

Follow this and additional works at: https://digitalcommons.ric.edu/etd

Part of the Art Education Commons

\section{Recommended Citation}

Woratzeck, Emily, "A Pre-Service Art Educator's Explorations of Design Education" (2015). Master's Theses, Dissertations, Graduate Research and Major Papers Overview. 136.

https://digitalcommons.ric.edu/etd/136

This Thesis is brought to you for free and open access by the Master's Theses, Dissertations, Graduate Research and Major Papers at Digital Commons @ RIC. It has been accepted for inclusion in Master's Theses, Dissertations, Graduate Research and Major Papers Overview by an authorized administrator of Digital Commons @ RIC. For more information, please contact digitalcommons@ric.edu. 


\title{
A PRE-SERVICE ART EDUCATOR'S EXPLORATIONS \\ OF DESIGN EDUCATION
}

\author{
A Thesis Presented \\ By Emily Woratzeck
}

Approved:

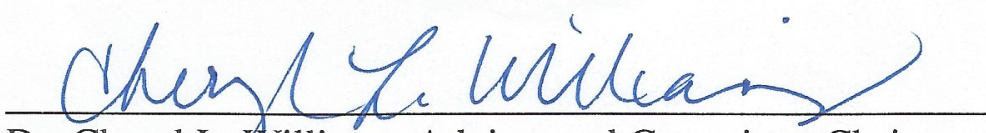
Dr. Cheryl L. Williams, Adviser and Committee Chair

Juti H th

Droulie Horwitz, Committee Member

Johan van Aswgen, Committee Member

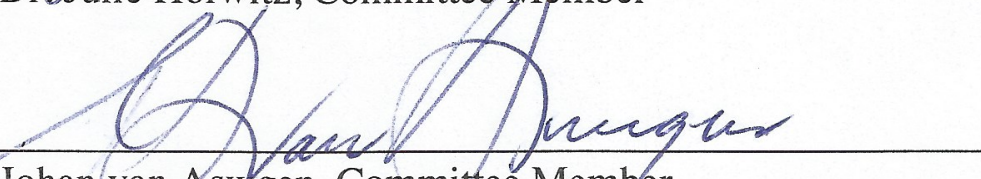

Lancy Berklrader

Prof. Nancy Bockbrader, Chair, Department of Art

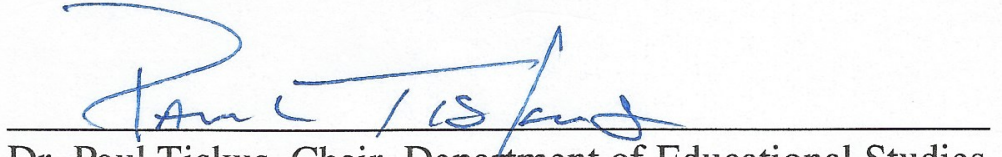

Dr. Paul Tiskus, Chair, Department of Educational Studies

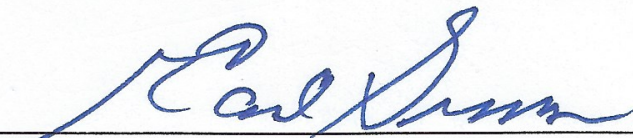

Dr. Earl Simson, Dean, Faculty of Arts and Sciences



Dr. Donakd Halquist, Dean,

Feinstein school of Education and Human Development



Dr. Leslie A. Schuster, Interim Dean, Graduate Studies



$\frac{5 / 20 / 15}{\text { Date }}$

$\frac{\cos / 20 / 2015}{\text { Date }}$
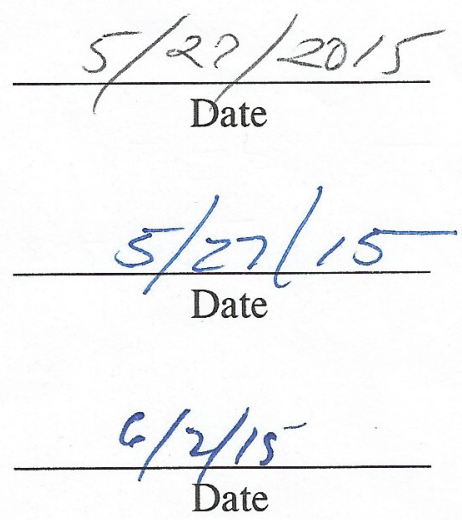

$\frac{M y 292015}{\text { Date }}$

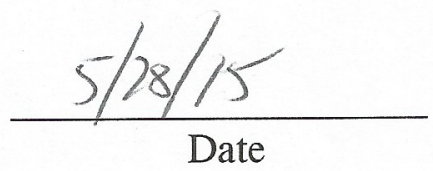




\title{
A PRE-SERVICE ART EDUCATOR'S EXPLORATIONS OF DESIGN EDUCATION
}

\author{
By \\ Emily Woratzeck
}

\begin{abstract}
A Thesis Submitted in Partial Fulfillment
of the Requirements for the Master of Arts in Teaching in Art Education Department of Art

Faculty of Arts and Sciences

Rhode Island College

2015
\end{abstract}


Copyright by

Emily Woratzeck

2015 


\begin{abstract}
This research was meant as an exploration of design education from a variety of angles. These investigations informed me, a pre-service art educator, in how I can teach design within my curriculum as well as advocate for design education in my professional career. I focused on two aspects of design: designed products representing the human made world that surrounds us, sometimes referred to as applied arts; and the design process, or design thinking, a reflective process. In an attempt to get a full view of the importance of and applications for design in the art education classroom, I researched through both literature and practice.

This research process began with a literature review that sought to name my own definitions of design and explore its relationship with art and education. This literature, as well as my personal experiences designing, fueled the planning and implementation of a qualitative teacher action research project. The project was based on the question "what happens for the teacher, the students, and myself when I teach a unit on design and the design process?" Through a reflective process and triangulation of data from this project, I began to identify my interests in the importance of learning about design and the importance of teaching the design process as a tool to students.

While there were many outcomes and findings in this research project, it also spurred questions. A secondary literature review more deeply investigated the history of design within art education, as well as some of the current work advocating for design presented at the National Art Education Association (NAEA) 2015 convention. I observed that there is a deeper history of research about design
\end{abstract}


as products within art education movements, like the Industrial Drawing movement and the Owatonna Project, but less research about using the design process as a tool for student learning. This inspired further digging and analysis of different ways to apply design in the classroom.

I was able to apply and reflect on three additional lessons during my student teaching that focused on teaching the design process. The elementary lesson, where students designed a chair, focused on exposing young students to design and exploring though brainstorming. The other two lessons were implemented at the high school level. These allowed me to see how students would invest in two lengthy design projects. One was based on lighting design and involved students testing and manipulating materials to come to a design solution; the other focused on presenting, collaborating, and reflecting on ideas in the actual process of designing to create a wallpaper design that changed the mood of a room.

The conclusion of this research fuels the beginning of additional research, both personal and professional, regarding the importance of design education. The major outcomes that inspire additional exploration are: the design process promoting student ownership over learning; the design process as a visual history of ideas as both a tool for teachers and students; connecting students to the designed world; and teaching a reflective process such as the design process to promote student independence. The insights gained relating to these topics are meant to be applied to the specific context they were learned, but the implications of these important ideas are meant to inspire further explorations personally and within the art education and education fields. 


\section{DEDICATION}

I would like to dedicate this thesis project to Ross Lenzing, who encouraged me to become an art teacher and stuck with me along the way. 


\section{ACKNOWLEDGMENTS}

I would like to offer my sincerest thanks to my committee members - Dr. Cheryl Williams, Dr. Julie Horwitz, and Johan Van Aswegen - for their guidance, enthusiasm, and efforts into making this thesis possible. These three individuals taught me more than I can say. Each provided unique perspectives that enhanced my thesis experience, and I will be forever thankful.

I would also like to acknowledge the wonderful art teachers I worked with throughout the year in both my research project and student teaching placements. All three of these teachers generously allowed me into their classroom, invited me to work with their students, and gave me valuable guidance.

Additionally, I would like to thank the students for teaching me more than I could have imagined. Their hard work, creativity, imaginations, and personalities not only made this thesis possible, but also enriched my life. These students taught me how to be a better teacher. 


\section{TABLE OF CONTENTS}

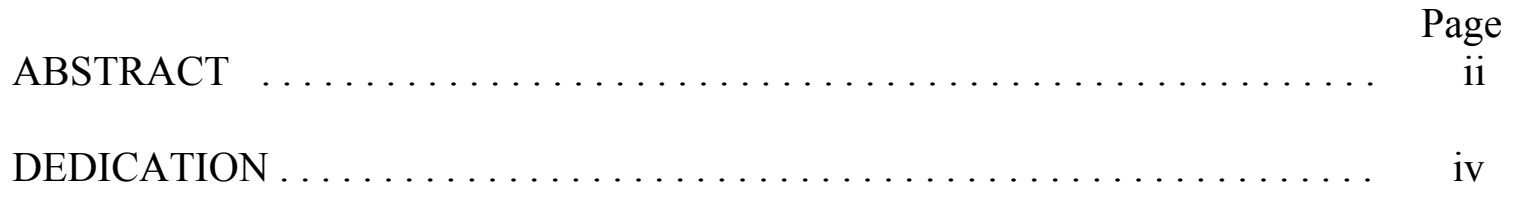

ACKNOWLEDGMENTS. . . . . . . . . . . . . $\ldots \ldots \ldots \ldots$

LIST OF FIGURES $\ldots \ldots \ldots \ldots \ldots \ldots \ldots \ldots \ldots \ldots \ldots \ldots \ldots \ldots \ldots \ldots$

\section{CHAPTERS}

1. INTRODUCTION $\ldots \ldots \ldots \ldots \ldots \ldots \ldots \ldots \ldots \ldots \ldots \ldots \ldots \ldots \ldots \ldots$

2. TEACHER ACTION RESEARCH PROJECT ............ 6

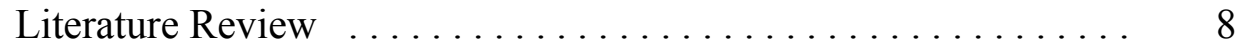

Methodology $\ldots \ldots \ldots \ldots \ldots \ldots \ldots \ldots \ldots \ldots \ldots \ldots \ldots \ldots \ldots \ldots \ldots \ldots$



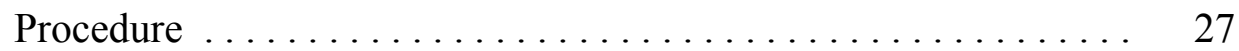

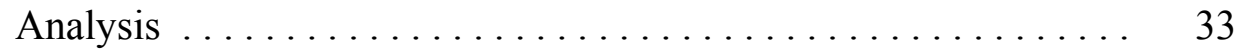

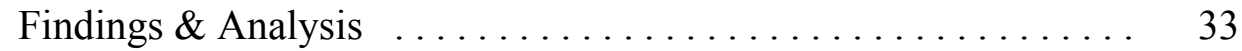

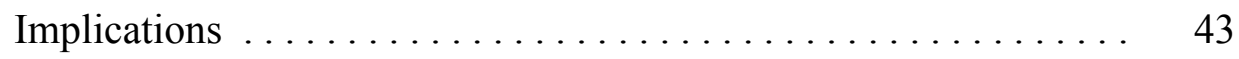



3. DESIGN IN ART EDUCATION: PAST \& PRESENT . . . . . . . . 46

Art \& Design in Everyday Life $\ldots \ldots \ldots \ldots \ldots \ldots \ldots \ldots \ldots .47$

Industrial Drawing Movement $\ldots \ldots \ldots \ldots \ldots \ldots \ldots \ldots$ 


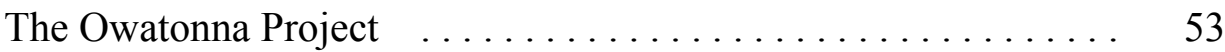

Additional Influences $\ldots \ldots \ldots \ldots \ldots \ldots \ldots \ldots \ldots \ldots \ldots$

Design in Contemporary Art Education $\ldots \ldots \ldots \ldots \ldots$

Final Thoughts ....................... 63

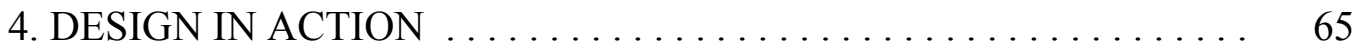

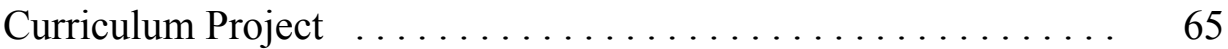

Student Teaching $\ldots \ldots \ldots \ldots \ldots \ldots \ldots \ldots \ldots \ldots \ldots \ldots \ldots$



5. CONCLUSION \& REFLECTION $\ldots \ldots \ldots \ldots \ldots \ldots \ldots \ldots \ldots \ldots$

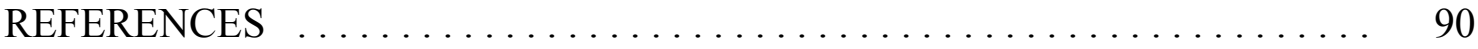

\section{APPENDICES}

APPENDIX A: PRELIMINARY TEACHER INTERVIEW . . . . . . . . 94

APPENDIX B: PRELIMINARY STUDENT SURVEY . . . . . . . . 95

APPENDIX C: DESIGN UNIT $\ldots \ldots \ldots \ldots \ldots \ldots \ldots \ldots \ldots \ldots$

APPENDIX D: OBJECT INVESTIGATION SHEET . . . . . . . . . . . . . 104

APPENDIX E: BRAINSTORM SHEET . . . . . . . . . . . . . 105

APPENDIX F: REFLECTION SHEET . . . . . . . . . . . . . 106

APPENDIX G: FINAL STUDENT SURVEY . . . . . . . . . . . . . 107

APPENDIX H: FINAL TEACHER INTERVIEW . . . . . . . . . . 108

APPENDIX I: THE LETTER CHAIR LESSON $\ldots \ldots \ldots \ldots$. . . . . . . . . . 109

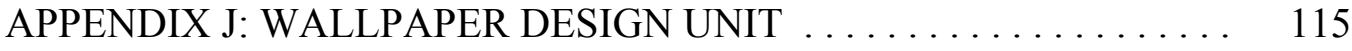

APPENDIX K: LIGHTING DESIGN LESSON . . . . . . . . . . . . . . . 127 


\section{LIST OF FIGURES}

1.1-1.7 Personal Work, Personal Design Process - Chair Project ........... Page

2.1-2.5 Student Work, Re-Design Process Images . . . . . . . . . . . . . . . 32

3.1-3.9 Student Work, Chair Design Process Images . . . . . . . . . . 76

4.1-4.9 Student Work, Wallpaper Design Process Images . . . . . . . . . . . . . . 79

5.1-5.9 Student Work, Lighting Design Process Images . . . . . . . . . . 82 


\section{CHAPTER 1 \\ INTRODUCTION}

I began my undergraduate studies at the Rhode Island School of Design (RISD) in the Painting Department, and I proceeded to graduate four years later with a Bachelor of Fine Arts in furniture design. During my first year at RISD I was exposed to new opportunities for creative inquiry that I had not previously been aware of, opportunities in design. I distinctly remember asking others and myself why I had not previously been aware that things like furniture design, textile design, graphic design, or industrial design existed as fields of study and possible career paths. Before that point, since as long as I could remember, the only application for pursuing art for me had been painting and the fine arts. After learning about design and the design process from RISD and working as both a product and graphic designer for three years, I see the importance of illuminating the beauty and complexity of our designed environments. This is part of what drove me to study art education at Rhode Island College and has since developed into my belief that design should be promoted in K-12 art education programs. My past inspired me to pursue a thesis that explores the what, how, and why of design on a deeper and educational level. My goals for this thesis project were to learn how I could emphasize and effectively teach design and the design process, and advocate for design education in my career as an art educator. 


\section{PERSONAL DESIGN PROCESS - CHAIR PROJECT}

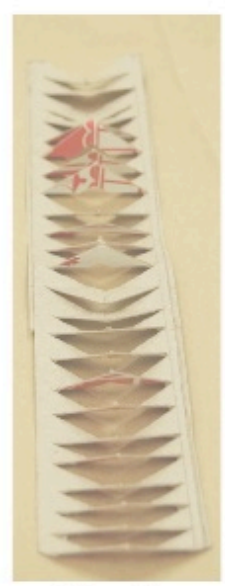

Figure 1.1

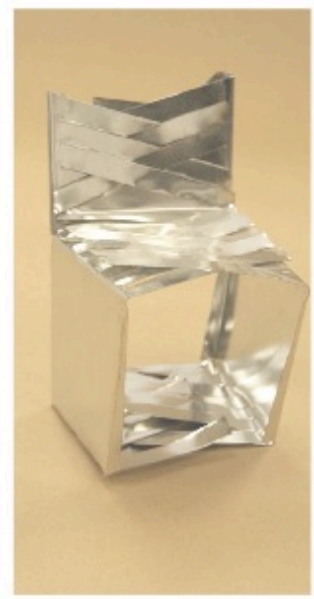

Figure 1.5

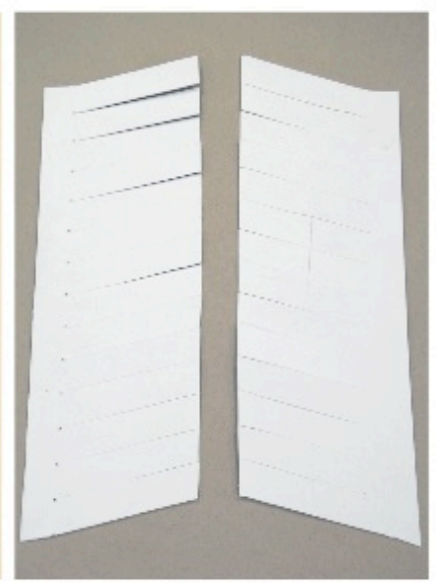

Figure 1.2

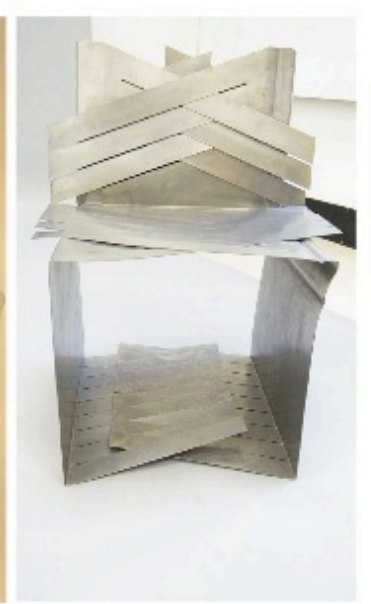

Figure 1.6



Figure 1.3

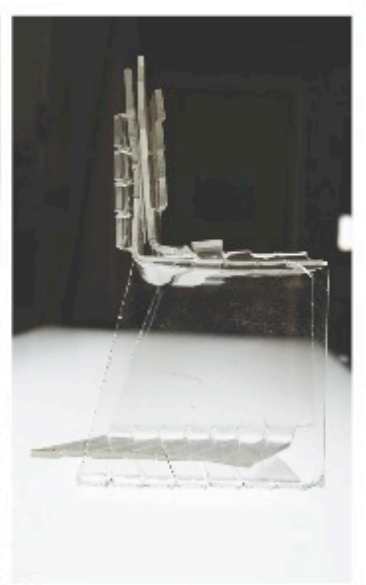

Figure 1.4

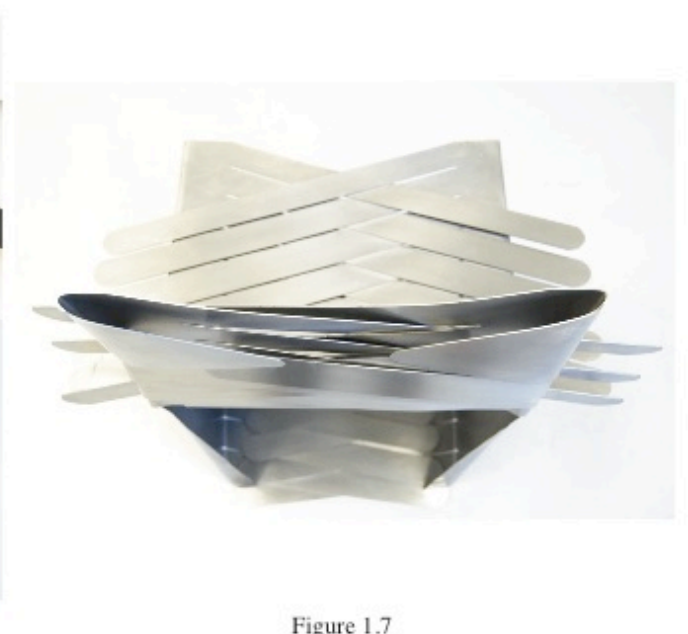

Figure 1.7

Figures 1.1-1.7: These images are an example of some of my personal design work. They represent a selection of stages in the design process where I created a prototype for a steel chair. My journey was influenced greatly by material exploration, where I went from creating in plastic (Figure 1.3) to metal (Figure 1.5).

I began my journey by investigating a mixture of literature written about design, design education, the design process, educational psychology, and art education. In response to my readings, I reflected both on the ideas I learned and also my experiences 
learning to design. The literature helped me define what I view as design and the design process, as both of these terms are debated and have multiple meanings. I was also able to explore the history of art, craft, and design and reflect upon how they affected one another and how this carried into the view of these fields today. The compilation of this look into the literature, along with my thoughts and reflections drove me to pursue creating and implementing a research project. With the help of my professor, Dr. Julie Horwitz, and her suggestion for locating this research within the qualitative teacher action research field, I learned about and implemented an extensive research project detailed in Chapter 2.

From my analysis of and reflection on this research project, I developed more questions and was driven to further research the relationship of design within art education. While there is a long history between these two fields, I focused a second literature review on more influential historical movements within the field of art education that I believe relate significantly to today's view of design: the Industrial Drawing Movement and the Owatonna Project. Additionally, during the time that I began researching design education, the National Art Education Association began embracing design and even held their 2015 National Convention around design as a theme. While I was unable to attend, I was able to procure information about several of the convention presentations regarding some of the current research happening in art education around design. My investigation of past and present design education initiatives, which I present in Chapter 3 helped me to better situate my interests in design in relation to the design research community. 
Spurred by my research project and additional literature review, I took some of my theories into practice through the creation of a K-6 curriculum and implementation of various design lessons during my student teaching. In Chapter 4, where I apply some of my ideas about design education and put them into action, I was able to reflect, learn, and observe how I could potentially teach design in my future classroom. First, I imagined how I could break down the design process and balance a curriculum for K-6 students that equally promotes art and design. I was then able to create lessons based on design concepts and the design process that I researched for both elementary and secondary students, implement them, and reflect on them. The opportunity to do this especially helped me define myself as a teacher and gave me even deeper insights into the importance of design education.

My research was driven by multiple broad questions. These questions will not be answered in my thesis, but inspired and drove me throughout my thesis project. They begin with: is design currently being taught in $\mathrm{K}-12$ art education programs?; how is design being taught?; is the design process being taught?; and how much design is taught in comparison to art? In preliminary investigations for my thesis, I found some statistics that support my belief that design may be taught in some art education classrooms, but not equally to art and not including the design process. A close look at the National Visual Arts Standards in the new National Core Arts Standards reveals this. These standards are only partially inclusive of design and hardly mention the design process. I understand that these standards do not represent what is happening in every art classroom throughout the country; however, it is clear that while design does exist in art education, the emphasis placed on design is unequal to art. I will discuss this in further detail in 
Chapter 2. Additional overarching questions that have inspired my research but that cannot be answered in the scope of this project are: where does design occur in art education?; does the design process occur even though it is not stated?; and why is there not more focus on design in K-12 art education?

To summarize, for my thesis project, I have researched the topic of design education from multiple angles in multiple literature reviews, a qualitative teacher action research project that investigates student and teacher responses to including design and the design process, and through practice in my student teaching placements. It is the beginning of my own discovery and reflective teaching practice that will change and develop over time as I continue to learn and grow. It is a reflection of my own learning and insights as an art and design educator, and while it brings up important ideas for other art educators to consider, it does not claim to apply new discoveries to the broad world of art education. Rather, and most importantly, it is a reflection and investigation of the variety of contexts in which I was teaching. This thesis serves as a personal exploration and journey that will fuel research throughout my career as an art educator. 


\section{CHAPTER 2}

\section{TEACHER ACTION RESEARCH PROJECT}

Helvetica is a common typeface; it is the default for all Macintosh computers, was created in 1950 (Kupferschmid, 2011), and stars in its own film, Helvetica (Hustwit, 2007). This typeface, or font, is something many of us use every day without thinking to write papers, emails, thoughts, and work; yet it has a story of its own to tell. The story lies in its design, and this story could be told for almost anything that humans have ever made including: the clothes we wear, the computers we use, the cars we drive, the chairs we sit in, even the tube our toothpaste comes in. All of these things exist because they were developed, investigated, drawn, modeled, and tested by people - designers. The story of objects is something referred to as the design process, and it can take months or sometimes years to be told. It is a tale often hidden in plain sight because, it is part of all things in the human made environment. The designed world is a place we all live in, but it has become almost so common that we forget it is there. As a future art educator, I am interested in bringing this designed world and the stories it has to tell to light.

As an undergraduate, I studied furniture design at the Rhode Island School of Design (RISD). This exposed me to the world of design and asked me to think about design every day. It changed my perception of where and how I live. Learning and using the design process, or the story of objects, changed how I think. My positive experience 
with design has made me interested in promoting the design world within art education. Design has historically had a home within art education at varying degrees of importance, but I am interested in advocating for its importance in inclusion in all classrooms at all age levels. The world of art education in the United States is currently embracing design more as shown by the National Art Education Association devoting its 2015 National Conference to the subject. I am interested in contributing to this conversation and understanding how the practice of teaching design and the design process affects students. I decided to do this study as a pre-service art educator to learn how I could promote and effectively teach design and the design process in my future career.

This chapter presents my path from developing a teacher action research project to executing it. It begins with a literature review that contextualizes the world of design and its relationship to art education, as well as details some of the learning styles that I believe design education promotes. I move on to explain the nature of my teacher action research project, along with the method in which I performed the study. The analysis and findings section uncovers three themes that were derived from the study: design, control, and confidence. In this section, I explain the themes, their relationship, and how they affected the participants in this study. Last, I explore what implications this study has for the Art Education field and myself as a pre-service art educator. Given its specific context and limitations, I discuss what trajectory I may take in researching this in the future, as well as what directions this study may lead others to investigate.

Overall, I hope to better understand and define what is valuable about teaching design and the design process. Design, in its nature, focuses on using new connections to 
innovate and create. It is my hope that this study will provide scaffolding for other educators to bridge design into their curricula.

\section{Literature Review}

\section{What is Design?}

The word design is complex because of its commonality in everyday use. Even when constraining the definition to an academic context, there are multiple meanings and complexities. Charman (2013) explains, "as an attribute of almost everything in the material world, it eludes easy definition" (p. 121). Within this study, the word design means two different things. Lawson (2003) in his introduction to How Designers Think describes this division noting, "that 'design' is both a noun and a verb and can refer either to the end product or to the process" (p. 4). Both the product and process definition of design are used in this study and will be explained below. However, one definition encompasses both the product and the process of design and lays an underlying structure for the argument of design's importance explored in this study. The following definition of design is from Montana-Hoyos and Lemaitre (2010):

The planning and creation of an artificial (human-made) product (understanding by product a service, system, space or object), driven by problem-solving to fulfill human necessities (of utility, comfort, beauty, emotion and communication, among others). In summary and over-simplifying it, we could say that design as a human activity is mainly our conscious action to modify our environment and create the artificial world. (p. 15)

Montana-Hoyos and Lemaitre's (2010) definition of design is important in this study, because it humanizes design as an innovative practice that humans naturally practice. 
Design is not foreign or but part of human nature, and it can be as simple as choosing the clothing you wear, because that clothing choice modifies your environment. It is something anyone can participate in and enjoy. Design is part of being human.

\section{Product}

Design, as a product, in Montana-Hoyos \& Lemaitre's (2010) definition, is inclusive, cited as "a service, system, space or object" (p. 15). Seeing design as more than just a physical object is valuable to realize the ingenuity that surrounds everything. Heskett (2001) explains that there are "different professional subcategories of design, such as architectural design, engineering, computer, product, industrial, graphic, communication, information, interior, and so on" (p. 18). Many types of design involve multiple facets of design. In architecture, for example, the end goal is to design one building, but there are thousands of things that need to be taken into consideration both in the interior and exterior of the structure that equate to many different design challenges. For example, the overall form of the Guggenheim Museum is a tall cylinder. When Frank Lloyd Wright designed the Guggenheim Museum in New York his "spiral ramp design was meant to enhance the viewer's experience of consecutive exposure; the visitor was supposed to take the elevator to the top and walk down the ramp" (Shiner 2001, p. 280). Wright solved not only the challenges of the physical presence of the museum building, but the system for the activity of viewing artwork inside.

What design products all have in common is a balance of utility and significance. Explained by Pink (2006):

A graphic designer must whip up a brochure that is easy to read. That's utility. But at its most effective, her brochure must also transmit ideas or emotions that 
the words themselves cannot convey. That's significance. A furniture designer must craft a table that stands up properly and supports weight (utility). But the table must also possess and aesthetic appeal that transcends functionality (significance). (p. 70)

All designs have these two aspects: an ability to be used and an ability to have meaning. Sometimes the use is physical, like the table, but other times it is more abstract, like the communication in the brochure. The meaning or significance of the object may be in a visual form, such as the "aesthetic appeal" of the table or appealing to another sense. Sudjic (2009) explains that design "is also about making objects that feel good to touch and use" (p. 32). It is the utility that people need, but the significance that people want. In Sudjic's (2009) book, The Language of Things, he describes his experience choosing between two models of Apple laptops. "Even though its slightly higher specification made it more expensive, I knew as soon as I saw it that I would end up buying it. The black version looked sleek, technocratic and composed" (p. 17). Sudjic displays here how his want for the aesthetic appeal, or significance, of this laptop ruled out the logic that it was the more expensive of the two. It is not surprising then that design has become a valued part of almost any industry. The designer's job is to create designs that are useful but are differentiated by significance or consumer appeal. For example, Norio Ohga, a former chairman of Sony, stated, "at Sony, we assume that all products of our competitors have basically the same technology, price, performance, and features. Design is the only thing that differentiates one product from another in the marketplace" (Pink, 2006, p. 78). Design's definition now includes a reason behind the purchase or use of the systems, objects, and spaces around us. Design is such a huge part of our daily lives, and it should not be taken for granted and deserves more space and focus in curriculum. 


\section{Process}

"Design is one of the basic characteristics of what it is to be human," says Heskett (2002, p. 4) in his book Toothpicks and Logos. All humans practice some form of design every day when they change or modify their environment. To design within the world of design takes this modification to the next level. A designer thinks not only of "how things are but how they might be" (Charman, 2013, p. 127). The designer is constantly questioning the world around her asking what if? Design "links creativity and innovation. It shapes ideas to become practical and attractive propositions for users and consumers" (Charman, 2013, p. 122). Design is both creative in its initial idea but then more practical in how these ideas relate to the world and become usable. Like the utility and significance of design as product, design as process has a similar balance. The creativity and innovation to modify one's environment is combined with a process to come to a usable solution practiced by designers. Though this process may vary slightly from person to person, there is a common thread in how designers describe the design process. Lawson's (2005) definition of the design process, "a constant cycle of analysis, evaluation, and synthesis" (p. 40) best describes this commonality and is used as an overarching definition in this study.

This process takes creative ideas and refines them into a product through research, assessment, and creation. Another way to think of this is taking something rough or raw and slowly crystallizing it as a core solution or idea (Dorst, Kees \& Cross, 2001). The design process is cyclical, but it has definitive steps. If it were to be a line, it would be one that looped back on itself in many ways but still had a directional trajectory. A more step-by-step breakdown of the process is given by educators Vande Zande, Warnock, 
Nikoomanesh, and Van Dexter (2014) in Art Education as a six-step process: "define the problem," "investigate and research," "generate ideas," "make the prototype," "present," and "evaluate and revise" (pp. 20-26). With this definition, it is clearer that while a big part of the design process is thinking and brainstorming, equally important are making a prototype, in other words trying the idea out. Once the prototype is created the designer and others evaluate its strengths and weaknesses and take them into account for revision. Designers are creating something new, but they are always testing, reflecting, and revising to perfect their ideas.

\section{Design and Art}

Becoming a designer usually begins with pursuing a Bachelor of Fine Arts or B.F.A. Most art schools or art programs within larger universities have B.F.A. programs focused on specific types of design such as graphic design, industrial design, or fashion design, along with fine art courses such as painting, drawing, and sculpture. This illustrates the close relationship and even overlap between the two fields. However, this relationship is not entirely equal. Most people know who Picasso was, but not as many could say what Eames was famous for. Design is so closely tied with art, yet they are still very separate, and this relationship exists because of each field's history. The history of this relationship begins in the Middle Ages. Schrijver (2012) describes this relationship as follows:

In classical times there was a hierarchy dividing intellectual and manual activities. During the Middle Ages this division developed into the concept of the seven liberal and the seven mechanical arts. The artes liberals composing of grammar, rhetoric, dialectics, mathematics, geometry, astronomy, and music were deemed to be superior to the artes mechanicae: weaving, arms and armour production, navigation, agriculture, hunting, medicine and acting. Strange as it may seem to 
us now, but due to their applications painting, sculpture and goldsmithing belonged to the category of 'arms and armour production. (p. 7)

What Schrijver is explaining is, in this time period, what we now think of as fine arts, painting and sculpture, were thought to be much more functional and thus related to "manual activities" rather than "intellectual" activities. Painting and sculpture, at this time, were used to document and record events and people. A painter was a position that the wealthy would hire someone for, and this person would paint what his or her employer wanted to record. These activities were also closely associated with the actual physical labor of painting or sculpting, and this was something working class people did.

While the division of intellectual versus manual stays the same, the activities in these categories change. In the early nineteenth century:

'Art' was no longer simply a generic term for any human making and performance, as understood by the old system of art, nor even shorthand for the category of Fine Art constructed in the late $18^{\text {th }}$ century but had become the name of an autonomous realm and transcendent force. (Shiner, 2001, pp. 194-195)

Art became associated with something more than just making, acquiring associations with the spiritual realm. It was these ideas that began to move art from a manual activity to an intellectual activity. This formed the more "modern ideal of the artist as genius" (Shiner, 2001, p. 200). Now, "the painter was no longer the righteous craftsman true to age-old traditions; but an independent creator, who did what he himself thought to be right" (Schrijver, 2012, p. 15). The artist as a genius is very similar to how we view artists today. The famous painters like Monet, Van Gogh, and Picasso are revered now because of their artistic and creative genius. They were thought to possess something special and almost magical in their ability to create paintings. Based on my reading, it 
seems that this view of art disassociated it from the manual and functional activities that are involved in making it and moved art to a higher status of intellectual activity.

"The fine arts, it was now said, are a matter of inspiration and genius and meant to be enjoyed for themselves in moments of refined pleasure, whereas the crafts and popular arts require only skill and rules and are meant for mere use or entertainment" (Shiner, 2001, p. 5). As "refined pleasure," the fine arts are for those who have a concern for taste and aesthetic. The people who have the means and time to view, write, and talk about art are those in the upper class. Craft objects, things associated with "mere use," were thought to require no intellectual ability to create, just manual skill and rule following. These objects were also part of the popular culture and affordable to most. Many people could afford common household items. Even though the elite were able to afford lavish editions of these objects, the making and availability ties craft down to a lower status. Design as a functional entity grew out of the world of craft and now carries with it the ghost of craft's history. When Schofield (1995) deliberates, "perhaps it is because the nature of design is primarily functional that it has been taken for granted so long” (p. 66), she is on to something.

This means that while art has been revered as the work of geniuses, craft and design, or folk art and applied art, have not had a history of being studied with the intense deliberation of art. In Charman's article, she depicts art and design's relationship, quoting Sudjic, "whereas the shelves are crowded and creaking under the weight of art criticism, there is space aplenty for similar insightful writing about design" (Sudjic, as cited by Charman, 2013, p. 127). Design and craft have been focused on in the contemporary art world, but even within the current information, "the majority of writing about design in 
blogs, magazines and exhibition review, is that it is too journalistic and promotional in flavor - that is, too related to design's commercial context and goals - to be genuinely critical" (Charman, 2013, p. 126). Charman is saying that the context of the writing about design is the problem. I understand this to me that instead of being written by art critics or art historians researching at colleges or universities, the majority of writing about design comes from people practicing in the field without the collegiate stamp of approval. The underlying structure of the relationship between art and design, or the genius and the useful, even influences the way scholars view writings on design as less valid than those by art critics. The art and craft split is still relevant in today, and while boundaries that have been created are being shaken by some, how art is taught to the public within K-12 schools seems closely tied to this history and likely contributes to the smaller emphasis on design within these programs.

\section{Design and Art Education}

"Where is Design in the K-12 Curriculum? (And Why Isn't It Taught in Art Education Programs?)" are the questions that titled a 2013 article by Lozner, published by AIGA, the professional association for design. The two questions Lozner confronts us with are complex and complicated to answer. The first question is even beyond the scope of this study, as it deals with all types of education and not just art education. The second question, though more specific, is also something almost impossible to know, because there is no nationwide mandated curriculum for art education. Every state has a say in how they teach art and even within states. often the curriculum varies from district to district. While much of the answer to Lozner's second question is a result of the 
relationship between art and craft detailed in the section above, there are other factors within the field of Art Education that have influenced design's degree of inclusion.

To get a rough idea of what is currently being taught in Art Education, a good place to start is the most current 2014 National Core Arts Standards embraced by the National Art Education Association. These standards are not mandatory, but states may chose to adopt them. Reading through these new standards reveals that the word art (including artwork or artist) is used 243 times, while the words design (including designer or designs) is used 51 times. It is important to note that art and design were used together in statements such as "create works of art or design" 39 times, meaning that design came up alone in only 12 instances, while art was used alone in 204 instances. Additionally, out of the 15 anchor standards, only 1 focuses on design, and within that there is no mention of the design process. While a deeper answer to Lozner's question would be much more complex than simply looking at the current standards, these statistics underscore that while design does exist in Art Education, the current emphasis placed on design is unequal to art and does not include the design process. While there is a new push for the inclusion of design (e.g., the 2015 NAEA convention has chosen to focus on design) historically "design as an ideology is an under-researched area within the field of art and design education," said Schofield (1995, p. 65). This means that though the area has begun to be researched, there is a long way to go before knowledge about design education is equal to art education.

The focus of the current art education philosophy in the U.S. is a combination of three rationales: creative self-expression; comprehensive art education; and visual culture in art education (Day \& Hurwitz, 2012). Creative self-expression is primarily influenced 
by Viktor Lowenfeld who "combined a primary emphasis on the development of creativity with his theory of personality integration through arts activities" (Day \& Hurwitz, 2012, p. 17). This student-centered approach combines with discipline-based art education or DBAE that "emphasizes the art knowledge, skills, and understanding necessary for the general education of all students" (Day \& Hurwitz, 2012, p. 18) to form the main foundational philosophy for our current art education atmosphere. The phrase elements and principles of design, probably the most common use of the word design in art education, is closely tied to the DBAE content focus in art education. This phrase refers to aspects of a work of art or design such as: "line, texture, color, form, value, and space" (National Art Education Association, 1994, p. 32). This accounts for a strong use of the word design within art education, not as this study defines it, but in the elements and principles. The visual culture in art education aspect is "focused on the study of the visual culture, from mass media and advertising, that students experiences in their everyday lives" (Day \& Hurwitz, 2012, p. 18). Visual culture art education is a relatively newer shift that encompasses subject matter with complex concepts that art educators are still working to understand and use (Duncum, 2012). The more contemporary rationale of visual culture is most closely related to design and marks a shift in art education ideologies towards a more inclusive definition of art.

\section{Why Learning Design is Important}

So far, explanations of what design is, how it is used, its relation to art, and where it exists in art education have been discussed. With this foundational knowledge, the question "why argue for design education?" can begin to be understood and 
explained. In the President's Committee on the Arts and Humanities publication, Reinvesting in Arts Education: Winning America's Future Through Creative Schools (2011), Arne Duncan, U.S. Secretary of Education, states: “Today's workers need more than just skills and knowledge to be productive and innovative participants in the workforce. Just look at the inventors of the iPhone and the developers of Google: they are innovative as well as intelligent" (p. 1). In case there was any confusion, the individuals Duncan is referring to are designers, specifically software, systems, interface, and product designers. They used a design process similar to Lawson's (2005) above to design the iPhone and develop Google. Duncan is saying that innovating is essential for students to learn to contribute to the contemporary society we live in. Contributing to current society or future society without learning about design could have its problems.

In a world groaning under the weight of material culture with yet more objects being designed, produced, consumed, and discarded at a terrifying pace, Poynor's call for time-sensitive design criticism that is at once cognizant of, and situated within, the complexities of modern day life is directly and urgently relevant to teaching and understanding design today. (Charman 2013, p. 27)

I have come to believe that because design is all around us as an aspect of all physical things we use, teaching about the designed world exposes that the designs we make affect the world we live in. Designers of today and the future are thinking about complex problems like how to design with a more positive effect on our natural environment. As Pink (2006) states, "Good design can change the world. (And so, alas, can bad design.)" (p. 81). If Duncan wants our students to be innovative iPhone designers, then learning about the objects we design is one priority, and learning how to think like a designer, or the design process, is the other. 
Learning to design provides "a focus on innovation, creativity, critical thinking, problem solving, communication and collaboration" (Carroll, Goldman, Britos, Koh, Royalty \& Hornstein, 2010, p. 38). Teaching the design process would provide students with tools to be more inventive, so they potentially could design something like Google or the iPhone. The design process within education has been assigned the term design thinking. "Design thinking does not encourage students to jump to immediate solutions; instead, the focus is on exploring all aspects of problems through multiple sources and iterations" (Carroll, Goldman, Britos, Koh, Royalty \& Hornstein, 2010, p. 39). However, teaching design does not start and end with preparing students for the work force: the design process is a tool students can use in all parts of their lives. Vande Zande, Warnock, Nikoomanesh, and Van Dexter (2014) have a similar view of design education, where the design process provides "a framework for training students to identify and solve complex, multidisciplinary, open-ended problems that people routinely encounter in many situations" (p. 20). The design process is a tool that once learned can be taken out and applied in all aspects of a person's life.

The design process teaches problem solving as a framework to see failure and setbacks as opportunities to learn. Long (2012) writes, in an article about design thinking, 'I wanted to celebrate the words of Samuel Beckett: 'Fail, fail more. Fail better.' And I wanted to do so with an eye toward empowering students to thrive" (p. 17). I take Long's points to mean that the idea of failure is not a negative one in the design process because the goal of the cycle is to locate where the product is failing and fix it. The process is about constantly looking at a design and seeing what works, what does not work, and what would improve it. This makes finding where something fails a good thing, because 
it is an opportunity to learn. Embracing failure and moving forward to fix it are ideas currently being embraced by educational psychologists. Two current topics of conversation are grit and mindset. First grit, defined by Duckworth, Peterson, Matthews, and Kelly (2007), is "perseverance and passion for long-term goals. Grit entails working strenuously toward challenges, maintaining effort and interest over years despite failure, adversity, and plateaus in progress" (pp. 1087 -1088). Grit is thought to be something developed in people, not something people are born with (Duckworth, Peterson, Matthews \& Kelly, 2007). In the same vein, the idea of "resilience - or whether students respond positively to challenges - is crucial for success in school and in life," as presented by Yeager and Dweck (2012, p. 302) also addresses the idea of students overcoming obstacles. In Dweck's (2006) book Mindset: The New Psychology of Success, she talks about developing a growth mindset as "the belief that intelligence can be developed" (p. 245). Dweck (2006) discusses how people with growth mindsets tend to "embrace challenges, persist in the face of setback, see effort as a path to mastery, learn from criticism, and find lessons and inspiration in the success of others which results in them reaching higher levels of achievement" (p. 245). The point of presenting these current ideas is not to agree or disagree with them, but to present the idea that in order for a student to "persist in the face of setback" the student would need some sort of tool or framework. I believe that the design process could be one of these tools.

Where the research in this literature review ends, the purpose of my study begins. Design is such an important and multifaceted world. It is not possible, nor helpful, for me to attempt to investigate it from all angles. Thus, this study seeks to understand what happens when I teach design and reflect on my teaching experienes, which will be most 
helpful to me as a pre-service Art Educator. However, it is my hope that my experiences and findings in this study are the beginning of my own conversation about design education.

\section{Methodology}

In an educational environment that is often cutting back on art programs, teaching design is an opportunity to connect the creative learning found in art and design directly to the contemporary world. The world of art education is currently beginning to embrace teaching and understand design, but because of its historical lack of focus on design education, now it is more important than ever to add to the research. Design needs to be taught in more schools, to all ages, and through more research projects, to show how it benefits students. Design needs to be inserted into more curriculums, so all students have access to learning it. The nature of this study is then embedded in the theories of democratic schooling, which is presented by Noffke and Stevenson (1995) as, "what many who advocate greater democracy in schooling share is a sense that what exists is not what ought to be” (p. 8). Noffke and Stevenson's (1995) statement is about identifying what changes would benefit the education of students and then making those changes. My goal of researching teaching design is to investigate how it affects a specific group of students in a specific context to hopefully support that teaching more design is a change that needs to be made in our schools. 


\section{Qualitative}

By situating the first steps of my study in the category of qualitative research, I am able to explore and analyze what I find as I find it rather than trying to prove something I already think. This means that while I have some thoughts of what outcomes this study may have, unlike quantitative research, I am not going into the study attempting to prove or disprove a hypothesis. For this reason, I have chosen the research question: "What happens for the art teacher, the students, and myself when I teach a design unit in an elementary art education classroom?" True to the category of qualitative research, "this is an open-ended, general statement identifying the area of interest" (Anderson, Herr, \& Sigrid Nihlen, 1994, p. 114). The broadness of my research question allows room for discovery promoting inclusiveness of findings rather than exclusiveness. This allows the space for more to be learned about the impact of teaching design.

While the research question is broad, the findings are specific to the context of the school and the population of the students. "Qualitative research does not seek to generalize one study to all other similar studies; instead it seeks to explain behavior in one setting, which, if it reminds the reader of his or her own setting, has been successful" (Anderson, Herr, \& Nihlen, 1994, p. 110). The findings of this study will only claim to explain what has happened for the group of participants I studied. While it may suggest further research in other areas, it does not attempt to apply the outcomes to the world of art education. However, this study does strive to inspire and drive more research surrounding the subject of design by providing information and conclusions that generate questions and further implications. The hope is that more studies created in this line of questioning will inspire change and action. However, this action starts with one group of 
participants in a specific school environment defined as teacher action research and explained below.

\section{Teacher Action Research}

So much research is done on schooling in the United States; yet so little of it is based on studies involving the perspective of the students, teachers, administrators, counselors, special subject teachers, nurses, psychologists, cafeteria workers, secretaries, school crossing guards, bus drivers, parents, and school committee members, whose individual and collective experience constitutes schooling. (Seidman, 1991, p. 4)

This research took place in a real world, elementary art education classroom and adds to Seidman's (1991) description of the collective experience that constitutes schooling. Using a natural setting as a laboratory, rather than attempting to create a completely controlled environment, is a defining quality of qualitative research. More specifically, that this research was done in a school setting defines it as teacher action research (Anderson, Herr, \& Sigrid Nihlen, 1994). The nature of performing this research in the classroom context gave me, "the researcher a sense of immediacy and depth of understanding by virtue of his or her position and by the chosen research paradigm" (Anderson, Herr, \& Sigrid Nihlen, 1994, p. 111). As a pre-service teacher researcher, my experience of what happened during the unit, and how my role as teacher in influenced it, became tied to the findings and outcomes of the study. It also generally benefited my understanding of how to improve my teaching, which is learning that would be lost in another type of research. Additionally, as a teacher and researcher I was able to view my data from multiple perspectives, another benefit of practicing teacher action research. Being an active part of the lesson, as the teacher, allowed additional insights into the 
causes and effects of the unit, as well as a concentration on studying my own teaching practice.

A guiding objective of this research was to better understand, improve upon, and situate my current practice (Noffke \& Stevenson, 1995). By teaching my unit on design, I came to understand how better to teach design, how better to teach students in general, and how better to teach the students in the specific context of my research classroom. The improvement of practice is part of naming teacher action research as my methodology. In an article from Zeichner and Gore (1995), the authors cite Biott (1983) and Rudduck (1985), saying:

Action research into the preservice teacher education curriculum has stressed the importance of establishing habits of "self-monitoring" during initial training so that teachers can enter the profession with the dispositions and skills that will enable them to continue to learn from experience and become better at teaching throughout their careers. ( $p$. 113)

I hope to establish and build the self-monitoring practice into my everyday teaching practice, and the reflective process of this research allows me to accomplish this.

The influence of reflection in this research not only impacts my own practice as a teacher, but it is also built into the process of the research itself influencing the ultimate trajectory of the project. This is another aspect of the action research method. Noffke and Stevenson (1995) discuss action research as a cyclical process that emphasizes how "educators are partially correct, yet in continual need of revision, in their thoughts and actions" (p. 4). Thus, within each lesson, I taught and collected data to analyze and reflect on and then altered my plan and practice for the next lesson. I benefited by using this reflective process in this research project, because it allowed me to address the data that was compiled during the study and make action or approach changes based on that data. 
This allowed more control over the trajectory of my research translating into the collection of more useful data. Luttrell (2000) discusses these types of choices, or "good enough" methods, as "thinking about research decisions in terms of what is lost and what is gained, rather than what might be ideal" (p. 500). It is important to remember that while the researcher has the power to make changes, they will not know what is ideal until the completion of the study, defining the choices they made as "good enough." In fact, even while interpreting the data and outcomes at the end of the action, the researcher has to make decisions about what to discuss and what to leave out. Lutrell's (2000) "good enough" concept acknowledges that these decisions affect the study, but have to be made to effectively move on and present the findings and outcomes of what happened.

\section{Method}

As a form of qualitative research, data for this study consisted of spoken and written accounts of participants, as well as my own reflective journaling. The research question for this study; "what happens for the teacher, the students, and myself when I teach a design unit in an elementary art education classroom?"; both asks and implies that there are many levels of understanding to be learned from the project. Seidman (1991) proposes that for multi-leveled research, multiple methods are appropriate. These multiple methods will allow the triangulation of data which Anderson, Herr, and Sigrid Nihlen (1994) describe as allowing "the researcher to maximize time and to see the same scene from different angles" (p. 115). The ability to triangulate data is imperative to 
understanding the context of the study and analyzing the outcomes, and the method I used, described below, allowed me to optimize this triangulation.

\section{Recruitment}

Participants were recruited with the help of my advisor, Dr. Julie Horwitz, who has worked with and developed a network of many teachers in districts across Rhode Island. Through her consultation, the art teacher was selected. I conferred with the art teacher to select a class of students to teach the design unit. The selection of a 4th grade class was determined based first on my interests in exploring the effects of design education on students in grades 2,3 , or 4 . The rest of the selection was primarily based on schedule. The teacher allowed me to teach 4 or 5 class periods of approximately 40 minutes; participated in 2, 30 minute, audio-recorded interviews; and allowed me to observe 2 class periods prior to my unit. I also conferred with the teacher as to what class this unit would most match her art education objectives.

\section{Consent and Assent}

During my initial discussion with the art teacher participant, I explained to her that all information collected from the email is confidential, information collected would not affect her employment status in any way, and her name would not be used in the study. Once the art teacher was selected, I provided her with the adult consent form. I explained to the teacher that the nature of the study was to examine what happens when design and the design process is taught to a class of elementary students. It explained that the research was conducted as part of a graduate thesis and upon completion will be available in the Adams Library at Rhode Island College. 
The consent of the students' parents was acquired before students participated in the unit, informing parents that allowing their child to participate in the study would not negatively affect students physically or emotionally in anyway. Parents were informed that students' identities would remain confidential and that no images of students would be used in the study. Then the assent of students was attained, where they were informed that they did not have to agree to participate in the study, and if they did they could choose to stop participation at any time. After parents and students gave consent and assent, I was able to begin the unit part of the study.

\section{Procedure}

In this study, data was collected through one pre and one post interview with the art teacher, one pre and one post survey with the students, 2 feedback sheets from students, as well as the drawings and models that made up the students' projects. Additionally, observations from the lessons were collected through research journal entries in which I reflected on what happened in each lesson of the unit. All forms of data are only available to my two thesis advisors, Dr. Julie Horwitz and Dr. Cheryl Williams, and myself. These multiple forms of data were collected using the procedure below.

Once consent and assent were obtained, I conducted a preliminary ethnographic interview using a combination of Seidman's (1991) and Anderson, Herr, and Sigrid Nihlen (1994) methods of questioning with the art teacher. In the interview, I sought to understand the teacher's thoughts about incorporating design into Art Education by asking questions about the subject matter and skills she taught, her educational 
philosophy, and her experience in art and design both prior to teaching and at present (Appendix A).

I then observed the class of students whom I taught my design unit to twice. In these observations, I took notes, with a pen and paper, using Anderson, Herr, and Sigrid Nihlen's (1994) method of note-taking where “observations are recorded in a field notebook in as exact a manner as possible, with clear, unbiased language that avoids high inference descriptors such as nice, pretty, angry, and stylish and focuses on letting words paint a clear picture of the event for the reader" (p. 129). I chose to observe and to familiarize myself with the classroom management style of the teacher and the students in the class.

I then conducted a preliminary student survey using the analytic survey methods of Anderson, Herr, and Sigrid Nihlen's (1994), which concentrated on questions regarding why (Appendix B). This took place in the classroom. Through this survey, I sought to illicit information about the students' initial thoughts of design and the design process.

Directly after the survey, I began teaching the first lesson of my mini design unit. The unit was 5 lessons long. This unit began with a lesson on taking a closer look at designed objects in the everyday world (Appendix C). Students were introduced to the idea of designed products through the example of a backpack and then asked to explain why the backpack looked and functioned the way it did as a group. Then students worked in small groups analyzing various objects I had brought from my home, including: a watering can, sneaker, toothbrush, water bottle, wallet, and piggy bank. Students drew and labeled the objects, as well as answered questions about how the appearance, form, 
and materials of the object related to its function prompted by the object investigation sheet (Appendix D).

The next lessons began the larger project of the unit, which was to re-design an object that students used in their lives. Students began this project by brainstorming ideas of what object they wanted to change and how they might re-imagine it using a brainstorming sheet (Appendix E). In this class, students shared their ideas with their group and got feedback on what others liked most. The students then did a larger drawing of the object they wished to design. The next lesson had students work on a sketch model of this object using Model Magic. Then students reflected on this model and a partner's model using the reflection sheet (Appendix F). For the last two lessons students used their reflection sheets to make changes and create a final model of their piece. At the end of the last lesson, students got to take a look at all the projects created and then had a small class discussion about what happened. After each class period, I wrote down my own reflections and observations of the class in a reflective journal.

At the conclusion of the lesson, the students were given the final survey, which sought to understand how the students' thoughts of design, the design process, and problem solving had or had not been affected by their participation in the design unit (Appendix G). I also gave the teacher written questions, and I additionally conducted a short final interview (Appendix H). The written interview was filled out by the teacher at her convenience while the conducted interview was audio recorded. Similar to the student survey, this interview sought to gain understanding of the unit from the teacher's perspective, regarding incorporating design into art education by asking questions about what she observed during the class in regards to the students and also in my instruction. 


\section{Site \& Participants}

The group of participants in this study includes one elementary art teacher, who will be called Ms. Smith for the purposes of this study, as well as 21, 4th grade students. The student body includes 12 female students and 9 male students. 19 students are Latino, and 2 students are Caucasian. The class sessions took place in the students' homeroom classroom and not in the art room. This study took place at an elementary school in Rhode Island. The school is located in an urban area and has a student body of about 438 students (Rhode Island Education Data Reporting, 2015). 86 percent of the student body was eligible for free or subsidized lunch in the 2013-2014 school year, compared with Rhode Island's state average of 47 percent (Rhode Island Education Data Reporting, 2015). Compared to Rhode Island's state average, 39 percent more of the students at the participating school are coming from low-income families. Additionally, 20 percent of the students at this school received ESL or Bilingual services in 2013-2014, compared with Rhode Island's 6 percent (Rhode Island Education Data Reporting, 2015). The most significant statistic is that 86 percent of students are eligible for free or subsidized lunch translating to a majority of students coming from low-income families which means that even before these students come to school and try to learn they face a variety of other problems associated with low-income. Hodgkinson (1991) describes some of these problems as " poverty, neglect, sickness, handicapping conditions, and lack of adult protection and nurturance" (p. 10). He goes on to say, "there is no point in trying to teach hungry or sick children" (1991, p. 10). What Hodgkinson means here is that when students are facing issues like poverty, they have a lot more on their mind than learning 
in school, which puts them at risk from the beginning of their education. It is important to know that the population of students I am working with may be facing obstacles in their home lives that could interfere with their learning, because it affects the way I teach and interact with students. Additionally, it is important to know that I am studying what happens when teaching in this specific population, because it will influence my analysis and findings. 


\section{RE-DESIGN PROCESS IMAGES}

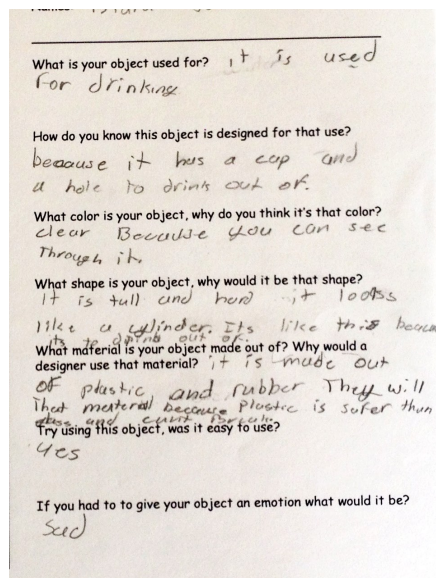

Figure 2.1



Figure 2.3



Figure 2.2

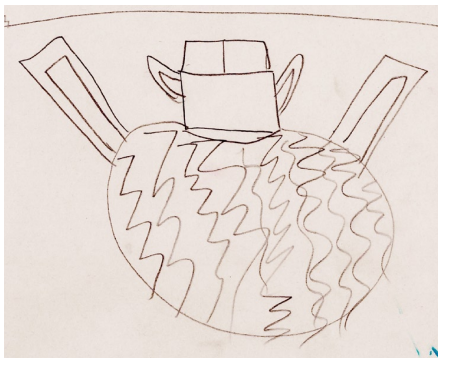

Figure 2.4

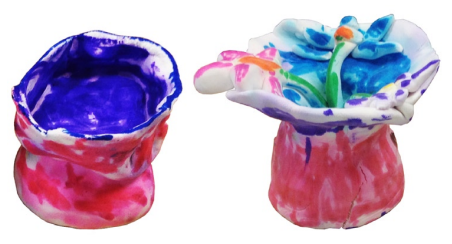

Figure 2.5

Figures 2.1-2.5: These images are selections of multiple students work throughout the design unit. Figure 2.1 is an example of the object exploration sheet, and shows the written response from a student regarding her investigation of a water bottle. Figure 2.2 represents one students brainstorm sketch journey, where they sketched in response to questions such as, "How could you change your object so that a friend likes it more?" Figure 2.3 and 2.4 are examples of final sketches for two students re-designed objects. Figure 2.5 is an example of one students sketch model and final model. 


\begin{abstract}
Analysis
I analyzed my data using Wolcott (1994) method of a three-part, cyclical system involving description, analysis, and interpretation. Data description means paying close attention to what has been originally recorded and treating that record as fact. Wolcott (1994) states that, "the underlying assumption, or hope, is that the data 'speak for themselves"' (p. 10). When analyzing, often following description but not always, the goal is to look for "key factors and identify relationships among them" (Wolcott, 1994, p 10). Then, often but not always following analysis, interpretation of the data, where the researcher hopes to make sense of the information they have (Wolcott, 1994, p. 10). I followed this process of data analysis both during my teaching of the unit itself, as performing teacher action research requires, and at the end of the study to learn and explain the findings and analysis.
\end{abstract}

\title{
Findings \& Analysis
}

The broadness of my research question: "what happens for the art teacher, the students, and myself when I teach a unit on design and the design process in an elementary art classroom?" was chosen to promote to the inclusiveness of my findings, as discussed in my methodology. Within the whole fabric, of this study I have chosen to focus on the findings and analysis that will most inform me as a pre-service teacher. The findings that I have taken away from this experience are a result of the relationship that formed between three themes emerged from the study. These three themes were difficult 
to pin down because of their heavy interaction with each other; this initially made them hard to tease apart. In my attempt to separate them and follow specific threads, I came across places where the themes affect each other or where the threads crossed. These points of crossover are where my findings are focused.

The themes, or threads, which I have singled-out are: design, control, and confidence. I define these themes as follows:

Design - how one understands design, either as a physical product, a process, or method of thinking, or some of both.

Control - the dominant force in the student-teacher relationship.

Confidence - the belief of efficacy for a group or individual.

These themes are not stagnant but shift and adjust based on how various factors affect them. Three of these various factors are the students, the teacher, and myself. The next section will describe how these themes relate, where they interact, and what that means for the outcomes of the study.

\section{Design X Control}

When I first observed Ms. Smith's class, I saw lessons based on the product they created. The projects were planned out with specific steps and materials for the students to follow. The main objectives were accomplishing the steps laid out as well as displaying understanding of the art concepts and physical skills taught. For example, a first grade lesson I observed was teaching students to trace shapes and cut them out to make a bear face. The students were instructed in each step of the making process and the goal was to make their bear match the example bear as closely as possible, focusing on 
the objectives of tracing shapes and cutting with scissors. Another example, a fourth grade lesson I observed was a similar step-by-step process to create an abstract graphic piece. Students had some freedom within steps, but were not involved in the process of deciding how and what to make. The objectives of this lesson where to have students practice pattern making and positive and negative space. Ms. Smith focused on teaching how to make things and what specific elements and principles of design the class was learning each day.

Ms. Smith began this study primarily defining design as the elements and principles of design. In our preliminary interview when I asked Ms. Smith how she defined design and how it fit in with art education she stated, "for elementary we do the basic, um, color, shapes, lines, and textures, arranging space" (11/4/2014, Lines 110-111). These are examples of the elements and principles of design, visual tools of language used in both art and design. I asked some follow-up questions, but our discussion stayed focused on these elements and principles, confirming that she understood design primarily as the elements and principles of design within her art classroom. At the end of the interview, Smith asked me my views of design, and she discovered that part of my definition included products. At this point, she changed her answer to include products, mostly in the form of graphic design "we made all kinds of posters, business cards, um...magazine covers..." (11/4/2014, Lines 199-201). Based on this interview, Ms. Smith's definition of design includes some products and the elements and principles of design. The graphic products fall into the category of defining design as a product; the elements and principles of design would also fall into this category, because they are used to describe and think about products of art and design, not the process of making. 
Thus, Ms. Smith's definition stays in the realm of product, or the end result. The lessons I observed in Ms. Smith's art classroom were also much more product driven than process driven, whether they were about design or not. From my interview and observations, I believe that Ms. Smith's focus on product puts the control of these projects in the hands of the teacher. This way of teaching allows the teacher to have primary control over the results of the lesson. Students are following directions, and, thus, while they are getting to practice skills they have learned through mimicking demonstrations, what they are mainly thinking about is accomplishing specific instruction and trying to do what they saw the teacher do. During the preliminary interview, when discussing what Ms. Smith's least favorite thing to teach, she states, "the hardest thing is, like when we start school, everything's very basic. Some of them can't cut, they don't know how to use a glue bottle" (11/4/2014, Line 95-96). She continued on and explained why she teaches these skills saying, "which in other communities they probably know how to use all those materials, "cause they have them at home, but... [trails off]" (Line 11/4/2014, 105-106). Ms. Smith is saying that she believes the students in this school's lower income population do not have the same access to materials and, thus, do not practice using those materials as often as other wealthier students might. This implies that Ms. Smith chooses to teach more controlled lessons because she feels her students are lacking skills that she believes are necessary before more complex projects can be accomplished. As a result, it seems that, Ms. Smith teaches to product more than process; based on my observations she appears to give students visual, physical goals to strive to achieve, promoting conforming and mimicry rather than individual thought. It is my 
belief that seeing design as product, or product heavy thinking in general, gives the teacher primary control over the thoughts and actions of students.

Considering the teacher's views, it is not surprising that without any exposure to the unit the students as a group defined design primarily as an image or product that is a result of making or decorating. Students gave a variety of definitions split fairly evenly within the categories of image, decoration, and making. A majority of the examples of design they gave were in the category of image, but 4 out of 21 students gave a product as the example. After the unit was completed, there was a large shift in the students' definition of design. The final survey asked students, "What was your favorite thing you learned or did during these lessons? And, why?" All 21 of the students described learning a process or described a process as part of their answer. These results overwhelmingly show that this group of students learned that design involved a process and a way of thinking. Along with this shift in definition from product to process, came a shift of control from teacher to student. In addition to students' description of design as a process, many also spoke about choice. Here are some students' responses to questions about what they learned in general or about design:

It doesn't matter how you design it. It is your choice.

You can do it your way.

I learned that we can make things how we want to.

These are just a few examples of powerful statements that students wrote in their final survey. It is clear that many of these students felt in control of their project and their learning. This is because, instead of being taught the steps of how to make something, they were taught the steps of how to think about making something. The students became 
involved in the process and the decision-making in their own work, and I believe they strongly valued this. Learning the design process was important, because it gave students control in their project. Giving students more control in this way is important, because it gives them ownership over their own ideas and their own learning. It tells students that what they have to say and what they want to make is valuable.

\section{Control X Confidence}

While I was planning my unit on design, and even during the time I was teaching, I wrote about my uncertainty in how students would react to learning the design process. I was concerned with the amount of choice and control the students were going to have in their project, especially after the limited control that I saw in observing Ms. Smith's lessons. "Would that ask too much of students? Is my lesson going to be too complex? Too free? Too difficult?” (9/27/2014, Journal Excerpt). I wanted to be able to give students more control, but I was worried having this control might frustrate them if they did not understand the process I was trying to teach them and make them feel less confident. At this point in my project I had low confidence in my students' abilities but my confidence in the students was very tied to the confidence I had in myself as a teacher. I had not had very much teaching experience or experience with this specific group of students, so I was not sure if I would be able to teach the class the design process and have them use it. I was not sure how much control to give them. However, as I observed the students in class and their work, my confidence in their abilities grew.

At the end of the first lesson, there was a turning point in my confidence in myself and in my students: 
I then asked them [the students] if they liked doing the project, and they all said 'yes' very loudly. I asked them why, and one boy said that it was just fun, why was it fun, he didn't know, it just was... and then a girl raised her hand and she said she liked it and something like, it made her think about the objects she had every day, or about objects differently. That was awesome. (November 12th, 2014, Journal Excerpt)

This moment solidified two things for this unit; the first was that the students liked what they were learning. This was important for me, because it meant that they did not feel I was asking them to do something too difficult, but they were enjoying the project. The second realization was from the comment one girl made, "it made her think about the objects she had every day, or about objects differently" this student verbalized one of my goals for students to get from this lesson. I wanted the object investigation to spur further exploration of objects that students come across every day. Having a student vocalize this goal after one lesson with me teaching her was powerful. While this was just one student's experience, it made me more confident in my ability to teach students and their ability to learn what I was teaching them. This confidence was important for me to continue the lesson and feel that I was able to give students control.

The students continued to prove their abilities to learn and take control throughout the lesson. The work the students completed in the first class marked their ability to investigate their objects and think more deeply about the objects functions. I found that the majority of students in the class were able to identify reasons for design and functional decisions in the objects they explored. Meaning that students understood that objects were made of plastic to make them waterproof or durable, or a watering can was designed to look like an elephant to make it appealing to an audience. As the unit went on, I could physically see student engagement and excitement in the form of the amount of work they created. During the brainstorm lesson, I asked students to draw at least 4 
different ideas for their re-designed object. All but one student did at least 4 drawings, and 7 students created more than 4 . I actually had 5 students create 8 different sketches. The students were engaged in their brainstorming; they had lots of ideas and clearly wanted to draw them all. These observations and events not only increased my confidence in teaching, but I also believe the students' confidence increased.

One of the most telling points that control and confidence were related and affected one another happened when the two intersected in the last lessons. Students made two models of their redesign out of Model Magic, self-drying clay. While I taught students a few ways to manipulate this material (coiling, flattening, cutting, and rolling), I wanted them to try the material themselves to understand what it would do. Giving control of material exploration to the students here showed how much more confidence I had in their ability to figure things out. However, this material manipulation proved the most challenging to students compared to any other part of the lesson. Many students asked for help during the lessons with Model Magic, especially during the first lesson, and only 2 of the first models closely matched the drawing design students created, meaning they had trouble manipulating the material. During the second lesson with Model Magic, when I told students they needed to make a final model, I was met with resistance from some. Yet, only 1 student changed their object in the second model, and 11 students made models that were improvements from their first model. The students' actions correlate with the final survey: 10 students said that making the model was the most difficult part of the lesson which they overcame by trying or asking for help; however, 11 students said that making their model was their favorite part. In this situation, it seems that giving control to students and allowing them to overcome difficulties is 
something that can build their confidence. The question then is how difficult should the challenge be so that it can push students but not cause them to give up?

The building part of the lesson was also the part that Ms. Smith gave me the most feedback on. Ms. Smith wrote in part of the final interview in response to the question "What part of the unit do you feel was least successful, and what would you recommend I do differently?" that it should have been "more directed on Model Magic construction." (12/9/2014, Interview Questionnaire). It was during the second lesson with Model Magic that Ms. Smith also became involved in the classroom. Until this point, Ms. Smith had not interacted with the students or myself during the class, but here she helped students with the modeling. She could tell that this was a difficult part of the lesson. Ms. Smith's feedback was right in a number of ways. If I had spent more time demonstrating and having students practice using the material before having them make their model, I believe that they would have been more successful at building the model, meaning the outcome of the products they created would have looked more like what they had designed. I also believe time played a large role in the students' building success, as they only had 20 minutes to build the first model and 40 minutes for the second. I should have given them more time to experiment if experimentation was how I envisioned them working with the material. I may have had too much confidence in what I thought students could do with this new material within a short timeframe, and, thus, gave them more control than they were ready for.

However, if I had instructed students more on the use of the material would they have felt as much like they had overcome a challenge? Did students learn more from working with the material than was shown? If I had asked students to draw one more 
version of their design after modeling, would I have seen a change related to the modeling? I cannot be sure what students learned about the material, but I saw a few of them invent ways of working with the Model Magic that they had not been shown. Would that have been lost with more instruction? The confidence and control seems to function on an ever-changing balance between students and teachers. The feedback from all participants indicates the unbalance of confidence and control for this part of the lesson. Many students noted that making their model was their favorite part of the lesson, even though it was also the most difficult. Looking at this after seeing what the students had to say about the lesson and how the students' models improved makes me ask the question: if students had been taught more and given less control, would they have learned as much? This part of the study proves both very interesting but messy, possibly a point for future investigation.

\section{Confidence X Design}

The last question on the final survey asks, "What will you design next? How will you do it?" To this question: 11 students identified objects they wished to design next; 6 students identified an object and also the process they would use to make it; 1 student described a process; and one student did not answer. The answers of products that students gave for their future designs ranged greatly, some examples include: baskets, shoes, clothing, "a dinner robot," "a robot snake," a playground, and a classroom. These answers combined with the answers relating to choice and learning about process mentioned above, indicate that students learned the process of designing and felt confident on some level to apply it to a different type of product. This leads me to believe 
that, at least in some way, teaching the design process to these students made them feel more confident in their ability to imagine and create something. It is uncertain whether they will remember this weeks, months or years later given their short exposure to this type of thinking, but the confidence was there at the end of the unit. For these students, learning the design process gave them at least momentary confidence in their own thoughts and ideas. Understanding this is one of the most important things I have learned from this study, and is something that I believe has merit for future research within the field of design thinking.

\section{Implications}

That being said, all of the findings in this study are only proven applicable to the immediate context of the study. This study is not claiming that what was learned, or what I believe was learned, in this specific situation could be applied to another group of students in another place. This study was small and involved only 21 students for 5 weeks. However, the effects of teaching design as a process to these students showed that engaging students in the design process facilitated some important ideas about students' learning, thinking, and confidence. It also illuminated some observations about what and how art and design is being taught. These outcomes provoke many questions and thoughts such as: Would similar positive outcomes happen with other students, in different places, and at different ages? Questions like these drive me to want to investigate the effects of teaching design in different contexts and for longer periods to gain a fuller understanding of how learning the design process can affect students. 
Within education and art education, I think an investigation of different kinds of processes is a next step. Questions like: What kind of processes are we currently teaching in schools? How does the artistic process, the creative process, or the engineering process relate to the design process? How are these processes different and could they be more inclusive of each other? What happens when students are exposed to a creative process all throughout their education from kindergarten through senior year? Also, is the design process already happening in schools but being called something else? Within design education and design thinking, I think one of the most important questions is: How does design thinking and the design process affect confidence in students? These and many other questions are areas of further investigation that will take time to explore and an effort by many researchers.

\section{Conclusions}

This study marked the beginning of my investigation of the impacts of design and design thinking on students and teachers. While the end result made me think that there are many wonderful possibilities and opportunities in teaching design, the most important learning that happened in the study provoked more questions. As a person at the beginning of my teaching career, it is more important for me to go in questioning and thinking, rather than believing I have all the answers. What was responsible for this was involving myself in the reflective process. This process allowed me to come to conclusions and develop more questions based on these ideas. It showed me that the questions I thought I was asking were very different than what I was really asking. The 
steps of researching, planning, implementing, and reflecting in this study helped me understand how I can go about asking these questions in a productive way instead of ignoring or dismissing them. In this way, I would be using these questions to develop ideas and actions rather than only dwelling on what I think should change. This is what I believe it means to be productively critical, and while it is slightly exhausting at times, it is an exciting mindset to be in. 


\section{CHAPTER 3}

\section{DESIGN IN ART EDUCATION: PAST \& PRESENT}

At the conclusion of my qualitative teacher action research project, I found that my investigation spurred many questions. In my literature review prior to executing my research project, I focused on defining current ideas of design and the design process, what those ideas mean and why I think they are important. However, something my action research project inspired me to investigate more deeply was design's relationship to art education in the past and how this translates to the present. The purpose of the research of literature that I then conducted and present in this chapter was for me to learn more about the historical views of design within the art education field and also learn more about some of the current research related to design presented at the 2015 National Art Education Association national convention, The Art of Design: Form, Function, and the Future of Visual Arts Education. This chapter does not attempt to provide an all-inclusive chronological history of design in art education; rather it aims to show some of the major historical influences on the relationship between the two. The main purpose is to get a better picture of how design and design thinking have been thought of in the past within art education in America, and my larger goal is to use and reflect on this historical knowledge to inform my future teaching and research. 


\section{Art \& Design In Everyday Life}

"Education about visual art did and does exist outside of schools" (Smith 1996, p. 11). While it is essential to think of the trajectory of art education within the public school environment, it is also important to remember that art education is and was something learned in day-to-day life, as Smith states in the quote above. In fact, people have been learning about and creating the visual world long before schools even existed in many cultures. For example:

In Australia aborigines did their extraordinarily interesting rock and bark paintings, the Native Americans build San Xavier del Bac (with Spanishinfluenced tutelage by clergymen) in the Sonoran Desert, and the Pueblo Indians created a great potter tradition in their small communities. Art forms were utilitarian and, besides the examples just named, have included quilts, painted and carved furniture, wrought-iron devices, and so fourth. (Smith, 1996, p. 17)

The examples of how a few cultures relate to art and art education, provided above by Smith, could probably be applied to any culture throughout history. It is important to reflect on in these kinds of non-traditional and more life-integrated forms of art education because in this format art is very much tied to life and to utility. As Hodik (1992) states, "art was as functional as it was expressive, and there was not a distinction between fine and applied art as much as a distinction between things well or badly made" (p. 154). The idea that the expressive and the utilitarian existed for centuries as more united than divided is so important, because it reminds us that the real purpose of both art and design is the same: to better the lives of people either through utility or expression and often both at the same time. 
Acknowledging the purpose of art education and where its roots were formed long ago is important, and much more could be added regarding humans' long relationship with making art and tools. However, my main goal in beginning with the idea that art and design is something that humans have always been doing and learning applies to the framework of art education in the United States. Smith (1996) quotes Bailyn (1960) saying:

The Puritans would have been puzzled by our insistence on art in schools, not because they were against all art, but because art or craft was something learned at home in the extended family that included children, apprentices, and servants. (Smith 1996, p. 14)

The idea of art and craft as a normal part of everyday life, learned at home or through other means, is where art education in the United States originated. To me, these ideas reflect how integrated learning arts, and in many ways learning to design and problem solve, was built into the colonies of early America. This ideology, that art and design directly relate to the improvement of people's lives, and was something people taught to one another in order to create their homes, tools, and needs, represents the heart of what I see as the beginning of art education in America.

In fact, the founding ideology of art education as utility was promoted, in 1749, by Benjamin Franklin. This marks the beginning of incorporating the arts into school curricula. Eisner (1972) discusses Ben Franklin advocating for art education saying, "to Franklin, as well as to other pioneers in American education, the arts had a utilitarian or materialistic value" (p. 29). Art was taught to meet the needs of a growing nation and was seen as a skill for life, closely associated with crafts and design rather than fine art. Interestingly, utility and function, ideas so closely 
associated with design, were the primary reason that art education became part of our schools. People needed to learn these art skills for society; it was part of building America and making it what it is today. Art education relating to society at during this time period highlights that at any point in history much of the educational focus chosen for students is in response to what is happening in the environment around them. Eisner (1972) describes this saying, "art education is one component in the school program and adapts to the demands of context" (p. 52).

With context in mind, I have chosen to focus this second literature review on two specific historical movements in art education that I believe hold a strong influence over how design education is viewed today. The movements are: the Industrial Drawing Movement, often thought of as the official start of art education in our public schools, and the Owatonna Project. I look at the two events through the framework of the following question: what can I learn from this movement in its specific context and how does that apply to the context of today?

\section{Industrial Drawing Movement}

One event, The Industrial Drawing Act of 1870 in Massachusetts, and one man, Walter Smith, are primarily attributed with the development of the Industrial Drawing Movement (Smith, 1996). These two ingredients were key to this movement's existence, though there were many other elements at work. Not only did this combination spur the beginning of this movement, but also the Industrial Drawing Movement is generally thought to be "the real beginning of serious 
attempts to include art in the curriculum" (Smith, 1996, p. 24). As I mentioned above, context is key to art education, or any education for that matter. Understanding what was happening in the United States at the time of this movement is important. First, I will provide some historical context feeding the ideals of the Industrial Drawing Movement and then I will explain how this translated in to the classroom. At the end of this section, I will discuss what I think is applicable to today's world of art and design education.

“By the late 1860’s Massachusetts was the most industrialized state in the nation" (Stankiewicz 2001, p. 8). The state sought to compete internationally, and to do this, they needed to export manufactured goods in place of raw materials. This meant designing and producing things like textiles, furniture, and other decorative objects that were desirable not only for function, but also for artistic and aesthetic qualities (Stankiewicz, 2001). The Board of Education in Massachusetts saw education as a means to train students to compete in this industrial economy through artistic skill saying:

The material prosperity of the State depends chiefly upon the profits of its manufactories. That these profits might be immensely augmented by the application of higher artistic skill, is no longer doubted by any well informed person. (Chalmers 2000, p. 62)

The importance of artistic skill in industry at this time can be equated with today's emphasis on bettering our society and competing globally with science, technology, engineering, and math. Artistic skill was associated with success and was thought of as a breadwinning field (Eisner, 1972).

What is important, however, is that the idea of these artistic skills was quite different than the contemporary idea of an artistic or creative skill today. The 
primary means in which Massachusetts and Walter Smith strove to advance industry through art was with teaching industrial drawing and drafting. Students learned to draw lines, geometric shapes, and observational line drawings (Stankiewicz, 2001). "Students were expected to learn the rules and scientific principles of drawing and not simply to copy images. Pretty pictures, the goal of genteel art instruction, were to be avoided" (Stankiewicz 2001, p. 11). Szekely (2012) in Art Teaching: Elementary Through Middle School described the history of art education through a series of stories depicting what it may have been like to be in an art classroom at the time. What he described for the Industrial Drawing Movement was a class of students learning to draw by observing a teacher draw on the board and then copying this. Szekely (2012) explained how young students would learn simple lines and geometric forms and then build on these skills to draw more advanced objects. "From $6^{\text {th }}$ grade on, examples of historic ornament were introduced; by eighth grade students might be asked to apply their designs to specific objects: wallpaper, ink stands, and so on" (Stankiewicz 1990, p. 90). Learning to draw was very regimented, but as students built on their skills they had some ability to be more creative.

The goals of the Industrial Drawing Movement were primarily based on industry. However, Smith's goals for the students were more child-centered and holistic. Below are a few excerpts from Smith's propositions about art education:

1. All children who can be taught to read, write, and cipher, can be taught to draw.

2. Drawing is required to be taught to every child as an element of general education, like reading, writing and arithmetic.

3. As an elementary subject it should be taught by the regular teachers, and not be special instructors. 
4. The true foundation of Drawing in general education is to develop accuracy of perception and to exercise the imagination, thereby tending to produce a love of order and to nourish originality (Chalmers 2000, p. 79).

What is important to note in Smith's list is his emphasis on everyone being able to learn to draw and that through drawing students should learn ways to be creative. I think that Smith and other Industrial Drawing Movement proponents thought of drawing as an alphabet that could be learned and then applied to creative thought. Children were learning to draw lines and shapes in a way that mimics how they learned letters and sentences. Putting these lines and shapes together would form stories, essays, poetry, and any sort of creative expression. Though I think the hope was to have this creative energy fuel business, at least there was some thought of students as individuals.

The Industrial Drawing Movement, something founded on the needs of society, parallels contemporary ideas of design and design thinking today in a number of ways. The most obvious is that this movement was concerned with the design and manufacture of goods that people use in everyday life. This movement was not so concerned with fine art; rather the emphasis was placed on utility and function. In fact, the goal of making objects more desirable through artistic choices is very similar to how Pink (2006) described the utility and significance of objects. However, the way in which these design skills were taught was more through mimicking and observational instruction and less through design thinking or the design process. The style of teaching in Industrial Drawing Movement differs greatly from how art and design is taught today. However, as I read about this movement, I wondered if because of the close connection it shares with today's purposes of 
design education, a view of design as only something that can benefit industry exists. Many of today's arguments for design are similar to the Industrial Drawing Movement, but I have found and believe that learning about design and the design process benefits students personally rather than just giving them skills for the benefit of society. I wonder if the association of this mimetic style of teaching, so often seen as a negative in art education today, affects how some view design. Some may associate design more with mass production than to a way of learning about the world and the creative process. It is difficult to gauge what beliefs art educators hold today, but in some ways I could see the historical undertow of this movement shadowing some of the positives of design education.

\section{The Owatonna Project}

Another event in the history of art education closely related to the ideas of design today is called the Owatonna Project, or the Owatonna Art Project. The Owatonna project was a community-based art project funded by the federal government in the 1930's that took place in a town in Minnesota (Day \& Hurwitz, 2012). "The premise of the project," states Hodik (1992), "was that art needed to be unified and placed back into its oldest role as a functional solution to the problems of everyday life" (p. 156). The grounding ideas of this project were to see art as a way of life rather than something extra. Real life choices such as: "decisions about draperies, room layout, landscaping, furniture, dress, automobiles, and so forth were decisions and ones that the school could help people make more effectively" 
(Eisner 1972, p. 54). The idea was to make art more applicable to an average person to see how it could affect their daily lives rather than just learning about art they might see in a museum.

This project was funded by a grant through the Carnegie Corporation (Saunders, 1985). There where three phases of the project:

The first was to survey the community to determine what role art played within it and where the emphasis in the curriculum should be placed. The second was to develop a course of study in art for the schools. The third dealt with the possibilities of art in the daily life of the community. (Efland 1990, p. 207)

A group of researchers who were strangers to this Minnesota town proposed the Owatonna Project. What is important, and displayed in the three phases, is that part of the proposal was first to study the community and people they were working with. Instead of deciding what the community was going to learn based on expertise, the group of researchers first learned more about the people they wanted to teach. Saunders (1985) describes a quote from the Fifth Annual Report (1942) that "from these findings, they developed an art program in the schools that would be, 'functional, contemporary, and related to the lives and interest of the members of the community'" (p. 152). These thoughts are key because the researchers wanted this program to matter to the people of the community, helping the community identify what was important for them to learn. This approach of art education was very different than other methods before this time period. Saunders (1985) quotes the Fifth Annual Report:

In most cases there is a complete disregard for the importance of modern industrial design, present-day developments in architecture, or community planning, garden design - in fact, an under emphasis on all those aspects of art which are closest to the lives of most individuals. (p. 153) 
Relating art and design to the community and the individual were of utmost importance in the Owatonna Project.

The Owatonna Project was accomplished from collaboration of teachers and the community on multiple levels. School curriculum emphasized art and how it related to life, even within subjects other than art. Speakers were brought in, and they held adult classes to involve and promote the ideas in the adult community (Saunders, 1985). Edwin Ziegfeld, one of the main researchers who held multiple roles within the program, was actively analyzing the outcomes and adjusting the objects of the project (Efland, 1990). For example, after the first year of implementing the project, Ziegfeld developed a list of new objectives for the second year which included things like: "To develop an awareness and appreciation of art in the environment; To develop the ability to solve everyday art problems; and To become increasingly interested in improving the environment through the thoughtful solving of art problems" (Efland 1990, p. 208). Zeigfeld, who served as the project's director after Haggerty, the previous director, died in 1937, created a report detailing the indicators of the programs success (Efland, 1990). He sighted several factors including: the projects continued funding by the Owatonna public school district; a large amount of requests for art classes and speakers by the community; an increase in the number of art related books checked out from the library; and a large number of direct praises from the community (Efland, 1990). Despite the Owatonna Project being cut short at the onset of WWII (Day \& Hurwitz 2012), Faulkner and Ziegfeld continued writing about the ideals of the 
Owatonna Project. Specifically, in their book Art Today (originally published in

1941, with the fifth edition published 1963), which served the purpose of increasing,

The understanding and enjoyment of all the visual arts, to create awareness of the extent to which they influence the quality of living, and to suggest ways by which the visual arts can be made to improve the condition of man (Faulkner \& Ziegfeld, 1963 p.v).

Faulkner and Ziegfeld (1963) promoted the ideals of the Owatonna Project through this and other writings that made their way into aspects of other art education researchers' initiatives and publications. For example, Chapman (1978) infuses art and design fairly equally in Approaches to Art Education, with a great awareness of the affects art has on a person's daily life. Though I was not able to review her vast amount of publications, something I see Chapman (1978) adding to Faulkner and Ziegfeld's (1963) ideas is more of a consideration and application to children's artistic development. For example, she speaks of the importance of architecture and environmental design, but then relates it to the child saying:

Regardless of the kind of home or neighborhood in which they live, children find cozy corners, favorite hangouts, and hiding places from which they can derive a measure of privacy and psychological warmth. These experiences serve as a background from which further sensitivity to architecture and the environment can be developed. (Chapman 1978, p. 325)

Here she brings the ideas of architecture and dwellings into the world of a young person, proposing this as a place to relate and teach from.

The ideas from the Owatonna Project, Faulkner, Ziegfeld, and Chapman are wonderful and all very related. They directly relate to many aspects of design and design thinking from the interest of relating the world of art or design to the individual, to using art and design to solve problems in everyday life, and even in 
relation to the reflective approach of the project. “From looking at one's home, city, nation, visiting historic districts and architectural wonders, environmental art education continues to be of interest in the field of study to this day" (Szekely \& Bucknam 2012, p. 11). Reading about Ziegfeld, Faulkner, and Chapman's research causes me to question why this kind of design, art, and community infused education is not a bigger part of our current public school curriculum. There are some charter schools and afterschool programs with this type of approach. For example, in Rhode Island, the DownCity Design program carries much of the same types of goals and ideology as the Owatonna Project, but with more of an emphasis on design thinking. However, this kind of complex and possibly expensive approach might not be as desirable to many public school systems.

\section{Additional Influences}

The two historical movements in art education that I discussed above represent what I believe to be the most linked to today's ideas of design education. However, there are other places in history that provided influence for today's view of design and design thinking. For example, the work of Victor D'Amico on creativity and Viktor Lowenfeld's ideas of children's developmental growth through art have certainly made an impact on considering the importance of creativity, process thinking, and how students learn (Day \& Hurwitz 2012). Additionally, the German Bauhaus movement in the 1930's, which most directly affected college and university art and design programs, contributed to a more inclusive understanding 
of design and the idea of form following function (Day \& Hurwitz 2012). These and other developments in the art education field are important to acknowledge and contribute to the development of current views on design and design thinking. However, as their relationship is less direct I have chosen not to include an extensive look at them.

\section{Design in Contemporary Art Education}

Choosing to focus my thesis project on design and design thinking grew out of the lesser amount of research done in the area of design education. However, since the time that I chose to explore design and design thinking as a thesis topic, the art education community also decided to embrace and focus more ideas on design. In fact, the National Art Education Association (NAEA) 2015 national convention theme was The Art of Design: Form, Function, and the Future of Visual Arts Education. A group called DIG, Design Issues Group, was formed by members of the NAEA, and it has taken a stance on design within art education stating:

Design education presents unique opportunities for learning and is an essential component of a comprehensive visual arts program. Design is the application of knowledge and skills to intentionally shape and create messages, things, places, and experiences that are useful, practical, and aesthetic. Design education engages students in process, products, histories and critical sensibilities associated with design. Design education involves students in interdisciplinary problem-solving that draws upon the sciences and humanities to address both present and anticipated problems, question and issues. (DIG, 2013)

In this declaration, I see echoes of art education's history, with a consideration of a contemporary context where design is seen as a tool to positively affect students 
and society. NAEA's stance and promotion of design through focusing on it as the national convention theme and professional interest groups such as DIG, is both exciting and promising. However, the timing has proved somewhat difficult in terms of addressing this in my thesis, as the rise in interest in the field coinciding with my own research has been like trying to catch a moving target. Another reason I have chosen to include this second literature review is to share and review some of the most recent advances on my thesis topic, primarily from the NAEA 2015 convention.

While I was unable to attend the convention, I was able to look at multiple presentation handouts, articles, and groups associated with this new art education focus. I am not able to review all the resources involved in the convention, but what I was able to see is exciting. The presentations and articles represent a diverse exploration of the topic of design that is unique to individual art educators. I hope that the diversity of these perspectives grow and that I am able to contribute my own perspective at some point in my career. To offer a view of the new topics and ideas about design from the 2015 NAEA convention I have divided the information I was able to view into three broad topics: Process, Real-Word Design, and Technology. Below, I have included a synopsis and review of selected presentations within these categories.

\section{Process}

Process, inclusive of the creative, artistic, and design process, was a prevalent theme in the materials from the 2015 NAEA convention. The approaches to process were various, but the large number of presentations about process is exciting. One 
way process was approached is in the category of the ability to assess the process. Masterson (2015) provided some insights into assessing process rather than product, even providing a proposed rubric that focuses on investigation, inventiveness, modeling, and self-assessment. This is a promising starting point, as sometimes it is difficult to think about assessing a student's process in a measurable way. Masterson (2015) suggested looking at how many different investigations a student tried and how often they chose to collaborate and reflect with others about their work. Along the same lines, Gillard (2015) proposed ways to measure and assess process through sketchbooks. She proposed objectives for sketchbook projects where the sketchbook was used for reference and citation, visual exploration, and a jumping-off-point for student discussion. Another form of approaching process assessment was presented by Plishker and Hammonds (2015); they discussed how to approach talking about feedback with students. The design process I have presented is a reflective process, and Plishker and Hammonds (2015) provided different strategies to help students give peer and individual feedback. They defined what was important about feedback for teachers and students, and they gave some examples of how to start this dialogue such as: scaling student interest in projects, descriptive feedback, and conversations starters.

Besides focusing on the assessment of process, many presenters were excited to embrace the failure and mistake-making aspects of process. Nosalik (2015) presented ideas about the learning that occurs from trial and error, with a focus on engineering. Taylor (2015) presented a lesson for middle school students focused on bridge building. In this lesson, Taylor had students test their bridges with 
different weights at different points in the process. Both Nosalik and Taylor were concerned with the learning that occurs when something physically does not work and how some students learn better in this kind of problem-solving environment. Smith (2015) presents failure as an opportunity to learn, or the idea of the happy accident. She focuses the ideas of what can inspire us from something that goes wrong, even while using a tool like a 3D printer.

\section{Real-World Design}

The definition of design, how one can interact with it, and how it relates to art, was another focus in my review of selected NAEA 2015 convention materials. This theme occurred in many presentations, particularly in the key-note speakers, Tim Gunn, of Project Runway, and Rosanne Somerson, President of Rhode Island School of Design. Vande Zande (2015), a prominent design education researcher, gave a presentation about the similarities and differences between art and design. This compare and contrast between the two areas was important, especially in defining the purposes for art and design. Often, the word design, or the term elements and principles of design, are applied to the creation or appearance of artwork. This contributes to the confusion between the two. Vande Zande (2015) provided ideas about art being for self expression, while design solves a specific problem, and how art can end in individual enjoyment, while design may do this but also needs to function effectively. The dialogue between the two that was presented is important because talking about the concepts of art and design help create a deeper understanding of how they can work together. 
Real-world design also applied to designs that were built and used by real people. Bryant (2015) gave an exciting example of this with "The Tinkeryard" which her elementary students designed and built. At first glace, the kindergarten imagined playground that Byrant shows seems too good to be true. However, after reading her explanation of how the students drew and built models, participating in the design process, that where then translated by instructors into plans, the outcome seems more credible. The young students built their designs guided by the instructor. They created a playground with stations that promoted design thinking (Bryant 2015). This presentation is exciting, but I think it is something that requires more information. It is not clear to me how involved the students actually were in the design process. However, the great part of this project was that students got to experience their ideas in physical form on a large scale.

\section{Technology}

With the increase of prototyping technology though 3D printing, CNC, laser cutting, and many more computer-aided equipment, there is an excitement of how to incorporate these technologies within design. There were multiple presentations from art educators who had utilized this type of equipment to carry out the design process. One, who I included in my process topic above, was Smith (2015) who embraced the failures in 3D printing as inspiration for designs. Using 3D printing can be difficult because it involves programming files to print correctly. Instead of getting frustrated with these difficulties, Smith (2015) encouraged her students to learn from the issues and push to explore the capabilities of a new tool. 
Another presenter, Gentili (2015), gave a presentation on her journey of incorporating a 3D printer in the art classroom. Gentili showcased multiple projects students had created, including castles, snowmen, and animals. She showed how the students used computers and iPads to model their designs before printing them. Incorporating technology is very important in the classroom, especially as many designers in the industry prototype in this way. However, I think that occasionally excitement for new technology will outweigh the ideas behind the projects created. The images of the snowmen and animals created by the students were exciting, but I feel that they were more craft projects made without function, than design projects. Though Gentili presented a design process, it was unclear whether students were solving a specific problem and creating something with a function, or just playing with a new tool. All these activities are important, but in my opinion the technology is only as good as the thinking behind it.

\section{Final Thoughts}

The additional exploration of both historical and contemporary ideas in design education proved inspiring to me. I am particularly interested in learning even more about the Owatonna project and thinking about how this kind of idea could be pushed in a contemporary art and design program. In terms of contemporary research, I have tried to investigate a variety of worthwhile recent initiatives regarding design education, but I know that there is much more exploration for me to do. However, reading a selection of current research has 
helped me see that my focus in better understanding the effects of the design process on students, teachers, schools, and communities is something important and in need of further exploration. I hope to continue exploring through contacts and resources I have found in the current design education environment in my teaching career. 


\section{CHAPTER 4 \\ DESIGN IN ACTION}

Insights I gained from both field and literature research greatly influenced my practice and ideas of how to implement design in schools within an art education curriculum. After my research experiences, I was able to explore my ideas of design in two ways. The first was developing a curriculum for K-6 environments based on the experience on my elementary research site. The second was developing and implementing lessons at both the elementary and secondary levels that explore different approaches to teaching design and design thinking during my student teaching. This chapter serves as a summary of two additional explorations that add to my research and greatly influence my methods of teaching design in my future classroom.

\section{Curriculum Project}

I decided to specifically develop a design curriculum for K-6 programs for the art curriculum project required for my graduate art education curriculum course, because I felt that this is an area where the foundation of design thinking can be formed. As a K-6 art teacher, one is often the only teacher for one or multiple 
elementary schools and, thus, is in charge of introducing and developing a view of art and design for young students. It was important for me to think about how I would break down the important aspects of the design process into skills that could be learned and built upon over an elementary curriculum such as: experimenting, imagining, brainstorming, problem solving, and reflecting. I believe if students are exposed to design and practice design thinking at a young age, they may be able to apply these experiences and skills at the middle and high school levels. I have chosen to present this curriculum in a visual format so it may be used as is in a presentation to administrators, future employers, and colleagues. The visuals are meant to be simple, understandable, and reflective of the creativity and learning the curriculum promotes.






\title{
TABLE OF CONTENTS
}

\author{
OVERVIEW STATEMENT • PAGE 2
}

CONTEXT \& STANDARDS • PAGE 5

CURRICULUM PLAN • PAGE 6

ASSESSMENT STRATEGIES • PAGE 11

FUTURE ART ROOM • PAGE 12

BIBLIOGRAPHY • PAGE 13

REFLECTION ・ PAGE 14

\section{OVERVIEW STATEMENT}

I came to this curriculum by boiling down my thoughts as well as ideas from research I have done to what I think are some of the most important aspects of a k-6 art education. I then concentrated on designing a framework that would help students learn these over arching understandings in a way that would build on itself over their education in my classroom.

What resulted from my contemplation and exploration is a hierarchy of core ideas and understandings that serve as the undertow of my curriculum, guiding it through each year to keep students' learning on track and meaningful.

These core ideas are shown in the graphic below, where I depict my thoughts of the layers of learning in my future classroom and how those layers will fit together. Further description of my definition of these layers follows the graphic.




Students in elementary school are starting at the beginning of their educational journey. While all of us are continually discovering more about ourselves, it is especially important that young students start this exploration. In the art room I believe students can learn about themselves through exploring materials, expressing their feelings through artwork, and indulging in their own creative imaginations. In all my lessons I will strive to allow students to put themselves into their work always making things relevant and engaging. As students progress will encourage students to think about themselves through choice, expression, story, relating, connecting, and influencing.

It can be hard to think about, but we all developed ways to think and problem-solve at school and through experiences in our lives. I believe that the act of creating projects of art and design helps students develop their own thinking. I have chosen to focus on teaching the design process, defined by Lawson (2005) as "a constant cycle of analysis, evaluation, and synthesis" ( $\mathrm{p} 40$ ) and depicted below. I believe teaching this process gives students important skills to think through problems and become more creative and reflective in all aspects of their lives. I plan to teach this process in my art classroom as a way to make both art and design. My curriculum builds on itself starting young students off with exploring and then incorporating brainstorming. Next students will integrate these skills with modeling, finally applying them into a full design process that incorporates those three skills and adds reflection.

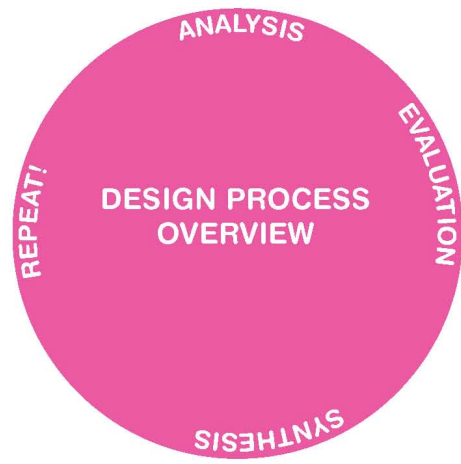

TRAJECTORY

Moving forward but sometimes cycling back.

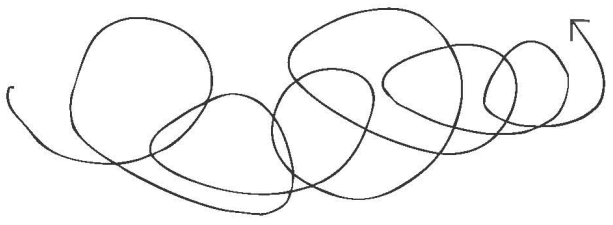

3

We are surrounded everyday by objects, images, and art that all originated in the visual arts world. While I am not attempting to teach a material culture or visual culture curriculum, I do see the importance of exposing students to the created world around them. For this curriculum I divide the visual world into art and design where art is primarily a visual form of meaning without physical function and design is a form of meaning with physical function. I understand that those definitions may seem a simplification, and that within these two worlds there exists many works that may fall in a grey area. However, my goal is to expose students equally to both art and design and this delineation helps ensure both are represented. To help do this, I have selected one example under each category to focus at each grade level ensuring breadth of exposure. I see this as a way for students to connect with their own lives. While career exposure is not everything, I also think connecting students to the world of designers will be especially important for them in considering their future. Additionally, connections like this can also teach my fellow teachers and administration, serving as advocacy for art education.

The visual language artists and designers use to express our creativity, ideas, emotions, and imagination are just as important as the letters and words I am writing in these paragraphs. Students need to learn ways to express their ideas visually, and this is where I see art techniques and the elements and principles of design falling. In preparation from middle and high school, it is important students have a knowledge of various techniques and a beginning understanding of the elements and principles of design. In my curriculum I have divided up the elements and principles of design in a progression from simplicity to complexity. For example my goal for students at the end of 1 st grade is to have a beginning understanding of line, color, form, and shape. Of course they will be peripherally exposed to other elements and principles of design by default in their beginning years, these understandings will spiral throughout their education. 


\section{CONTEXT}

This curriculum is designed for a K-6 elementary school program. Because I paired up some of the grades with similar learning goals this curriculum could be condensed slightly if say the school I teach at was grades 1-4 or grades 1-5. In terms of specific school context, I want to keep it open and then cater this curriculum to the school I teach at.

\section{STANDARDS}

I have created this curriculum with the new National Core Arts Standards in mind. While all schools in Rhode Island have not yet adopted these standards, it seemed that many of the teachers our class interviewed planed to begin incorporating the new National Standards.

The over arching Anchor Standards are as follows:

\section{Creating}

Anchor Standard \#1 - Generate and conceptualize artistic ideas and work.

Anchor Standard \#2 - Organize and develop artistic ideas and work.

Anchor Standard \#3 - Refine and complete artistic work.

Performing/Presenting/Producing

Anchor Standard \#4 - Analyze, interpret, and select artistic work for presentation.

Anchor Standard \#5 - Develop and refine artistic work for presentation.

Anchor Standard \# 6 - Convey meaning through presentation of artistic work.

\section{Responding}

Anchor Standard \#7 - Perceive and analyze artistic work

Anchor Standard \#8 - Interpret intent and meaning in artistic work

Anchor Standard \#9-Apply criteria to evaluate artistic work

\section{Connecting}

Anchor Standard \#10 - Synthesize and relate knowledge and personal experience to make art Anchor Standard \#11 - Relate artistic ideas and work with societal, cultural and historical context to deepen understanding.

\section{CURRICULUM PLAN}
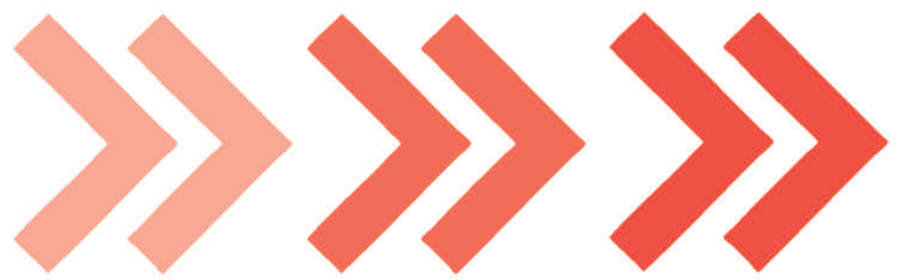


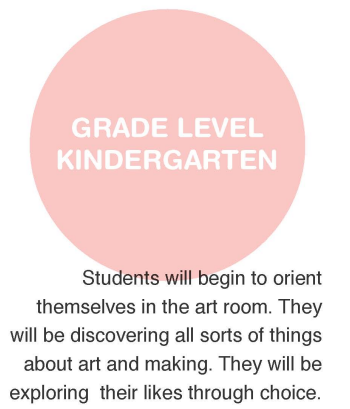

Young students are naturally experimental, but the goal of this year is to get students to try as many different materials as possible and see what they can discover.
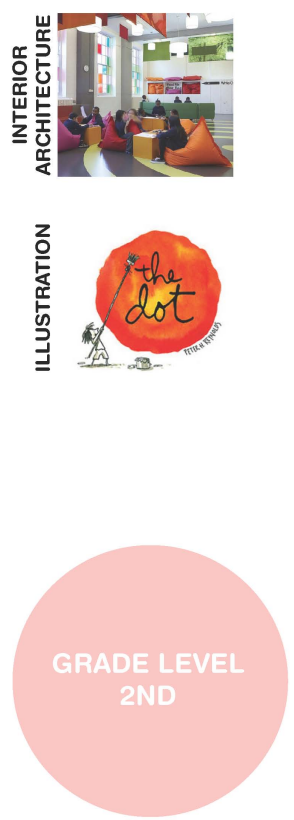

Art and design works will be related to the student and their lives on such topics as home,

family, friends, and history.

Students will rely heavily on their imaginations during the 2nd and $3 r d$ grade. They will imagine both designs of the future, as well as art that stretches their imagination from their


Students in Kindergarten and 1st grade will begin their art and design investigation through themselves. They will focus on exploring and discovering the materials and techniques in the classroom. They will be exposed to numerous examples of art and design during these first years and develop an understanding of LINE, COLOR, FORM, and SHAPE

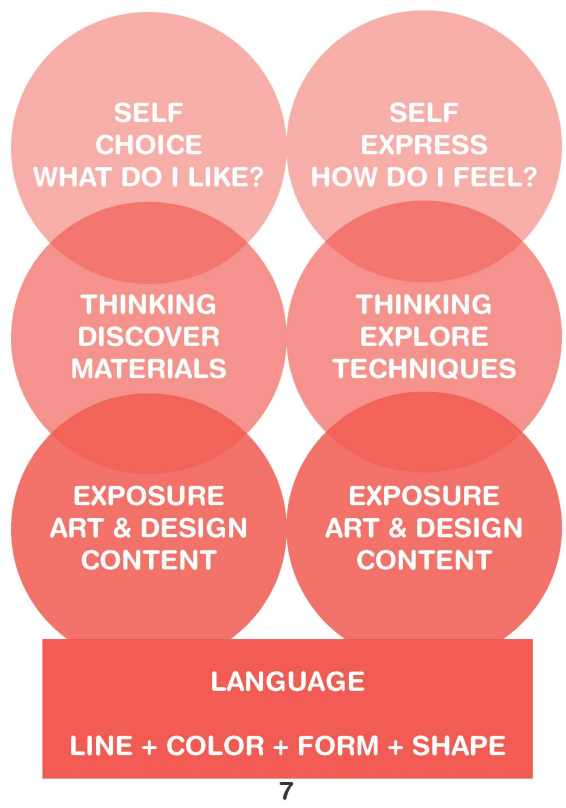

Students in the 2nd and 3rd grade have a groundwork understanding of art and design, and will continue to expand their knowledge. They will be introduced to more complex topics about their lives and use their imagination. They will develop a beginning understanding of more complex elements and principles of design through $2 \mathrm{D}$ and $3 \mathrm{D}$.
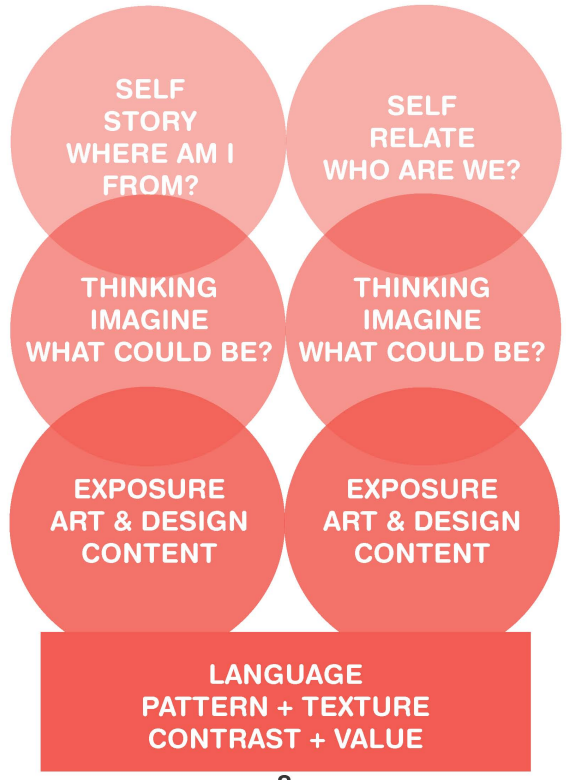

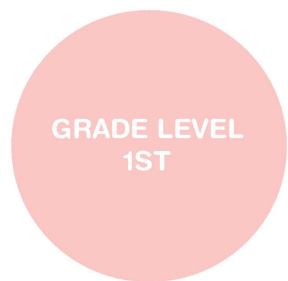

Students will start to be asked to express their emotions in their art and design. They will begin learning and exploring different ways to express.

Now that students have had exposure to a variety of materials, they will begin to both explore both on their

own and with guidance various ways to use the materials.
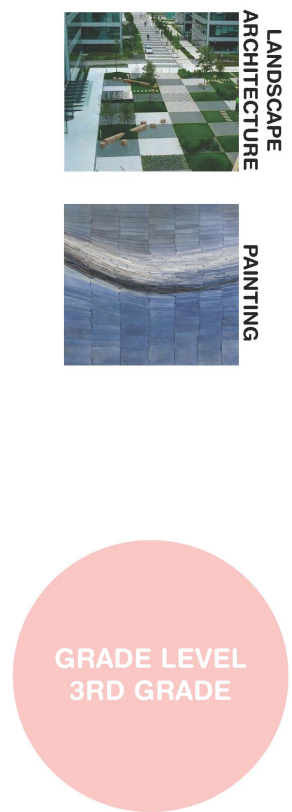

Students will begin more actively sharing with each other in the $3 \mathrm{rd}$ grade, learning how to relate to one another.

Students will rely heavily on their imaginations during the 2nd and 3rd grade. They will imagine both designs of the future, as well as art that stretches their imagination from their ideas of reality.

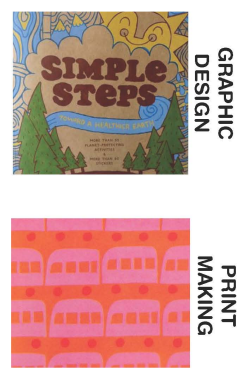




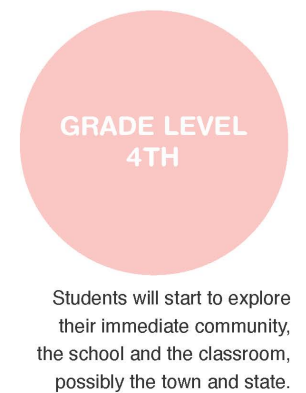

Students will be given real problems to try to brainstorm and create art or design work to solve. Not every project will have this trajectory, but they will be very familiar with problem solving by the end of 4 th grade.
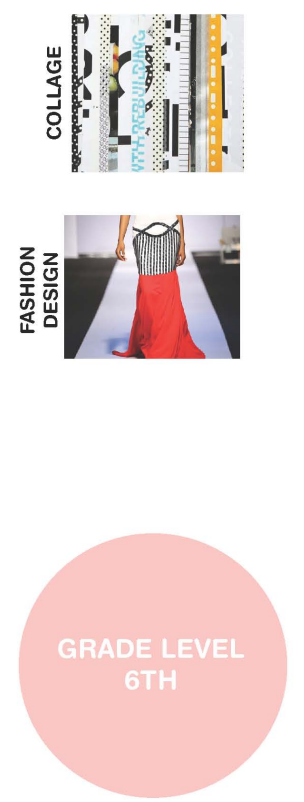

Students will begin to develop their voice, and they will be asked to create

art and design that have deeper meanings or messages.

Students will work more

independently as the year goes on directing themselves through the

design process. These students will create works based on these problems using both art and design.

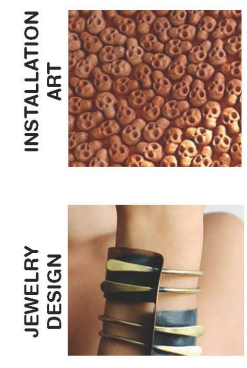

Students in 4 th and 5 th grade are beginning to put together and use parts of the design process as a way to solve problems. As they become more aware of themselves and

their peers, they will explore their communities through their art and design projects. Students will develop a basic understanding of RHYTHM, SCALE, and SPACE.

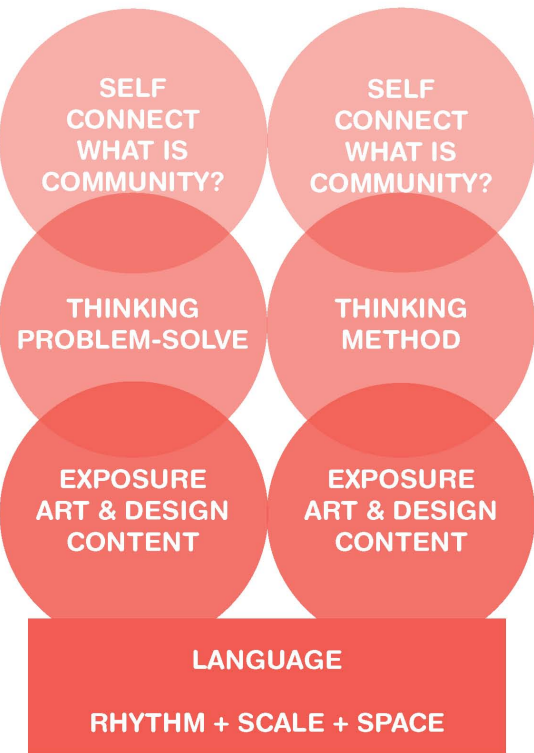

9





Students will explore their relationship to the world community, projects will be from communities from other parts of the world.

Students will continue practice problem solving and practice using methods to solve these problems guided by the instructor.

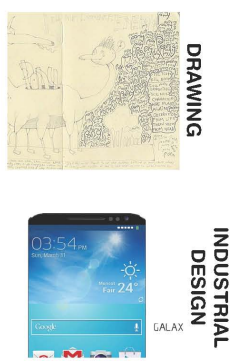

ore independent in their art making process. Many of the projects they will create this year will become more involved, as the students are now fery familiar with many techniques and ill of the elements and principles f design. Students will be introduced to BALANCE, and HARMONY.

apply these along with their prior of art and design to create more advanced work. 


\section{ASSESSMENT STRATEGIES}

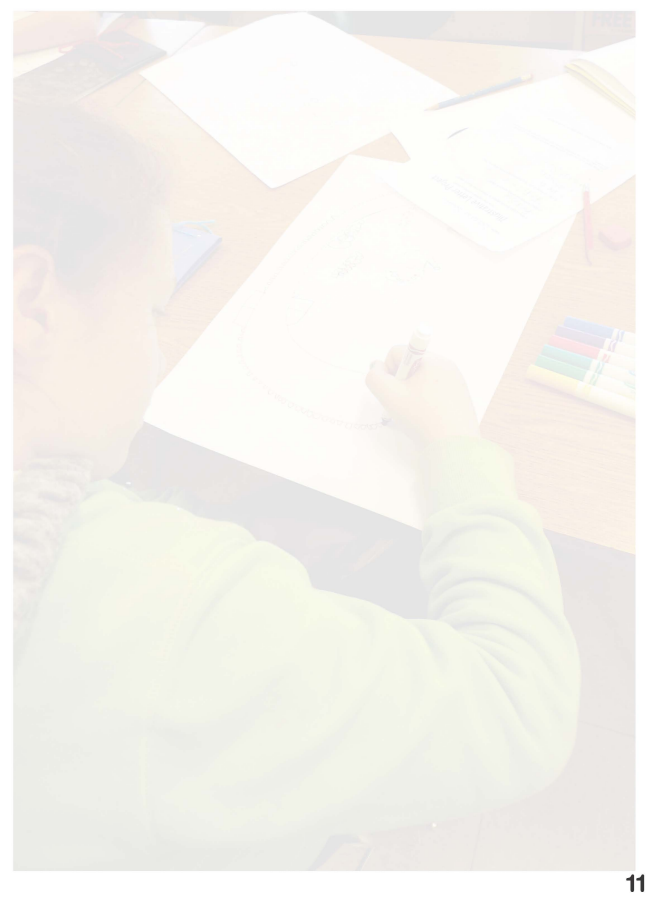

Students will be assessed both on individual projects and on their growth and change throughout the year. Each year students will keep a portfolio of their work (photographs will be taken of 3D work) and their progress over the year will be assessed based on the overall frameworks of understanding that I have outlined in the curriculum above. These frameworks of understanding double as student learning goals. Students will also write a final, age appropriate, self-reflection about their work in the art class at the end of each school year.

For individual projects, student learning objectives will be determined prior to the projects. These objectives will be assessed primarily using rubrics. As students become more independent they will have a more active roll in their assessment. They will practice self-reflection and peer-reflection often in my class both during and at the culmination of projects. Students will reflect both on their process

of working as well as their final pieces.

FUTURE ART ROOM

SUPPLIES

- CONSTRUCTION PAPER - WHITE DRAWING PAPER

- WATER COLOR PAPER

- NEWSPRINT

-\# 2 PENCILS

- VINE CHARCOAL

- ERASERS

- WHITE CONTE CRAYON

- CRAYONS

- WASHABLE MARKERS

COLORED PENCILS

- OIL PASTELS

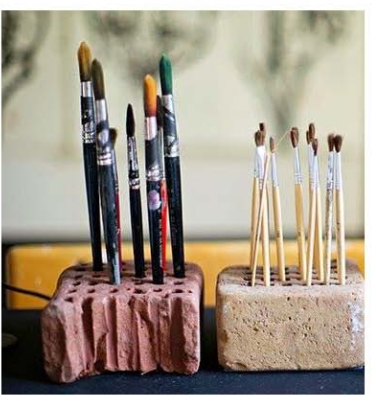

- TEMPERA PAINT

- WATER COLOR PAINT

- GLITTER + METALLIC PAINT

- GLUE (BOTTLES + STICKS)

- MASKING TAPE

- TISSUE PAPER

- YARN + BEADS

- MODEL MAGIC

- CHIP BOARD

- WOOD SCRAPS

- NATURALINSPIRATION OBJECTS

- RECYCLED MATERIALS

\section{CLASSROOM INSPIRATION}
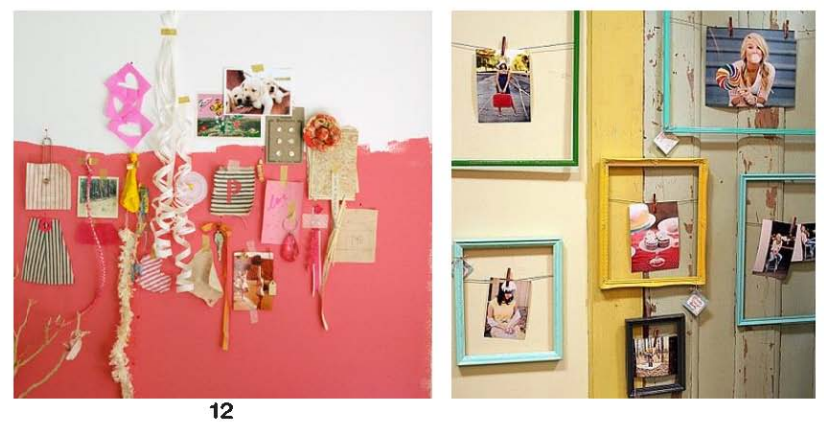

TECH \& EQUIPMENT

- ADOBE PHOTOSHOP

ADOBE ILLUSTRATOR

- ADOBE IN DESIGN

- GOOGLE SKETCH UP

- DIGITAL CAMERA

- PROJECTOR

- 3 DESKTOP COMPUTERS

- MICROSOFT SUITE 


\section{Student Teaching}

Following my experience and reflection during the qualitative teacher action research project, I was eager to continue to apply different methods of teaching design and the design process to further my learning. Fortunately, I was able to implement design-oriented lessons in both my elementary and secondary placements during student teaching. I took this opportunity to try out new ideas based on my previous learning, and also experience teaching design to upper level students. In total, I was able to teach three long design lessons that act more like units, one in elementary and two in high school. Below, I will summarize the lessons, my reasoning, and the outcomes as well as provide images of student work.

\section{The Letter Chair}

Based on my experience teaching a design unit during my research project, I developed a lesson on chair design for fourth grade students. In summary, this lesson was an introduction to furniture design and the design process. Students were first involved in a PowerPoint presentation and discussion about different kinds of chairs and asked probing questions such as: how do you think it would feel to sit in this chair, and why?, where would you put this chair, and why?, and do you like the way this chair looks, and why? Next, students were introduced to a design challenge: design and build a model of a chair based on a letter from the alphabet. Students explored their chair designs as groups and individuals, primarily through 
sketching. Once students had decided on a final design, they began the process of building. This process was done first through the creation of an armature of wire and cardboard. These structures were painted and then students were able to add the details of their designs with a variety of recycled materials. Finally, students reflected as groups and individually on their designs.

The planning of this unit was based on three things I wanted to try changing from my research project. The first was that the unit implemented in my research project was short, and, thus, time constraints affected the student work, specifically in their prototyping phase. Therefore, I lengthened the prototyping phase of the chair project lesson. I also felt that the choice in my research project to allow the redesign of any object was a little too open ended. Therefore, in the chair lesson, I limited the constraints on students, asking them to not only design a chair but also specifying that it needed to incorporate a letter of the alphabet. I felt that this would give students a jumping off point in their designs, and I explained these constraints to students as something similar to a financial or material constraint on a designer. I also felt that the choice of Model Magic and my limited instruction of its applications to students created some frustration for students. So, for the chair project, I had students use more solid materials like cardboard, wire, and tape, and I planned to provide much more specific instruction and demonstration on the use of these materials.

Unfortunately, due to the large number and timing of snow days during my student teaching placement, the trajectory of the lesson was greatly affected. I introduced students to the lesson, but then we would not meet for two or three 
weeks, affecting their understanding and continuity. It also meant that I had to shorten the lesson, removing the modeling aspect almost entirely. That said, I felt this lesson was valuable in many ways. It allowed me to practice having discussions about design, and seeing what questions students responded to the most. Students responded in a very positive way to the whole idea of the project and seemed to love talking about chair design. I posed the question at the end of the introductory discussion asking students how they might re-design the metal folding chairs they were sitting in. While there was no written response about this, it felt to me as if this question opened students' minds and changed their perspective, however slightly, about the world around them.

Additionally, the brainstorm sketches and final drawings students created were full of imagination and creativity. Students drew individually, but they also practiced drawing and presenting to the entire class. The shared experience of the brainstorm process in this lesson was something that seemed to hook students in. On the next page are images of multiple students' work during this design process. 


\section{CHAIR DESIGN PROCESS IMAGES}

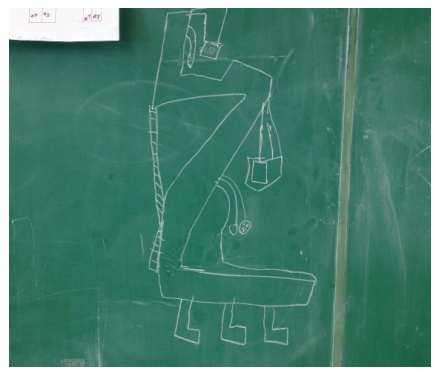

Figure 3.1

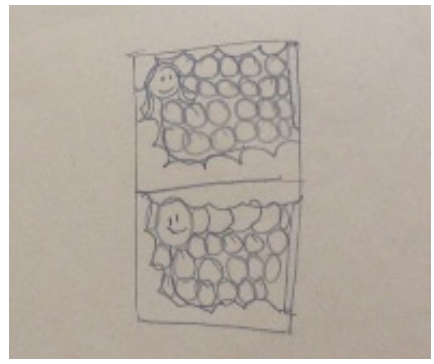

Figure 3.4

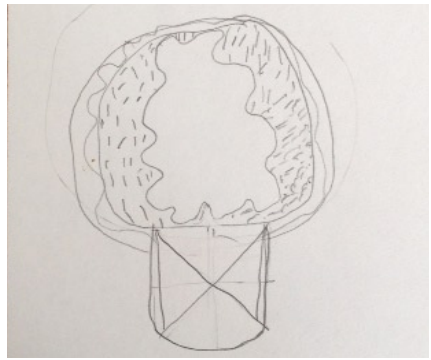

Figure 3.7

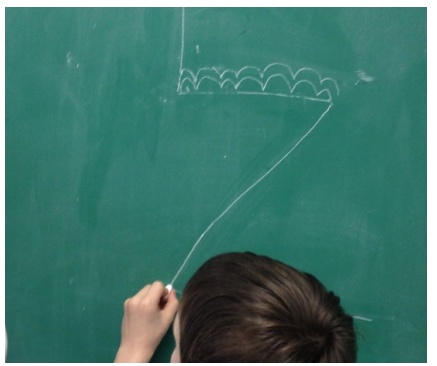

Figure 3.2

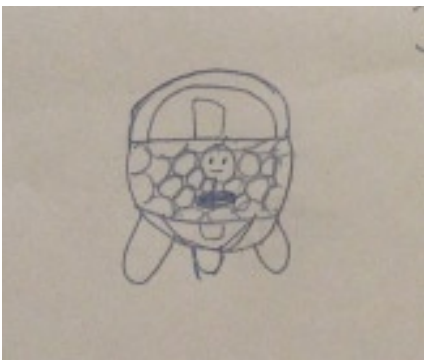

Figure 3.5

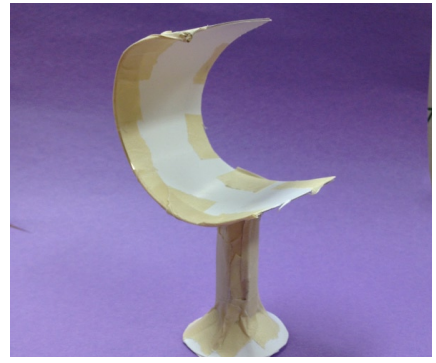

Figure 3.8

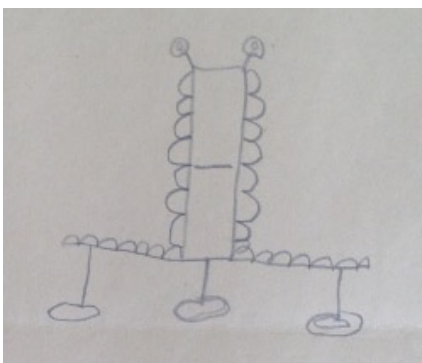

Figure 3.3

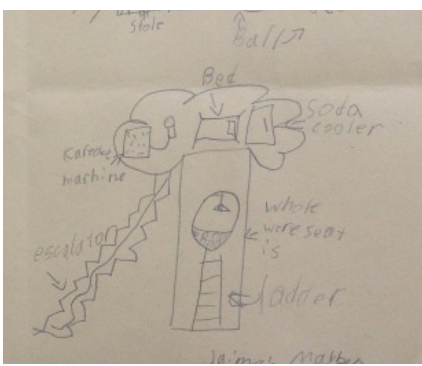

Figure 3.6

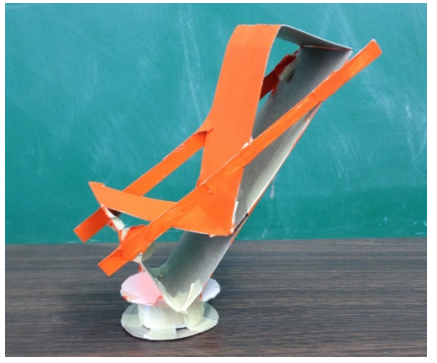

Figure 3.9

Figures 3.1-3.9: These images are selections of multiple students' work during their design process of their letter chair. Figures 3.1 and 3.2 are examples of the warm-up exercise where I asked students to draw an idea on the board in front of the other students. Figures 3.3 - 3.7 represent the different types of sketches students created when thinking of their ideas. Figure 3.8 represents the structural stage of model making. Figure 3.9 represents a model that has been painted.

After experiencing this lesson, and seeing how a disruptive schedule can so heavily affect student learning in a longer project, I felt that at the elementary level it might be more effective to divide an extensive project like this into smaller parts. 
In my own classroom I would break this lesson up into multiple projects, where it would be easier for students to pick up where they left off. Additionally, I would add to my school art curriculum more three-dimensional explorations of materials. While students did not complete their models, I was able to witness the beginning part of this process, and I found that working three dimensionally was something that students struggled with across the board. In my future art program, I aim to build in lessons where the focus is experimenting with materials to make threedimensional things. This would not only help students with building models but also promote spatial learning.

\section{Wallpaper Design}

My secondary level art education student teaching placement was done in a high school setting, where I taught students in grades 9-12. One class that I taught was Art 1, which incorporated two small groups of students, freshman through seniors, who were enrolled in this course for the entire year. These groups of students were very close with each other, and because of this, I decided to plan a unit that fed off of group reflection and critique as an aspect of the design process. I chose to focus this unit more on the process of design, making the products students were graded on various steps in the process. By doing, this I hoped to not only teach to the process, but also emphasize the importance of using a process to plan out a long project.

The lesson was based on designing wallpaper that would change the mood of a room through one or multiple elements and principles of design. The functions of 
these wallpaper designs were, therefore, very visual. I began this lesson asking students to reflect on and share interior spaces that had a strong visual affect on them. I asked them to tell their peers how these places affected their mood and what visual things they thought contributed to the creation of this mood. From there, I showed students examples of historical and contemporary wallpaper designs and dug deeper in the discussion of how the designs created mood by asking students to analyze the wallpaper in the presentation. Students design challenge was to create a wallpaper design that repeated and created a mood using the elements and principles of design.

The first project was creating brainstorm sketches as a way to warm up their thinking. Then students explored their ideas more deeply through the creation of an inspiration board of visual references as well as three additional sketches for their final ideas. They presented their inspiration boards to the class and received inprocess critique on their ideas. Last, students were asked to reflect on their peer critique and create and implement a plan for their final wallpaper design. Students then worked on creating a colored piece of their design's repeated pattern, which we worked together to repeat in a digital format. These final prototypes of the wallpaper were presented through a projection of the repeated pattern, along with the process materials that students created. As a group we viewed, discussed, and analyzed the success of each students work. On the next page is a compilation of images that show this project from process to product. 


\section{WALLPAPER DESIGN PROCESS IMAGES}

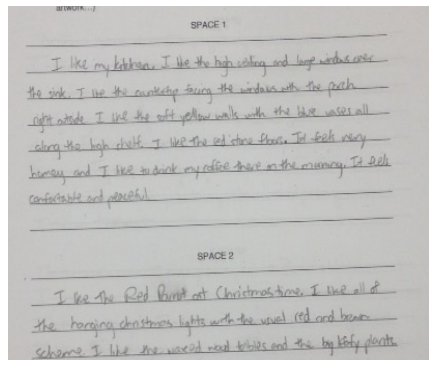

Figure 4.1

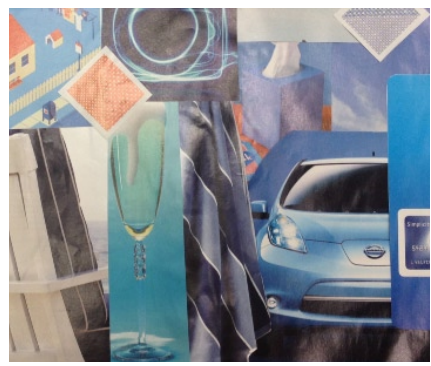

Figure 4.4

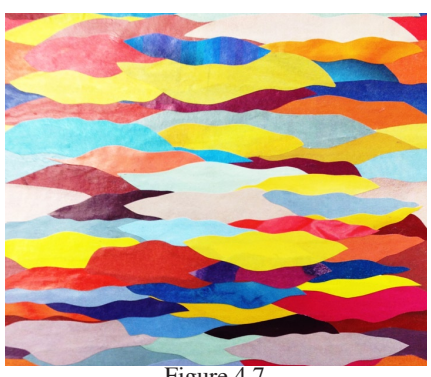

Figure 4.7

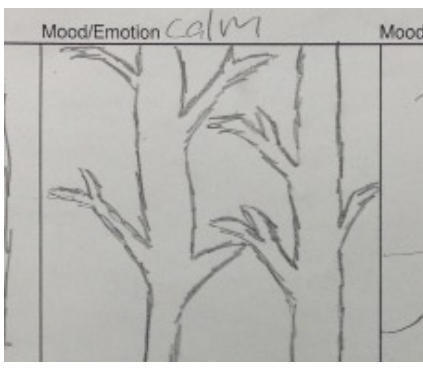

Figure 4.2



Figure 4.5

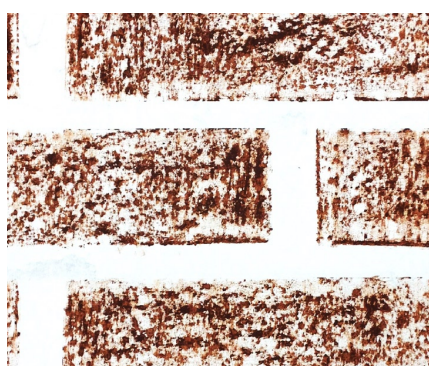

Figure 4.8

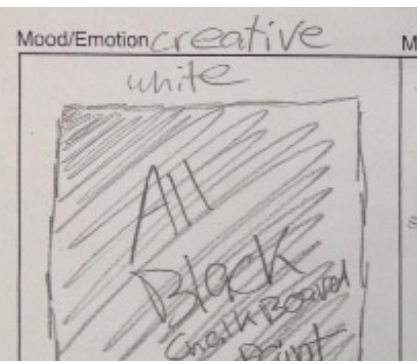

Figure 4.3



Figure 4.6



Figure 4.9

Figures 4.1-4.9: These images are selections of multiple students' work during their process designing wallpaper. Figure 4.1 is an example of a students initial reflection that asks the student to recall an interior space that made an impression on them. Figures 4.2 and 4.3 are examples of brainstorm sketches from students. Figures 4.4-4.6 are examples of how multiple students organized their inspiration boards for their final design. Figures 4.7-4.9 are examples of students' final wallpaper designs.

Students reflected on the design process and their project through a written reflection at the end of this unit. I found that most students valued the process and felt that it improved their final product. A majority of students said that they would 
use the process for other projects because of reasons relating to its ability to help deepen and organize their thinking. I saw students become very invested in this project; some students who often did not finish their work stayed after school to complete their wallpaper designs. While this could have been for multiple reasons, I think one reason is that each student felt proud of what they created and was invested in their ideas. This project allowed students to individually process, plan, decide, and control the outcome. Students had free range over choice of materials, and technique in how they would carry out their designs. I found that students often selected materials and methods that supported the mood of their wallpaper. For example, one student whose mood was "basic," created a simple wallpaper using the method of crayon rubbing on actual bricks. His solution was simple but very effective in supporting his mood, as the method itself was basic and lent to a basic visual design. I think that the freedom this project allowed and the responsibility each student had in carrying out their project promoted deeper learning and a feeling of pride in their work.

\section{Lighting Design}

To complement the more specific design process objectives and very visually functioning wallpaper project, I decided to focus my sculpture classes on designing a light. This project had a more organic reflective process and heavily promoted material exploration to create a successful final light prototype. In this lesson, students were first introduced to contemporary and unique types of lighting through a PowerPoint and discussion. Students were asked how the designers of the 
lights manipulated the light to make the design interesting. After this discussion, students were introduced to their challenge: to design a light that was either hanging or standing which manipulated the light from the bulb in an interesting way. From there, students created sketches of their ideas and moved quickly into the model making and material-testing phase. Students were required to make at least one model and one material test using a variety of recycled materials to form their final design. Students worked on these models and tests, constantly bringing them over to various light bulbs I had set up in the room to assess the effectiveness of their work. Once students had created their tests, they worked on and created a final prototype, which they presented to the class. At the conclusion, students reflected through writing on the success of their design and their experience making models. 


\section{LIGHTING DESIGN PROCESS IMAGES}

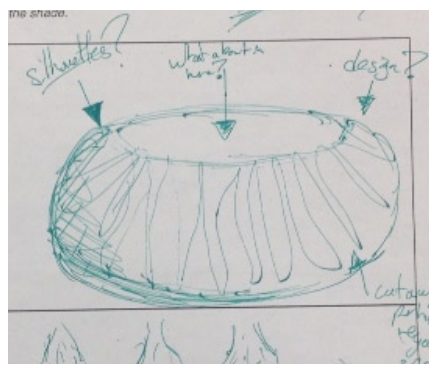

Figure 5.1

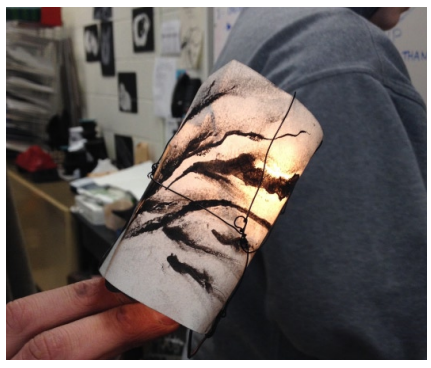

Figure 5.4

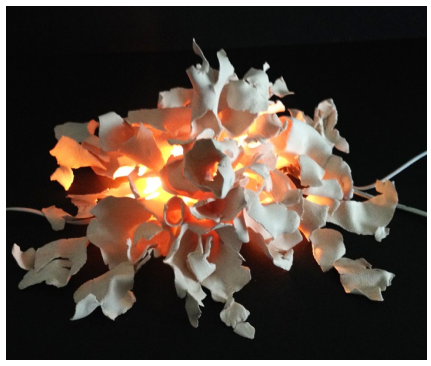

Figure 5.7

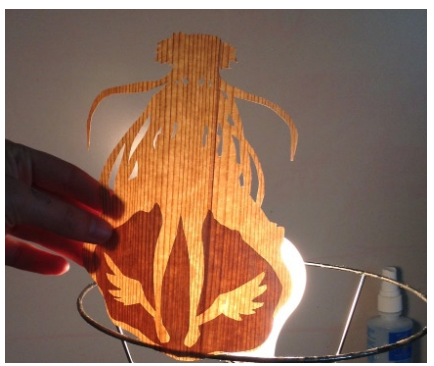

Figure 5.2



Figure 5.5

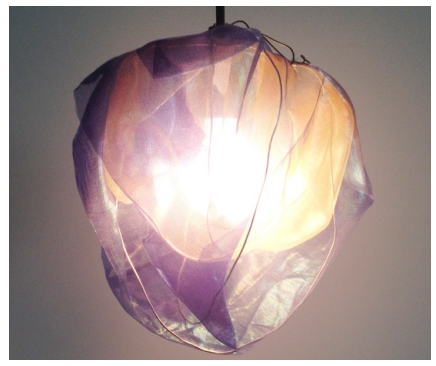

Figure 5.8



Figure 5.3

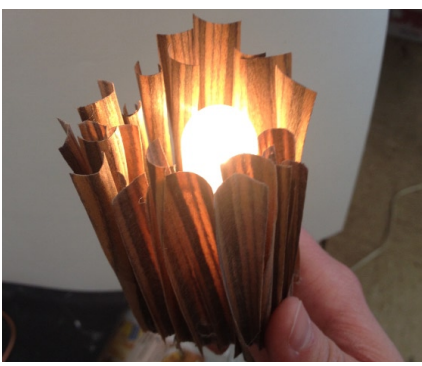

Figure 5.6

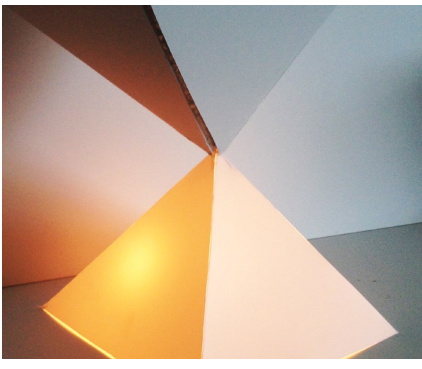

Figure 5.9

Figures 5.1-5.9: These images are selections of multiple students' work during their process designing a light. Figure 5.1 is an example of one student's brainstorm sketch. Figures 5.2-5.6 represent a variety of models and tests students' created during this project, which relied heavily on material manipulation. Figures 5.7-5.9 represent three examples of students' final prototypes for their lights.

I felt this lesson was very successful in organically involving students in the design process, because students had to physically figure out how to use their materials to get the best result. I made the spontaneous decision to set up three 
different kinds of light bulbs in the art room, one hanging, one on a stand, and one resting on the ground, to help students test their ideas. This turned out to be one of the most effective aspects of this project. Because there were only three lights, students naturally formed small groups and reflected on their models in process. It also provided me with three locations to visit and provide in-process feedback. Additionally, something I did not foresee as a success was the choice of a lighting project itself. As you will see on page 81, the final products students created were very successful. I think this was in part because of their hard work and testing, but I also think the nature of designing something to manipulate light creates products that can be visually successful in a variety of ways. Even students who had trouble working with the material were able to create unique and interesting designs. The fact that this type of design was so accessible to all levels makes me want to try this lesson with students of all ages.

\section{Final Thoughts}

The ability to take my research and apply it to both my curriculum project and multiple implemented lessons deepened my understanding of the effects of design. It provided me with multiple experiences from which I can reflect on and take from in my future teaching. In the future, I hope to use these and other experiences teaching design to revise my curriculum and create an inclusive K-12 curriculum project. Additionally, I hope to do more research based on my 
experience teaching design. Specifically, I am interested in applying a lesson like the lighting design to all age groups of students to compare and contrast my findings. I am thankful that I was able to explore design and the design process through a variety of formats, and I plan to continue to reflect on my teaching experiences. 


\section{CHAPTER 5}

\section{CONCLUSIONS \& REFLECTIONS}

This thesis project has provided me with a richness of research and experience in design and art education. I was able to explore design from multiple angles and experience teaching it in a variety of ways, which was extremely valuable to me in my professional growth. It has been a long but exciting journey. While in some ways my process of research was a little out of the normal order of things, I think it benefitted me greatly, because I was able to constantly reflect on and apply what I had learned to new situations, be it in writing or teaching. In actuality, I believe the compilation of this project utilized the design process heavily and, in a way, this thesis represents both product and process at the same time. This is most likely a reflection of something that has become more apparent throughout this research journey; so much of my drive to study design is because design is a framework that has become an essential part of the way I operate. It is something that I may have taken for granted, and this research has helped me understand both how design affects others, but also how design has so deeply affected my own life.

I have learned so much along the way, but this thesis project has also raised many more questions for investigation in the future. In Chapter 2, I was able to better define my ideas of design through reflection and literature, as well as explore what it means to be a teacher researcher in my teacher action research project. 
Chapter 3 allowed me to dig even further into the rich history of art education to highlight some influential movements from the past, as well as some current research that affects design education today. Here, I reflected on how valuable looking into past ideas can be. In Chapter 4, I was able to apply some of my knowledge about design and art education through the creation of a K-6 curriculum, as well as through planning and teaching multiple design lessons in my student teaching. This experience teaching design to students of all ages grounded my thoughts and confirmed my beliefs in the importance of teaching design as both product and process. However, I think that the most important mental shifts that occurred during this process should be discussed here.

I approached this thesis project excited to explore design and the design process primarily, because I believed it would give students tools to think and solve problems. Not only was I able to see this in action, but also, through multiple experiences, I feel I am able to now put in words what I find is important about the tools of design for students and teaching. Over and over again I saw students participating in the steps of the process, actively thinking and deciding on solutions for their projects. In the student reflections I read, an overwhelming number of students felt that parts or all of the design process were not only helpful but improved their ability to think and solve problems at hand. I have mulled over these experiences, observations, and students' words many times. What I have found from this reflection is that the design process allows the students and the teacher to visually see ideas at work. It serves as visual and physical history of thought that can be analyzed in the moment and revisited in the future. This physical history, or story 
of thinking, is amazing because it literally and concretely displays the connection of ideas an individual has along their path to solve a problem. This is what makes the design process so unique. In a classroom it benefits the students by making complex problems more concrete and understandable, as it physically saves and marks students' thoughts. In this way, students can come to one solution, try it out, save it, and then move on to a different solution, allowing for further expansion and exploration of ideas. However, they will always have the models or drawings they created to revisit and reflect upon. Having students create projects with the design process allows teachers to see in a visual way what and how students are thinking. I think this deepens a teacher's ability to assess student work and helps teachers find where students are having the most difficulty. The models, drawings, writings, and discussions that occur along the way create an individual support system for students to build on their own understandings.

Because this visual history is so literally out in the open, it promotes a collaborative atmosphere. Other students and teachers can see what is being worked on, which invites conversation and even just observation of what others are up to. Using reflective aspects and community critiques that the design process encourages, I think, helps students become more comfortable in discussing their work with others and learning from casual classroom interactions. I believe these kinds of unplanned, but teacher supported, student discussions lead to increased student engagement, a positive classroom community, and a deeper learning experience. I think this is because these types of environments show students how valuable their ideas are; they experience that what they think is important in 
helping others, as well as helping themselves. This quality of teaching design is something that, at first, I assumed was a natural by-product of this process or subject. However, I think that similar to my reflection on this paper and research approach being so embedded in the design process, my actual style of teaching is also heavily influenced by the design process. This is most likely because my best reference for teaching design is from my past design teachers, who have influenced my style of thinking. While I have not been able to name all that this realization means for me as a teacher, understanding that the way I think and teach is different from how others might is very valuable. This knowledge will help me identify in further research and reflection how I created situations within my classroom that I may have previously attributed to simply a natural happening.

While my project focused on teaching design as well as the design process, I think the most important learning that occurred was related to the implications of using the design process. I do think that talking and learning about design made my lessons more relatable and approachable for students. However, I do not think I focused on trying different ways to expose students to the designed world as deeply as I focused on teaching the process. That said, exploring the effects of exposing students to the designed world they live in is something I am interested in studying more deeply in the future.

I have found that in all aspects of my research, what I have learned has only created more questions for what I want to learn next. I want to know how teaching the design process at many levels affects students' lives. I wonder what parts of process thinking are shared within the design, creative, artistic, and reflective 
process. I want to keep teaching design and the design process and seeing what I learn and how I can change my own practice. To me the possibilities with design are endless, and I am grateful and excited that I will have the opportunity to keep learning. The further study that this research inspires is not just on a personal level. I believe that the field of art education and possibly education itself needs to investigate the implications and benefits of teaching design more deeply. Primarily, I think there should be more research done pertaining to the long-term effects of teaching the design process. I feel that the implications for teaching design are numerous and merit more exploration.

My project and written paper provides just a glimpse of the learning that has occurred on this journey. However, within that small glimpse, it is clear that design is an important area to investigate. It is exciting that this idea seems to be catching on with current research on design and design thinking. I remember thinking about what I was most interested in teaching at various points in my graduate career. I have always seen thinking about and teaching design as a flame that keeps burning in my mind. It is something that I come back to over and over again in my thoughts. After doing this research I can feel this flame, which has increased in size and strength. I look forward to where it takes me next. 


\section{REFERENCES}

Addison, N. \& L. Burgess. (2013). Debates in Art and design education. Oxon, UK: Routledge.

AIGA. (2014). AIGA design ed k12. Retrieved from http://www.aiga.org/Design-Ed-K12/ http://www.k12lab.org/

Amburgy, P. M. (1990) "Culture for the masses: Art education and progressive reforms 1880-1917." Framing the past: Essays on art education. Reston, VA: The National Art Education Association.

Anderson, G., Herr, K, \& Nihlen S. (1994). Studying your own school: An editor's guide to practitioner action research. Thousand Oaks, CA: Corwin Press.

Bryant, C. (April, 2015). “The tinker yard." School arts. 114, 12-21.

Carroll, M., Goldman, S., Britos, L., Koh, J. Royalty, A, \& M. Hornstein. (2010). Destination, imagination and the fires within: Design thinking in a middle school classroom. JADE. 29, 37-53.

Chalmers, F. G. (2000). A 19th century government drawing master: The Walters Smith reader. Reston, VA: National Art Education Association.

Chapman, L. H., (1978). Approaches to art in education. Harcourt Brace Jovanovich: New York, NY.

Cochran-Smith, M. \& S. L. Lytle. (1993). Inside outside: Teacher research and knowledge. New York, NY: Teachers College Press.

Cross, N. (2001). Designerly ways of knowing: Design discipline versus design science. Design Issues. The MIT Press: 17, 49-55.

Day, H. \& Hurwitz, A. (2012). Children and their art: Art education for elementary and middle schools. Boston, MA: Wadsworth, Cengage Learning.

DIG. (2015). NAEA DIG: Design issues group. Accessed May, 2015 from: http://digarted.weebly.com/. 
Duckworth, A. L., Peterson, C., Matthews, M. D., Kelly, \& D. R. (2007). Grit: Perseverance and passion for long-term goals. Journal of Personality and Social Psychology American Psychological Association: 92, 1087-1101.

Duncum, P. (May 2012) "Roaming the rhizomic playing field of visual culture in art education." Visual Inquiry. V2, Number 2, 111 - 122.

Dweck, C.S. (2006) Mindset: The new psychology of success, how we can learn to fulfill our potential. NY, NY: Random House.

Efland, A. (1990). A history of art education: Intellectual and social currents in teaching the visual arts. New York, NY: Teachers College Press.

Efland, A. \& Soucy, D. (1992). "Who was Isaac Edwards Clarke, Why did he do what he did, and why should we care?" The History of Art Education: Proceedings from the second Penn State Conference, 1989. The National Art Education Association: Reston, VA.

Eisner, E. W. (1972). Educating artistic vision. Macmillan Publishing Co., Inc.: New York, NY

Faulkner, R. \& Zeigfeld, E. (1963). Art Today: An introduction to the visual arts (5th ed.). Holt, Rinehart, and Winston, Inc.: New York, NY.

Gentili, A. M. (March, 2015). 3D design and printing in the art room. 2015 NAEA National Convention. New Orleans, LA.

Gillard, K. (March, 2015). Design thinking and proficiency with student sketchbooks. 2015 NAEA National Convention. New Orleans, LA.

Helvetica. Hustwit, Gary. Plexifilm, 2007, DVD.

Heskett, J. (2001) Past, present, and future in design for industry. Design issues. The MIT Press: 17, 18-26.

Hodgkinson, Harold. (1991, Sept) Reform versus reality. Phi Delta Kappan, v72, 8-16.

Hodik, J. (1992) "The art education of the designer: a case study of Alvin Lustig (1915-1955) and his contributions to art education." The History of Art Education: Proceedings from the second Penn State Conference, 1989. Reston, VA: The National Art Education Association.

Kupferschmid, Indra. (2011) The font bureau. Neue hass grotesk. Retrieved from: http://www.fontbureau.com/nhg/history/ 
Lancaster, J. (1986). Art, craft, and design in the primary school. NSEAD: Wiltshire, UK.

Lawson, B. (2004) What designers know. Oxford: Architectural Press.

Lawson, B. (2005) How designers think: The design process demystified. Oxford: Architectural Press.

Lozner, R. (2013, Jan 2). Where is design in the k-12 curriculum? (And why isn't it taught in Art education programs?). AIGA. Retrieved from http://www.aiga.org/where-is-design-in-the-K12-curriculum/.

Masterson, E. (March, 2015). A place for process. 2015 NAEA National Convention. New Orleans, LA.

Montana-Hoyos, C., \& Lemaitre, F. (2011). Systems thinking, disciplinarity and critical thinking in relation to creativity within contemporary Arts and design education. Studies in Learning, Evaluation, Innovation, and Development: 8, 12-25.

National Art Education Association. (1994). The national visual arts standards. Reston, VA: National Art Education Association.

Noffke, S. \& R. Stevenson. (1995). Educational action research: Becoming practically critical. New York, NY: Teachers College Press.

Nosalik, P. (March, 2015). Roylco's art of engineering. 2015 NAEA National Convention. New Orleans, LA.

Pink, D. H. (2006). A whole new mind: Why right brainers will rule the future. NY, NY: The Berkley Publishing Group.

Plishker, B. \& Hammonds, S. (March, 2015). Feedback: A bridge to teaching and learning. 2015 NAEA National Convention. New Orleans, LA.

President's Committee on the Arts and Humanities (2011). Reinvesting in Arts education: Winning America's future through creativity in schools. Washington D.C.: President's Committee on the Arts and Humanities.

Rayala, Martin. (1995). A guide to curriculum planning in art education. Milwaukee, WI: Wisconsin Department of Public Instruction.

Rhode Island Education Data Reporting. (2015, March 3). InfoWorks! Retrieved from: http://infoworks.ride.ri.gov. 
Saunders, R. J. (1985). “Owatonna: Art Education's Camelot.” The history of art education: Proceedings from the Penn State Conference. The Pennsylvania State University College of Arts and Architecture School of Visual Arts.

Schrijver, Ward. (2012) "New art for a new age.” GRK Magazine. 4-24.

Seidman, I. E. (1991). Interviewing as qualitative research. New York, NY: Teachers College Press.

Shiner, L. (2001). The invention of Art: A cultural history. Chicago, IL: The University of Chicago Press.

Smith, P. (1996). The history of American art education: Learning about art in American Schools. Greenwood Publishing Group, Inc. Wesport: CT.

Soucy, D. (1990) "A history of art education histories." Framing the past: Essays on art education. Reston, VA: The National Art Education Association.

Stankiewicz, M. A. (2001). Roots of art education practice. Worcester, MA: Davis Publications.

Szekely, G. \& J. A. Bucknam. (2012). Art teaching elementary through middle school. New York, NY: Routledge.

Taylor, K. V.(March, 2015). Collaborative construction: Building bridges. 2015 NAEA National Convention. New Orleans, LA.

Vande Zande, D., Warnock, L., Nikoomash, L., \& K. Van Dexter. (2014). The design process in the Art classroom: Building problem-solving skills for life and careers. Art Education. 67, 20-27.

Wolcott, H. (1995). Transforming qualitative data: Description, analysis, and interpretation. Thousand Oaks, CA: Sage Publications.

Yeager, D. S. \& Dweck, C.S. (2012). Mindsets that promote resilience: When students believe that personal characteristics can be developed. Educational Psychologist. 47, 302-314. 


\section{APPENDIX A: PRELIMINARY TEACHER INTERVIEW}

\section{Preliminary Art Teacher Interview \\ Interview Questions for Teacher:}

1. How did you decide to become an Art Education teacher? (I am asking what motivation she has behind becoming an art education teacher)

2. What is most the most important thing for students to take away from your classroom? (I am asking what she feels is core about her teaching)

3. What is your favorite lesson or unit you have done, and why? (I am trying to see what types of lessons she values)

4. What is your least favorite lesson or unit, and why? (I am trying to see what lessons she does not value)

5. How do you define design and how does it relate to art education? (I want to know her definition of design to compare with mine, and with the end interview)

6. Do you incorporate design into your lessons? If so, how do you do this? (I want to get a better understanding of what she thinks design is and how she feels it should be introduced to students)

7. Have you ever done a lesson incorporating design with the group of students I will be teaching? If so, what did you do? (I want to understand if the students I will be working with have been exposed to design lessons at all)

8. Do you practice art and/or design outside of your teaching? If so, what do you do most? (I want to know more about her personal drive for art making and designing, and see if that ties into the views she has about what to teach her students above) 


\section{APPENDIX B: PRELIMINARY STUDENT SURVEY}

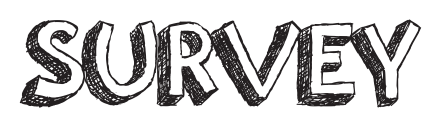

NAME:

1) What does problem-solving mean?

2) Tell me about a time you solved a problem. How did you do that? How did you feel when you did that?

3) What does design mean? Give an example.

4) What is a designer, and what do they do? 


\section{APPENDIX C: DESIGN UNIT}

\section{FIRST LESSON IN DESIGN UNIT:}

\section{Art Lesson Title: What's Your Function?}

Art Theme: (key art concept or art focus of this lesson) Product designers create objects that have functions.

Overarching Lesson Goal(s): (note the broad art understanding/s or enduring idea/s this lesson addresses)

This lesson will help students begin to think about why a designer would design an object, and what factors they need to consider in a product.

Overview: (summarize the key content covered and the sequence of art teaching and learning activities) Students will analyze objects that they use in every day life and specify their function. This will help students make the connection that objects are created by a designers who a specific intent. They will also be encouraged to think about function as both physical and aesthetic.

Grade Level/Class: $4^{\text {th }}$ grade, (and why this lesson is a good match for these students): Elementary students in this age bracket are usually in symbol making stage of artistic development (Lowenfeld 1987). Developmentally, students in this age group are inquisitive and excited about discovering new things, and generally have an active imagination (Day \& Hurwitz 2011). Asking students to investigate objects that they normally take for granted will provoke their natural inquisitive qualities.

Time Frame: 1, 50 -minute class periods

Art Lesson Objectives (with National Visual Arts Standard \#):

As a result of the instruction, students will:

Objective 1: Analyze designed objects of every day life in both class discussions and in a group project with an activity sheet.

\section{NVAS - Anchor Standard \# 7: Perceive and analyze artistic work}

Objective 2: Interpret the qualities of their design objects that contribute to their understanding of the function

NVAS - Anchor Standard \#8: Interpret intent and meaning in artistic work.

Objective 3: Relate the objects they are analyzing to the every day life of the user.

NVAS - Anchor Standard \#11 Relate artistic ideas and works with societal, cultural and historical context to deepen understanding.

Evaluation: (correlated with above art lesson objectives to measure student learning related to each objective)

Students will be evaluated using the Object Investigation sheet (attached). 
Essential Questions: (Throughout this lesson plan, add in italics or underline several Essential Questions that you will ask students while teaching this lesson. These are open-ended questions with no "one right answer" that promote critical thinking and problem solving. Identify your three most important Essential Questions here.)

1. What is a function?

2. Does a function have to be something you do?

3. What about the way objects look give you clues about what their function?

4. If you had to pick an emotion to describe your object, what would that be?

Your Personal Stake (Optional): (What could you say to students about why this lesson is personally meaningful to you?)

I studied design and worked as a furniture designer for a number of years.

Art Supplies and Equipment Needed - and any Safety Considerations:

Pencil

Paper

Copies of Object Investigation Sheet

Exemplary Artworks Focused Upon and Visuals: (preferably insert thumbnails as well as noting titles!)
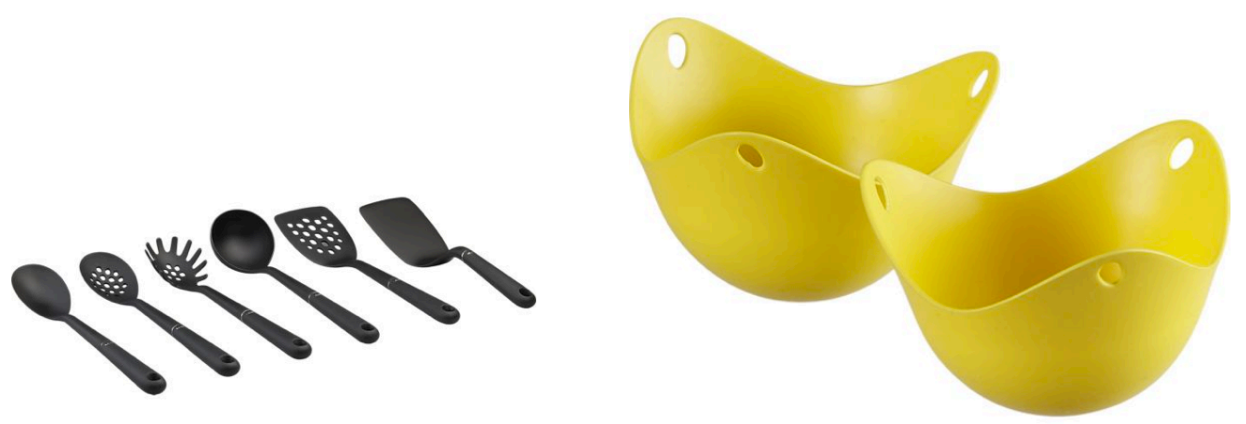

Design objects from Crate \& Barrel - these are representational of what I might bring in, which will be every day object.

Diversity of Art Content: (note how you have considered multicultural art/artists, women artists, and/or non-fine art, etc.)

The content of this lesson is primarily design, and thus satisfies the non-fine art category.

Interdisciplinary Connections (Optional): (do specify IF connected to Common Core State Standards!)

Art Vocabulary and Definitions: (write in developmentally appropriate wording)

Function - the purpose or use of something that exists

Object - something you can see and touch that is not alive

Designer - a person who plans something new to be made

Preparation Before Teaching:

Print Object Investigation Sheet

Gather Objects for Investigation 
Introductory Activity and any Pre-Assessment: (describe how you will first explore topic, art concepts, processes; note key instructional content in lesson plan and/or attach any PowerPoint or Prezi also note specifics of any pre-assessment)

The class will be introduced to this activity through and whole class discussion about a backpack. I will bring this backpack in and display it for students; I will tell them that someone designed this backpack. I will then prompt students with questions about the backpack's function:

What do I do with this backpack?

How does this backpack help me?

How do you know that?

What does this backpack look like, and why do you think it looks that way?

Who is this backpack for?

Would you want this backpack?

Art Lesson Activity and Formative Assessment: (plan specifics and number steps of studio demo and/or other art teaching and learning activities; also plan how you will gauge learning in process to guide you in re-teaching or modifying lesson)

Students will work in groups of 4 investigating their object using the Object Investigation sheet (attached). Each group of students will investigate one object that I bring in to class (Possible objects: Pen, Soap Dispenser, Cup, Bowl, Shoe, Sunglasses, Headphones, Backpack, Utensil, Packaging)

Closure and Summative Assessment: (plan and describe how you will reinforce desired learning and assess learning)

After students are wrapping up their Object Investigation sheets, I will ask them what they learned about their object that they didn't know before. I will collect their Object Investigation sheets to see how extensively they analyzed their object.

\section{Clean-up Procedures:}

No special clean up needed, just collecting papers

Accommodations for Students with Special Needs: (plan accommodations for 2-3 specific special needs)

1. If a student has trouble reading the Object Investigation sheet, I would have a partner in their group read the questions to them.

2. If a student is an ESL student, I will put them in a group with a student who is also bilingual and also provide individual help depending on the language skills of the other students in the group.

Unit Connection: (this art lesson is or could be part of an Art Unit focused on what? Think of sequencing art lessons!)

This will be the first lesson in a mini unit on design that introduces product design. The next lesson will focus on teaching students the design process. 


\section{SECOND LESSON IN DESIGN UNIT:}

\section{Art Lesson Title: REDESIGN CHALLENGE}

Art Theme: Learning and practicing the design process.

\section{Overarching Lesson Goal(s):}

Students will practice the design process, a cyclical process of analysis, synthesis, and reflection. Students will analyze their problem, create solutions, and then reflect on the effectiveness of their solution.

\section{Overview:}

Students will be given a design challenge, to redesign one of the objects we explored as a class, or an object from their everyday life. They will then take their design through multiple stages of the design process beginning with brainstorming and sketching, reflecting on this; then building a prototype and reflecting on this; finally, building a final prototype and having a class reflection on everyone's work. I want students to try out this process in various ways.

Throughout the lesson I will bring examples of prototypes and sketches from designers to show students examples of how prototyping and sketching can be done.

Grade Level/Class: $4^{\text {th }}$ grade, and why this lesson is a good match for these students: Elementary students in this age bracket are usually in symbol making stage of artistic development (Lowenfeld 1987). Developmentally, students in this age group are inquisitive and excited about discovering new things, and generally have an active imagination (Day \& Hurwitz 2011). Asking students to think about how they could make an object they explored, or an object that they use every day, better in a re-design will activate their imaginations.

Time Frame: 3-4 , 50 -minute class periods

Art Lesson Objectives (with National Visual Arts Standard \#):

As a result of the instruction, students will:

Objective 1: Create sketches and multiple 3D mixed-media models (prototypes) as part of the design process.

Anchor Standard \# 3: Refine and complete artistic work.

Objective 2: Present their ideas through sketches and multiple 3D mixed-media models (prototypes) to their classmates.

Anchor Standard \#6 Convey meaning through presentation of artistic work.

Objective 3: Reflect and analyze the work made by themselves and their peers through multiple class critiques and activity sheets.

Anchor Standard \# 7: Perceive and analyze artistic work

Objective 4: Connect the objects they are analyzing to their everyday lives.

Anchor Standard \#11 Relate artistic ideas and works with societal, cultural and historical context to deepen understanding. 


\section{Evaluation (correlated with above art unit goals):}

Students will be evaluated using a rubric that includes the following categories: (RUBRIC ATTACHED)

1) PROCESS: The progression of students' ideas between sketches, 3D mixed media models (prototypes), and reflections in how each informed the their creation of their final prototype.

2) PRESENTATION: The development of students presentation skills over the course of the unit.

3) REFLECTION: Students will be evaluated on their participation and constructive contribution to their classmates both partner reflections and whole class reflections, and on their development of these reflection skills over the course of the unit.

4) CONNECTION: Students will be evaluated on their group investigations of everyday objects and the decisions they are making in their object re-design.

\section{Essential Questions:}

1. What is the design process?

2. Why do designers brainstorm and sketch?

3. Why do designers make a prototype?

4. Why do designers make more than one prototype?

Your Personal Stake I studied design and worked as a furniture designer for a number of years, I will bring in one of my prototypes to show the class.

Art Supplies and Equipment Needed - and any Safety Considerations:

Pencil

Paper

Paint Brushes

Eraser

Foam Core boards

Recycle Center materials

Cardboard

String

Pipe Cleaners

Model Magic, Paper, Markers, Tempera Paint, Glue, Tape, Scissors

Projector (possibly for PowerPoint, or printed out visuals) 


\section{Exemplary Artworks Focused Upon and Visuals:}


KIDS ONLY SHAPED FOAM

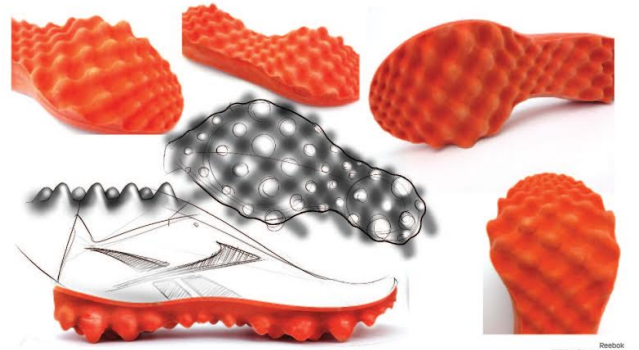

Reebok sent me the actual kids footwear prototypes and final products in the mail that I will be showing students, along with sketches, inspiration, and orthographic drawings of the footwear. This will exemplify the design process.

Diversity of Art Content: (note how you have considered multicultural art/artists, women artists, and/or non-fine art, etc.)

The content of this lesson is primarily design, and thus satisfies the non-fine art category.

Interdisciplinary Connections (Optional): (do specify IF connected to Common Core State Standards!)

Art Vocabulary and Definitions: (write in developmentally appropriate wording)

Design - to plan or make something for a specific purpose

Brainstorm - a time for creating multiple ideas, there are no wrong answers when brainstorming.

Reflect- to think back about something you have done or made and what you might do differently

Feedback- advice or comments from someone else about the object they made Prototype- a three dimensional representation of an object made out of materials available to test how the object will look and function

Sketch- a quick drawing to visually show ideas that is not concerned with accurate representation

\section{Preparation Before Teaching:}

Prepare presentation device (computer projector or over head)

Copies of brainstorming sheet and reflection sheet.

\section{Introductory Activity and any Pre-Assessment:}

This lesson is part of my teacher action research project, so their preliminary assessment will be the survey I give them at the beginning of the first class asking questions about design and the design process. 


\section{Art Lesson Activity and Formative Assessment}

\section{DAY 1}

\section{ACTIVITY 1}

Students are introduced to the challenge:

Your challenge is to redesign one of the objects we explored as a class, or an object from your everyday life. The first task is picking what object you want to redesign, and then brainstorming in quick drawings and words on this activity sheet. (20 min)

\section{ESSENTIAL QUESTIONS:}

How could you change this object to make it better (for you, an adult, a friend, or in general)?

Why does your idea make your object better?

\section{ACTIVITY 2}

Students will pass their completed drawings to 4 people (they are sitting in groups of 4) and each student will put a star next to the idea they like best based on the drawing. Students will get their sheets back and either choose one of the drawings that their classmates liked the most, or pick from the ones they liked best. (10 min)

\section{ACTIVITY 3}

Students will then do a larger, more detailed drawing of the design they wish to build. (20 $\min$ )

\section{DAY 2}

\section{ACTIVITY 4}

I will introduce students to prototypes, how they are 3D visual representations designers use to test their ideas. We will look at examples of Reebok shoes and my own work. (10 $\min$ )

(pass out caddies of student materials that have been pre-made)

Students will make their first prototype. They will be told that this is a quick activity to help them learn what to do next, they will have 15 minutes and the materials listed above.

\section{ACTIVITY 5}

Students will fill out a reflection sheet for themselves and their partner (5-10 min). We will talk as a class about these reflections. What did students learn about their designs? What did they learn from their peers?

\section{ACTIVITY 6}

Students will spend the last 10 minutes of class taking their reflections into account, and drawing or writing their new plan for their final prototype. 


\section{DAY 3}

\section{ACTIVITY 7}

Students will have 30 minutes to make their final prototype. They will be instructed to do the best they can to make a good visual 3D representation of their object.

\section{ACTIVITY 8}

Students will have 5-10 minutes to reflect on their own work and the work of a classmates (using the reflection sheet). Then the rest of class will be a discussion:

Did the students like doing the design process?

What did they learn?

What was their favorite part?

Why?

\section{Closure and Summative Assessment:}

Students will have 5-10 minutes to reflect on their own work and the work of a classmate's (using the reflection sheet). Then the rest of class will be a discussion about what they learned in a critique/ celebration where we look at everyone's final prototypes. Summative questions:

Did the students like doing the design process?

What did they learn?

What was their favorite part?

Why?

Who changed their idea after the first prototype? Who didn't?

Do you think your first prototype was better or your second?

Did you like making two prototypes?

The summative assessment will be the summative survey I give to students that asks them questions about what they learned about design.

\section{Clean-up Procedures:}

No special clean up needed, just putting away supplies.

Accommodations for Students with Special Needs: (plan accommodations for 2-3 specific special needs)

1. If a student had trouble with drawing or writing, I would let these students begin working with materials and just create multiple prototypes to show their ideas rather than sketches. If they were uncomfortable with this.

2. If a student in the class had ADHD and was distracted by all the materials and activity, I would put them at a separate desk so that they had more space to work and concentrate.

\section{Unit Connection:}

This will be the second in a mini unit on an introduction to design and the design process. 


\section{APPENDIX D: OBJECT INVESTIGATION SHEET}

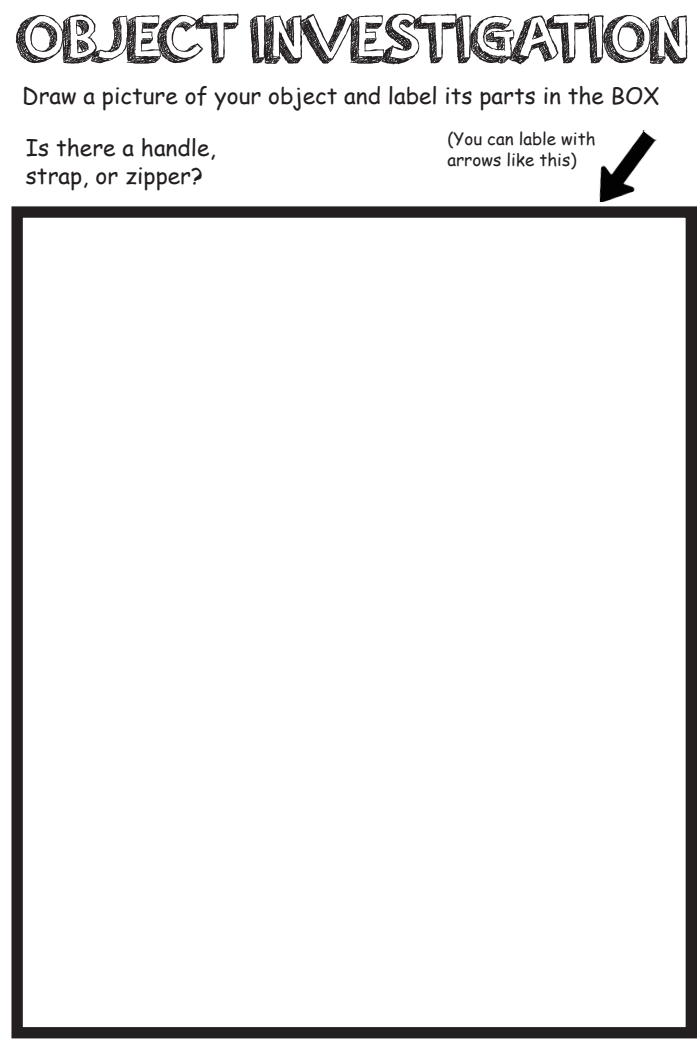

Names:

What is your object used for?

How do you know this object is designed for that use?

What color is your object, why do you think it's that color?

What shape is your object, why would it be that shape?

What material is your object made out of? Why would a designer use that material?

Try using this object, was it easy to use?

If you had to to give your object an emotion what would it be? 


\section{APPENDIX E: BRAINSTORM SHEET}

\section{BRAINSTORM}

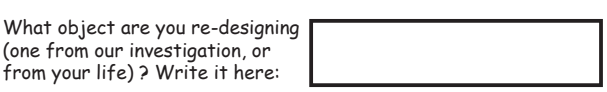

NAME:

\begin{tabular}{|l|l|}
\hline How could you change this object so that YOU like it more? & How could you change this object so that an ADULT likes is more? \\
\hline How could you change this object so that a FRIEND likes it more? & What OTHER way would you change it? \\
\hline
\end{tabular}

Which idea do you want to try MAKING? Why? 


\section{APPENDIX F: REFLECTION SHEET}

\section{REELECTION}

NAME:

CLASSMATE

What is your classmate's object?

What are two things you like most about their object, and why? 1 -

$2-$

What are two things you think they could change about their object to make it better, and why?

1 -

2-

\section{SELF}

What is your object?

What are two things you like most about your object, and why?

1 -

What are two things you would change about your object to make it better, and why?

2

\section{REELECTION}

NAME:

CLASSMATE

What is your classmate's object?

What are two things you like most about their object, and why? 1 -

2-

What are two things you think they could change about their object to make it better, and why? 1 -

2-

\section{SELF}

What is your object?

What are two things you like most about your object, and why? 1 -

2-

What are two things you would change about your object to make it better, and why?

1 -

2- 


\section{APPENDIX G: FINAL STUDENT SURVEY}

Name:

\section{CONGRATULATIONS ON YOUR DESIGISI}

Here are a few questions for you to help me!

1. What was your favorite thing you learned or did during these lessons? AND, Why?

2) What was one part of the lesson that was hard? AND, What did you do to overcome it?

3) What are two things you learned about design in our classes?

4) What will you design next? How will you do it?!

Do you have anything else you want me to know?

THANK YOU!!!!! 


\title{
APPENDIX H: FINAL TEACHER INTERVIEW
}

\author{
Final Interview with Art Teacher
}

1) Did observing this unit affect your ideas about design or the design process?

2) What part of this unit do you feel was most successful and what do you think students learned most

3) What part of this unit do you feel was least successful, and what would your recommend I do differently?

4) Was this unit similar to any you have taught, and if not would you consider teaching something similar in the future?

5) What advice would you give me as a beginning teacher? 


\section{APPENDIX I: THE LETTER CHAIR LESSON}

\section{Art Lesson Title: The Letter Chair}

Art Theme: Art is about making the ordinary extraordinary

\section{Overarching Lesson Goal(s):}

The students will be introduced to the world of design specifically furniture design. We will talk about what a designer is and how they designed the furniture they use everyday. The students will be asked to design a chair inspired by a letter of the alphabet and go through the design process (brainstorming, sketching, reflecting, prototyping, and final reflection) to make a small 3D model (5in Cube Max) of their letter chair.

\section{Overview:}

Students will be introduced to the world of chair design by a PowerPoint presentation of different types of chairs designed in the world today (included). They will analyze each chair through a class discussion and they will be asked to hypothesize whom the designer may have been designing for and why.

Next, students will be introduced to the chair design challenge; to design a chair based on a letter of the alphabet. Students will be shown some sample models of this chair, and we will discuss the criteria for their final model of the chair.

After students have been introduced to the project and the criteria for evaluation, students will begin a series of brainstorm sketches of their chair ideas. Students will reflect in small groups on these sketches and chose a final sketch to draw for their chair model plan. Students will then draw a more detailed model of their chair.

Last students will begin the model making process. I will direct them through 3 steps, making a form, shaping and texturing the form, and painting the chair. Once the chair models are complete, students will reflect on their chair and their work in the class with a paragraph reflection on what went well, and what they would do differently next time.

\section{Grade Level/Class: $4^{\text {th }}$ Grade}

This lesson is a good match for the $4^{\text {th }}$ grade students because these students are capable of a multi step project, and they have very active imaginations. This chair project will ask them to think creatively and problem-solve both the form and function of their chair, a task that will both draw on their imaginations and creativity while pushing them to do so in creative ways.

Time Frame: 5, 45 -minute class periods

\section{Art Lesson Objectives:}

As a result of the instruction, students will:

Objective 1: Design a chair through multiple brainstorm sketches that is based on a letter of the alphabet with brainstorm sketching.

RI GSE: VAD 3 (3-4) - 1 Students demonstrate the ability to communicate in the language of Visual Art and Design by B - creating a unique solution for a basic visual art or design problem.

Nat'l Visual Arts Standard - VA:Cr1.1.4a -Brainstorm multiple approaches to a creative art or design problem. 
Objective 2: Create a free-standing, scale model of their chair design that is structurally sound using chipboard, masking tape, wire, and popsicle sticks.

RI GSE: VAD 1 (3-4) - 2 Students demonstrate knowledge and skill of media, tools, techniques, and processes of Visual Art and Design by A, identifying and using media, tools, techniques, and processes with basic skill, while creating two- and three- dimensional works of art and design.

Nat'l Visual Arts Standard - Va: Cr2.1.4a - Explore and invent art-making techniques and approaches.

Objective 3: Reflect both in-process through peer discussion, and on their final chair model through a self-reflective paragraph on the strengths and weaknesses of their chair, and what they might do differently to improve their design on a future model.

RI GSE: VAD 4 - 2 Students reflect upon, analyze, and evaluate the work of self and others by contributing in individual or group discussions about work in which the student gives and receives constructive criticism.

Nat'l Visual Arts Standard - Va: Cr3.1.4a - Revise artwork in progress on the basis of insights gained through peer discussion.

\section{Evaluation:}

1. Students will be evaluated using a rubric on based how deeply they explored the possibilities of their chair design. This will be measured in a number of ways. First, how many sketches the student creates, the more sketches is an indicator of deeper exploration. Second, I will look at the detail in the sketches as more detail shows student thinking. Third, I will look at the uniqueness in their incorporation of the letter.

2. Students will be evaluated using a rubric on how sturdy their chair model is. The criteria will be whether the chair can stand on its own or not, and if the chair moves or wobbles when it is standing. The goal will be to build a sturdy chair model, using chipboard, masking tape, wire, and popsicle sticks, without, compromising the design of the chair.

3. Students will be evaluated using a rubric on how descriptive they were in their self-evaluation, and how well they explained their reasoning and ideas for improvement as well as their reasoning for success in different areas.

\section{Essential Questions:}

1. How can you change a letter by adding or subtracting to it to create a chair?

2. How can you use the materials to create a stable chair in a unique way? For example, what kinds of bends and folds can you create with wire and chipboard?

3. How can you express an emotion with your using the elements of line, shape, space, color, and form? For example, ask yourself: "How can I used line to make my chair design reveal happiness?", or "What kind of shape might represent the word 'sturdy"'?

\section{Your Personal Stake}

I will tell students that I did furniture design as my undergraduate degree and worked as a furniture designer for years before coming back to teaching. 
Art Supplies and Equipment Needed - and any Safety Considerations:

Masking tape

Model Magic

18G Wire cut to 12-inch lengths - For safety I will bend the tips of this wire back on themselves to prevent it scratching or poking someone, and I will tell students they need to work with the wire bending it on the table so it is not near other students' eyes.

\section{Chipboard cut to 8-inch $\mathrm{x}$ 8-inch squares}

Popsicle sticks

Drawing Paper

Tempera paint

Manila Paper $18 \times 24$

Paint brushes

Scissors

Pencils

Erasers

Rulers

Exemplary Artworks Focused Upon and Visuals:

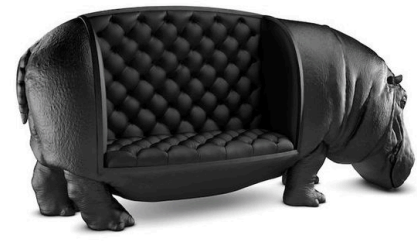

Maximo Riera - Series of animal chairs

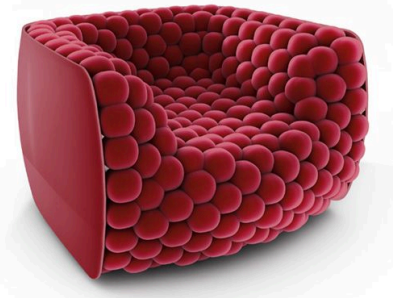

Carlo Colombo Blueberry's Armchair

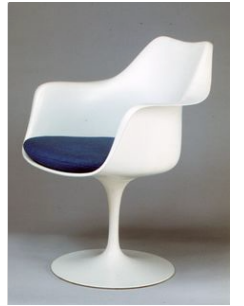

Eero Saarinen, Tulip ArmChair

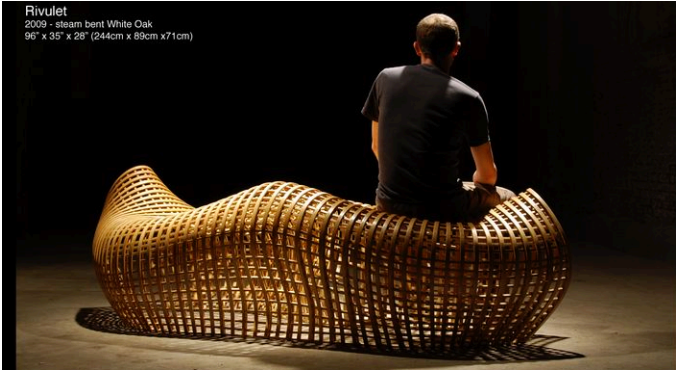

Matthias Pliessnig, Rivulet

Diversity of Art Content:

Non-Fine artists (designers) 


\section{Interdisciplinary Connections}

Connection to Math through measurement and scale.

Common Core Grade 4 Mathematics Content Emphasis for Measurement \& Data -Solve problems involving measurement and conversion of measurements from a larger unit to a smaller unit.

Students will be making models for their chairs that are $1 / 6^{\text {th }}$ the size of an actual chair. When creating the model structure, we will discuss the average chair seat height (18 inches) and the average chair back height (36 inches) and talk about how we need to build it smaller but still in the same scale so the proportions will be the same if their chair went into large-scale production. As a class I will ask them what $1 / 6^{\text {th }}$ scale would mean for these numbers, and we would divide the average chair heights by 6 to get the measurements for their models. They will use these measurements to base their chair structure on as they build.

\section{Art Vocabulary and Definitions:}

Scale Model - Artists and designers make scale models to help them understand how they will make a final design or artwork. They may also show models to clients if they are making this piece for someone. A model is usually a small scale 3 dimensional representation of a 3 dimensional sculpture or object an artist or designer creates. The models we create will be $1 / 6^{\text {th }}$ the size of an actual chair, this is the chair's scale.

Brainstorm Sketch - Artist and designers often brainstorm their ideas before making their final piece to help them be creative and come up with the best solutions. A brainstorm sketch is like brainstorming words, but it is with pictures. These sketches can be messy, and they can also be labeled. A brainstorm sketch is for the artist or designer to help get them thinking.

\section{Preparation Before Teaching:}

Make copies of brainstorm sketch example sheets

Make copies of letter example sheets (both straight and italicized)

Cut pieces of wire for students and bend back edges

Cut cardboard into smaller pieces for ease to work with

Divide up model magic into 1inch cubed amounts

\section{Introductory Activity and any Pre-Assessment:}

\section{Class 1}

(20-25 min) I will introduce this lesson through a PowerPoint presentation on chair design. I will begin a class discussion with students based on the chair designs in the PowerPoint in through questioning like:

What are some words you would use to describe this chair? What is an element or principle of design you see in this chair? Why would the designer create a chair that looked like this? Based on what you see, what kind of person might this chair be for and where would they use it?

\section{How would this chair feel to sit in?}

(15-20 min) I will give them their design challenge, to create a chair design and build a model of it based on a letter of the alphabet. I will show students examples I created of different sketches and models of chairs that are made with the same materials that they will use. I will ask them what ideas they have of how to make a letter into a chair, and invite students with ideas up to the board to draw what they might do. We will talk as a class about what students draw, and what other ways we could change a letter into the chair. 
I will ask students what they think would make a good chair design (using the examples). I will have the class come up with a list of criteria for a good chair design based on my objectives and I will write the list we come up with as a class on a sheet titled "Letter Chair Criteria" that will hang at the front of the class throughout the lessons.

\section{Art Lesson Activity and Formative Assessment:}

\section{Class 2}

(30 min) I question the students about what they remember about the letter chair project. We will go over the criteria of a good chair again, and remind them to think of how their chairs will balance. I will have students fold their drawing paper in half 2-times making 4 squares on each side for them to draw sketches. We will talk about brainstorm sketching, as defined above, and how it is to help them think of ideas. I will show examples of my sketches and an example sheet of other designers' sketches to show what they can look like. Students will then be asked to draw 4 or more ideas for their chair. They must try 2 different letters or letter styles in their sketches, and I will hand out sheets with example of straight letters and more stylized letters to help them think. They will draw these designs with pencil on paper, and they can use colored pencil to add color. Halfway through this time I will have students put their pencils down, push in their chairs, and without talking or commenting walk around the class to look at other students work for inspiration and ideas.

(10 min) At the end of class, students will turn to the students next to them, and using whisper voices, share their design ideas with each other. The partners will be asked what designs they like the most. The designers will then be told to take their partners advice into consideration when picking which chair they will model. They will then choose one design and draw it from the front and side view to model. *Note depending on how long they have been sketching in this class, I may or may not choose to do the turn and talk at the end of class 2 . Instead, I may have students identify in writing 1 place they are having trouble with their designs and 1 place they are feeling very confident.

\section{Class 3}

In the beginning of class I will have students finish up their final sketches. Then students will begin to build their chair structure out of wire, cardboard, popsicle sticks, and masking tape.

(15 - 20+ min) I will demo different ways to fold the cardboard, bend the wire, and attach the materials together to create strong forms. I will focus on showing rolling and bending cardboard, showing how much tape to use to keep the cardboard together, demoing how to mark and bend the wire, and how to test balance.

The rest of class students will create their structures while I walk around working one on one with students.

\section{Class 4}

If the students have created their chair structure, I will move on to model magic, if they are still working I will decide how much longer they need, and refresh their knowledge on how to create the structures.

In this class students will add more dimension and organic shapes as well as any upholstery or cushions to their form with model magic. They will add texture to the forms using popsicle sticks and pencils depressing into the model magic.

(10 - $15 \mathrm{~min}$ ) I will do a demo on how to roll out, cut, texture, and form model magic in different ways to add to the structure students create. I will focus on how to create rounded, flat and textured surfaces.

Students will work on their model magic additions until the end of class 


\section{Class 5}

(10 min) I will demonstrate how to paint the chair in different ways.

Students will work on painting their chairs for the rest of class.

\section{Closure and Summative Assessment:}

\section{Class 5 (or possibly part of 6)}

Students will write a self-reflection on their chair models. They will be asked to write $4-5$ sentences on what they like about their chair, and why; and how they would change it if they were going to produce the chair, and why.

\section{Clean-up Procedures:}

Building materials will be stored in shoeboxes

Chairs will be stored in shoeboxes while in progress

Paintbrushes will be put in water to soak at the end of class.

Accommodations for Students with Special Needs: (plan accommodations for 2-3 specific special needs)

There are two students that need slight accommodation in this class but because this school is one that my cooperating teacher and I visit only once a week, we do not have access to these students' IEPs if they exist. However, my cooperating teacher informed me of the needs of these students based on her observation, which is what my accommodations are based on as well.

1) One student has trouble staying on task, she often gets up out of her seat to talk to the teacher or myself. She is very capable, but has trouble staying focused. To accommodate and help keep her focused this student is seated at a desk near the front of the classroom separated from other students. The lesson criteria poster will also help for me to point out and for this student to reference when I see she is off task.

2) Another student has some trouble with motor skill based tasks though he is very focused and has good ideas. For the brainstorming sketches this student will be able to reference the letter style sheets for ideas and structure for his drawings. He will also be able to utilize labels and words for clarity of ideas. When working on the modeling segment of this lesson, I will work one-on-one with him as needed to assess and accommodate the materials and tools we are using as needed. Some possibilities include holding parts of his model so he can use both hands to work at times, and individual instruction on tool usage.

\section{Unit Connection:}

This lesson could be the first in a series of lessons thinking about product design.

\section{Resources for Art Content and Interdisciplinary Information:}

1. 1000 Chairs, Charlotte \& Peter Fiell, 2000

2. A Century of Chair Design, Editor Frank Russell, 1980

3. http://www.notcot.org/ - contemporary design website

4. http://www.cooperhewitt.org/ - Cooper Hewitt Museum website 


\section{APPENDIX J: WALLPAPER DESIGN UNIT}

\section{FIRST LESSON IN WALLPAPER DESIGN UNIT:}

\section{Art Lesson Title: Creating Mood in Interior Spaces}

Art Theme: Art is about Responding to Life Experiences.

\section{Overarching Lesson Goal(s):}

The goal of this lesson is to get students thinking about what visual things affect how a room feels, focusing on the walls of a room. To accomplish this, the lesson is designed to have students analyze both rooms they have experienced as well as images of wallpaper, and discuss what visual elements portray mood or emotion. Students will show their understanding through discussion as well as an individual brainstorm activity.

\section{Overview:}

Students will be given a reflection sheet that asks them to think about two interior spaces that have an impact on their mood. They will take a few minutes (10-15) to reflect on this place and what visual aspects contribute to the creation of a mood. Upon completing this reflection students will be invited to share what place they chose, and what visual things make up the mood or feeling of this space.

Then, students will be introduced to various kinds of wallpaper design through a PowerPoint. The class will be asked questions about what they see such as "what kind of room would this wallpaper be in, why?"; "how would this wallpaper make the room feel?"; and "what visual elements contribute to this mood?" The class will discuss the wallpaper, and I will focus on discussing the colors, patterns, negative/positive space and subject matter in the wallpaper.

After the PowerPoint, students will be asked to brainstorm and sketch ideas for wallpaper that gives a room a mood. They may choose their favorite interior space that they wrote about above, or they may chose another room. The worksheet will ask them to sketch 3 different ideas (though they have 6 spaces to explore) and explain what mood they are trying to create and how they have created it.

Grade Level/Class: ART 1 Grades 9-11 and why this lesson is a good match for these students: This lesson is a good match for these groups of ART 1 students in particular because these students are part of a STEAM initiative class, in which they learn about process thinking for creating art, design, and engineering. The lesson focuses on the first steps of the design process, to defining the problem and beginning to research and ideate. This lesson is part of a unit that will continue with the process where students will create a final prototype of their wallpaper design. Additionally, this lesson allows students to solve the problem in a way that can express their individuality and identity, which is important for an age group that is often focused on learning about and defining themselves as young adults.

Time Frame: 1 - 83 minute class

\section{Art Lesson Objectives:}

As a result of the instruction, students will:

Objective 1: Reflect individually on how visual aspects of two interior spaces affected the mood or feeling of these spaces.

RIGSE- VAD 4 (9-12) -1- A) Describing subject matter, media, techniques, processes, craftsmanship and relevant visual arts concepts seen in a work of art or design. 
Nat'I Visual Arts Standard - HS Accomplished VA: Re7. 1.Ila - Recognize and describe personal aesthetic and empathetic responses to the natural world and constructed environments.

Objective 2: Analyze wallpaper designs presented in a PowerPoint during a group discussion focused on thinking about how colors, patterns, negative/positive space and subject matter create or affect the mood of a room.

RIGSE VAD 2 (9-12) -1 - A) Evaluating several unique purposes for making visual art and design (e.g., telling a story; communicating ideas, personal beliefs, and emotions; creating functional objects; making political and social commentary).

Nat'I Visual Arts Standard - HS Proficient VA:Re 7.2.la - Analyze how one's understanding of the world is affected by experiencing visual imagery.

Objective 3: Create 3 sketches for wallpaper designs that create a mood using the elements and principles of design.

RIGSE - VAD 1 (9-12) - 1- A) Applying a variety of selected VAD concepts for two- and threedimensional works of art and interpreting and evaluating the effects.

Nat'I Visual Arts Standard HS Proficient - VA:Cr 1.2.la - Shape an artistic investigation of an aspect of present-day life using a contemporary practice of art or design.

Evaluation: (correlated with above art lesson objectives to measure student learning related to each objective)

Rubric (attached)

Essential Questions: (Throughout this lesson plan, add in italics or underline several Essential Questions that you will ask students while teaching this lesson. These are open-ended questions with no "one right answer" that promote critical thinking and problem solving. Identify your three most important Essential Questions here.)

How can the visual qualities of a room affect the way a room feels to be in? How can the elements and principles of design be used to create mood or emotion? How can wallpaper design affect the mood or feeling of a room?

\section{Your Personal Stake}

None

Art Supplies and Equipment Needed - and any Safety Considerations:

Pencils

Colored Pencils

Worksheets (on computer paper)

Projector

Exemplary Artworks Focused Upon and Visuals: (preferably insert thumbnails as well as noting titles!)

Below are a few examples of the artists designers I will discuss. For a more detailed look at the exemplar designs please look at the included PowerPoint. 


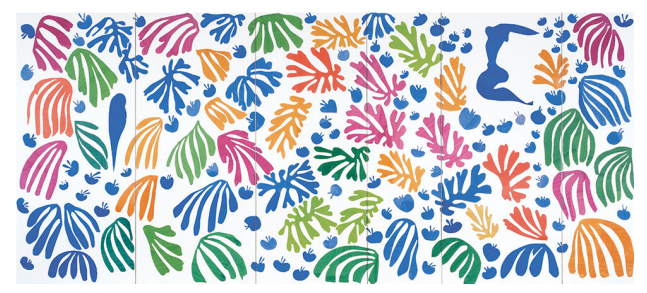

Matisse, The Parakeet and the Mermaid



William Morris, Pimpernel Floral Design



Cole and Son, Theme \& Variation

\section{Diversity of Art Content:}

The focus of wallpaper design, rather than fine art. Additionally, the designers are both male and female, and from a variety of backgrounds.

\section{Interdisciplinary Connections}

Focus on process thinking, something that these students are learning about in their science, math, technology, and engineering courses.

\section{Art Vocabulary and Definitions:}

Repeating Pattern: A pattern that repeats, it may be something small that repeats over and over like polka dots or strips, or it might be a more elaborate patter (see wallpaper examples).

Wallpaper: Paper with decorative patterns often in many colors that can be pasted on walls. Mood: A distinctive emotional quality or character.

Brainstorm Sketch: Sketching to help you think of ideas. The craftsmanship of these types of sketches is often (but not always) loose and "sketchy," however, sometimes designers choose to draw more detailed to figure out an idea or specific part of something they are designing.

\section{Preparation Before Teaching: \\ Copy intro reflection \\ Copy brainstorm sheet \\ Test PowerPoint}

\section{Introductory Activity and any Pre-Assessment:}

10-15 min intro - When students enter the room, they will be given a reflection sheet that asks them to think about two of their favorite interior places. Individually, students will write their reflections about these spaces on the sheet. They will be asked to think about what visual aspects make them like the spaces they choose. Students will have $10-15$ minutes to complete these reflections. 
5 - 10 min discussion - Upon completing this reflection students, will be invited to share what place they chose, and what visual things make them like this specific place. This discussion will prepare students to discuss the wallpaper in the PowerPoint to follow.

\section{Art Lesson Activity and Formative Assessment:}

20 - 30 min discussion - Students will be introduced to various kinds of wallpaper design through a PowerPoint. The class will be asked questions about what they see such as:

What kind of room would this wallpaper be in, why?

How would this wallpaper make the room feel?

What visual elements contribute to this mood?

What elements and principles of design did the designer use when making this wallpaper?

How do these elements and principles of design affect the mood of the wallpaper?

The class will discuss the wallpaper, and I will focus on having students address the colors, patterns, negative/positive space and subject matter in the wallpaper.

\section{Closure and Summative Assessment:}

20 - 30 min sketching - After the PowerPoint, students will be asked to brainstorm and sketch ideas for wallpaper that gives a room a mood. They may choose their favorite interior space that they reflected on, or they may chose another room. The worksheet will ask them to sketch 3 different ideas and explain what mood they are trying to create and how they have created it using different elements and principles of design. Students may sketch with pen or pencil and use colored pencil or marker to add color.

\section{Accommodations for Students with Special Needs:}

There are no students with special needs in either Art 1 course, and thus there would be no accommodations. However, I will differentiate my instruction on a case-by-case basis by consulting with students and helping them individualize their experience with this lesson.

If I did have students with special needs in my class below are some options for accommodation:

1) Student that has trouble hearing - I would sit them closer to the front of the room to they could better hear the instruction and include my key questions written in the presentation (instead of just vocalized) to help include these students in the discussion. I may also give them the option of providing a written response to questions.

2) Student with low control over fine motor skills - I would give this student options in this project. For any written reflection portion they would have the option to use a computer to write, or respond verbally to me in a one-on-one discussion. I would also give these students an option of designing their wallpaper or sketching digitally, where they could use images they found to express their brainstorm sketches.

\section{Unit Connection:}

This lesson is the first of 3 lessons on designing wallpaper to create a mood or emotion in a room. This is the introductory lesson to get students thinking about how they can use elements and principles of design to create mood or emotion. The sketches they create in this lesson will drive a visual research process and then the creation of a final wallpaper design that they will prototype. 


\section{SECOND LESSON IN WALLPAPER DESIGN UNIT:}

\section{Art Lesson Title: Creating an Inspiration Board and Sketches}

Art Theme: Art is about Communicating a Message

\section{Overarching Lesson Goal(s):}

The goal of this lesson is to have students practice visual research and idea presentation through an inspiration board and sketches that they will compile and present for critique to the class. The main purpose of this presentation and critique will be for students to practice presenting ideas, critiquing other students, and taking criticism into account when designing.

\section{Overview:}

Students will be introduced to the idea of creating an inspiration board through a quick PowerPoint presentation and discussion where I will show different examples of artists and designers that created inspiration boards.

Students will be given the assignment objectives and criteria and use their brainstorm drawing sheets which they created in the intro to this unit as a starting point for further exploration. Students will be able to look at magazines to clip images, do research in the library, or research online. They will be given 2 class periods to create their boards and 3 sketches for their repeating patterns of wallpaper.

When the boards have been completed, in the beginning of the $3^{\text {rd }}$ class period, we will have an in-process critique of student work. Students will present the ideas they have for their wallpaper design to the class, and the class will give feedback about what ideas they like most.

Students will then take the feedback into account and write a short statement about what they will change for their final wallpaper design.

Grade Level/Class: ART 1 Grades 9-11 and why this lesson is a good match for these students: This lesson is a good match for these groups of ART 1 students in particular because these students are part of a STEAM initiative class, in which they learn about process thinking for creating art, design, engineering, and so on. The lesson focuses on the first steps of the design process, to defining the problem and beginning to research and ideate. This lesson is part of a unit that will continue with the process where students will create a final prototype of their wallpaper design. Additionally, this lesson allows students to solve the problem in a way that can express their individuality and identity, which is important for an age group that is often focused on learning about and defining themselves as young adults.

Time Frame: $2.5-83$ minute class

Art Lesson Objectives:

As a result of the instruction, students will:

Objective 1: Create a plan for 3 wallpaper designs that incorporates both sketches and collected images on an inspiration board to display inspiration for color, pattern, and subject matter (or color and two other elements and principles of design that they choose).

RIGSE VAD 1 (9-12) B. Generating, applying, revising, and evaluating strategies and techniques to address artistic problems.

Nat'I Visual Arts Standard - HS Accomplished VA:Cr1.2. lla: Choose from a range of materials and methods of traditional and contemporary artistic practices to plan works of art and design. 
Objective 2: Present 3 ideas for wallpaper designs that create a mood/emotion/feeling (ideas may be similar or different from each other) in a 5-minute class presentation using their sketches and images collected on inspiration board.

RIGSE- VAD 3 (9-12) -1 B. Creating a unique solution for a visual art or design problem.

Nat'I Visual Arts Standard - VA: Pr6. 1. Illa: Curate a collection of objects, artifacts, or artwork to impart the viewer's understanding of social, cultural and/or political experiences.

Objective 3: Analyze their own wallpaper designs plans, and the work of their peers through class discussion based on the effectiveness of color, pattern, and subject matter to create a mood.

RIGSE - VAD 4 (9-12) -1 E. Contributing in individual or group discussions about work in which the student gives and receives constructive criticism.

Nat'I Visual Arts Standard HS Proficient - VA: Re7. 2. IIA. Evaluated the effectiveness of an image or images to influence ideas, feelings, and behaviors of specific audiences.

Evaluation: (correlated with above art lesson objectives to measure student learning related to each objective)

Rubric (attached)

Essential Questions: (Throughout this lesson plan, add in italics or underline several Essential Questions that you will ask students while teaching this lesson. These are open-ended questions with no "one right answer" that promote critical thinking and problem solving. Identify your three most important Essential Questions here.)

How can you combine found images together to plan unique designs?

How can you use the elements and principles of design to create a mood or emotion?

How can you present your ideas clearly to the class to display how your collected images connect to your sketches?

\title{
Your Personal Stake
}

I will bring in some inspiration boards I created, and another design I know created for past design projects.

\author{
Art Supplies and Equipment Needed - and any Safety Considerations: \\ Card Board \\ Glue \\ Magazines \\ Drawing Paper
}


Exemplary Artworks Focused Upon and Visuals: (preferably insert thumbnails as well as noting titles!)
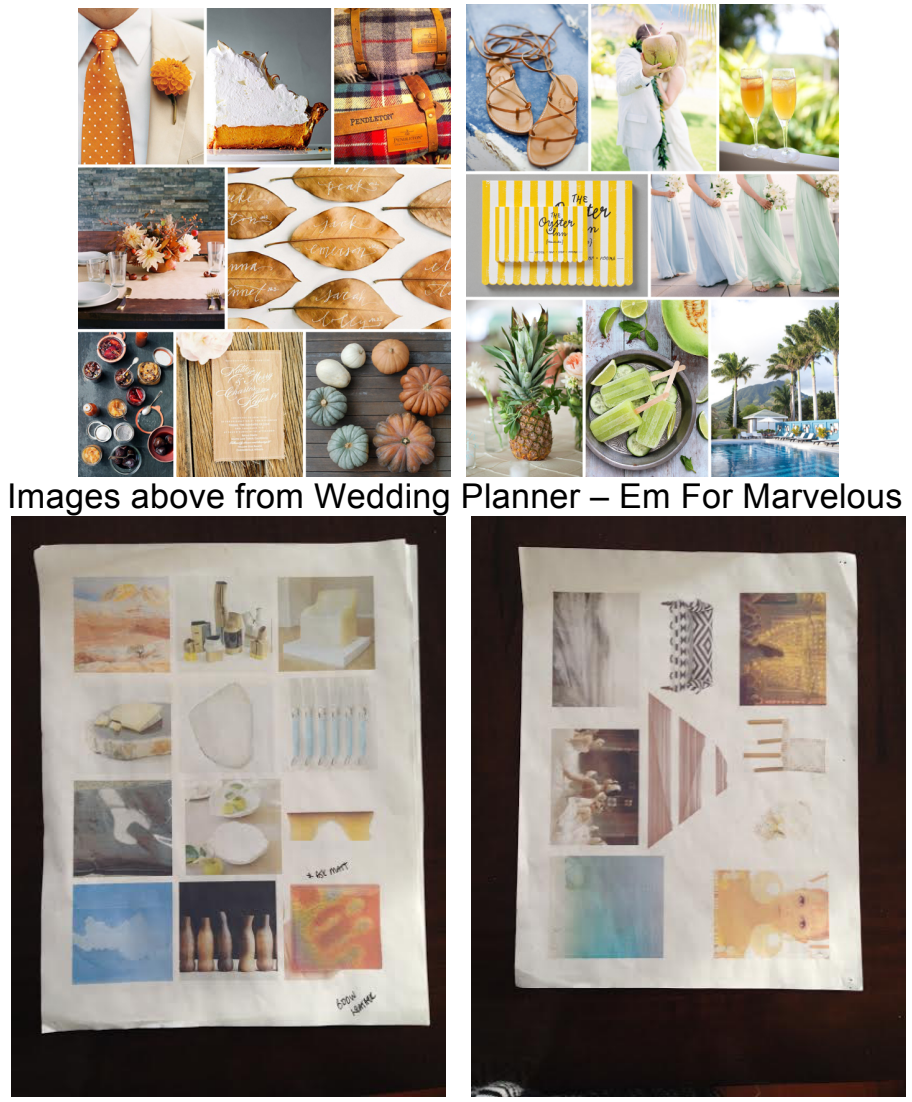

Images above are inspiration boards I created for furniture projects. I also have a few other inspiration boards from some free-lance designers in the area.

\section{Diversity of Art Content:}

The designers are both male and female, and from a variety of backgrounds.

\section{Interdisciplinary Connections}

STEAM (Science, technology, engineering, art, math): Focus on process thinking, something that these students are learning about in their science, math, technology, and engineering courses.

\section{Art Vocabulary and Definitions:}

Inspiration Board: A collection of found images, either digital or physical, with the purpose of designing a specific project. These images are used as references for designing and visual research. Words my also be used on an inspiration board.

Critique: In a critique usually there is a presenter and an audience. The presenter with show and talk about their ideas or a project they created. The audience will give feedback to the presenter about what they think works about the project and why, ask questions, and suggest changes to the presenter or other areas they should investigate. A critique is meant to be a constructive discussion, not an assessment of work created. 
Preliminary Sketches: Preliminary sketches are a step more finished than brainstorm sketches, they are usually more defined and created with a purpose. However, these sketches can still be loose representations of ideas. They may depict (in this assignment) specific patterns, as well as a visual of how the pattern would look in a room, or over a whole wall. They may be colored or black and white.

\section{Preparation Before Teaching: \\ Copies of assignment criteria \\ Test power point \\ Copies of critique reflection}

\section{Introductory Activity and any Pre-Assessment:}

Class 1-10-15 min: The class will look at both physical inspiration boards (I will bring in some examples from my own + another designer's boards) and some digital through a PowerPoint. We will also discuss how Pinterest may be used as an inspiration board. I will ask questions about the boards, we will discuss how one could take parts of different images and create a new design inspired by the ones on the boards. I will ask students to describe what kind of colors and patterns they would use if they were given the board or what other elements and principles of design they may include. I will also discuss that often designers are given company made boards already created and create artworks or designs based on this.

\section{Art Lesson Activity and Formative Assessment:}

Class 1- 60-70 min: Students will use brainstorm sketches as starting point, and will research visual ideas through, sketching, clipping images, research in library, create an inspiration board and sketches of ideas for their wallpaper designs that create a specific mood/emotion/feeling. I will do formative assessment with students as they work through one-on-one monitoring throughout the room.

Class 2-30-40 min: Students will work on completing their sketches and boards for the presentation. I will work with students individually to help them with these projects.

\section{Closure and Summative Assessment:}

Class 2 (or 3) - 30- 40 min: Students will participate in a group critique of their 3-5-min for each student to speak. Then the class will provide constructive criticism about what designs are more effective in portraying an emotion. The students will present in random order line up that I create, the student that is next in line will take notes for the student presenting.

10-15 min: At the end of the whole critique students will be asked to individually reflect and take the comments into account in a short paragraph about their plans for their final project.

\section{Accommodations for Students with Special Needs:}

In both Art 1 courses I teach there are no students with special needs or IEP plans. I will differentiate my instruction on a case-by-case basis and assess how the students are understanding the lesson as we are working.

Below are some examples of how I would make accommodations for this lesson in the future:

1) Visual impairment - I would give student preferential seating, and also pass around physical examples to make sure they can see everything clearly.

2) Student with behavioral needs - I would treat the needs of this student on a case-by-case basis and provide them with choices in how they wished to work on the project.

\section{Unit Connection:}

This is the second lesson in a unit of 3 lessons on designing wallpaper to create a mood or emotion in a room. This lesson focuses on the planning stage of the student's designs. Students will create inspiration boards and sketches that will drive their final designs, they will also receive feedback from peers, which they can consider when creating their final prototype. 


\section{THIRD LESSON IN WALLPAPER DESIGN UNIT: Art Lesson Title: Creating A Prototype}

Art Theme: Art is about Communicating a Message

\section{Overarching Lesson Goal(s):}

The goal of this lesson is to have students create and present a final prototype of a wallpaper design that would create a mood/emotion/feeling for a room. The presentation will include the process of making (the inspiration boards and sketches), a final color design of the section of the pattern that fits on an 81/2" x 11" paper, and a mock-wall where black and white copies are made and then connected to create the effect of wallpaper.

\section{Overview:}

Students will use the feedback they have received from their classmates from their inspiration board and sketches in the previous lesson to revise their ideas and create a final painted (or their choice of medium) prototype of a repeating design that conveys an emotion $/ \mathrm{mood} / \mathrm{feeling}$. The design constraint will be that they need to put their design on an 81/2" $\times 11$ " piece of paper (it does not have to fill the whole page), so that they can make copies to display how their pattern will repeat OR they must discuss with me how they plan to show their repeat if their pattern is larger (possibly manipulated in a digital format).

Students will work individually on their prototype for 2-3 class periods, and I will work with them one-on-one to trouble shoot any problems or individual needs.

When students have finished their designs, we will do a final presentation and critique / celebration where students display their process work and their large repeating pattern. The class will see each other's work and compare how students' designs solved the challenge differently, what students did well, and what they could consider for the future. Students will evaluate themselves through a written reflection.

Grade Level/Class: ART 1 Grades 9-11 and why this lesson is a good match for these students: This lesson is a good match for these groups of ART 1 students in particular because these students are part of a STEAM initiative class, in which they learn about process thinking for creating art, design, engineering, and so on. The lesson focuses on the final steps of the design process, where students create a final prototype of their design. The work will be based on the sketches, research, and inspiration boards they compiled in the first two lessons. Additionally, students will be creating designs that allow self-expression because they will be able to choose their mood/emotion/feeling and figure out how they personally can show this in their wallpaper design.

Time Frame: $4-5-83$ minute class

Art Lesson Objectives:

As a result of the instruction, students will:

Objective 1: Create a final color design of their wallpaper that portrays a mood/feeling/emotion which can be their choice of medium, they will also provide either a digital or printed version of their pattern in repeat.

RIGSE VAD 1 (9-12) B. Generating, applying, revising, and evaluating strategies and techniques to address artistic problems.

Nat'I Visual Arts Standard - HS Accomplished VA:Cr1.2. Ila: Choose from a range of materials and methods of traditional and contemporary artistic practices to plan works of art and design. 
Objective 2: Present their final idea and the process (sketches, inspiration boards, tests) that lead them to their design solution to the class.

RIGSE- VAD 1 (9-12) - 1, d: Documenting and evaluating personal progress through a portfolio of self-created art work identifying strengths and weaknesses.

Nat'I Visual Arts Standard - VA: Pr4 1.Ila: Analyze, select, and critique personal artwork for a collection or portfolio presentation.

Objective 3: Analyze their own wallpaper designs in a final reflection about what they felt was successful and what might change if they could do this project again.

RIGSE - VAD 4 (9-12) -1 E. Contributing in individual or group discussions about work in which the student gives and receives constructive criticism.

Nat'I Visual Arts Standard HS Proficient - VA: Re7. 2. IIA. Evaluated the effectiveness of an image or images to influence ideas, feelings, and behaviors of specific audiences.

Evaluation: (correlated with above art lesson objectives to measure student learning related to each objective)

Rubric (attached)

\section{Essential Questions:}

What will be the most effective medium for you to use to best create your final prototype?

How can you create an interesting design using repetition? (Is your design predictable or is the repeat hard to see? Why?)

How can you present your prototype and design process most effectively to the class?

How does the way you solved the design challenge relate and differ from your peers?

Art Supplies and Equipment Needed - and any Safety Considerations:

Possible:

Drawing Paper

Cardboard

Watercolor

Acrylic

Pencil

Pen

Eraser

\section{Exemplary Artworks Focused Upon and Visuals:}

See PowerPoint from lesson 1 of this unit

Diversity of Art Content: The designers are both male and female, and from a variety of backgrounds.

\section{Interdisciplinary Connections}

STEAM (Science, technology, engineering, art, math): Focus on process thinking, something that these students are learning about in their science, math, technology, and engineering courses.

\section{Art Vocabulary and Definitions:}

Final Prototype: A final prototype of a design can be functional but also still may be a mock-up or visual example of what the real product will be. For this project, the final prototype will be a 
mock-up both of the pattern (in the copied repeated pages) and the colors in a small colored section of the pattern. There is no capability to create real wallpaper, so these would serve as a visual of what the real life product would be.

Critique: In a critique usually there is a presenter and an audience. The presenter with show and talk about their ideas or a project they created. The audience will give feedback to the presenter about what they think works about the project and why, ask questions, and suggest changes to the presenter or other areas they should investigate. A critique is meant to be a constructive discussion, not an assessment of work created.

\section{Preparation Before Teaching:}

Create copies of final criteria sheet

Create copies of in process critique reflection.

Create copies of final reflection sheet

\section{Introductory Activity and any Pre-Assessment:}

Class 1-10 min: I will have a conversation with the class to ask them how they might use the reflection and feedback they received from the inspiration board and preliminary sketches presentation to focus their final project. I will ask them describing how they will take their feedback and their own thoughts into consideration to make their final prototype on the worksheet attached. This will also ask students to list the steps they need to accomplish to finish their project. Students may create a sketch of their final idea before the start their final prototype, but that they do not have to.

\section{Art Lesson Activity and Formative Assessment:}

Class 1- 60-70 min: Students will work on their final sketch or final prototype. I will meet oneon-one with students to discuss their plan of action as they begin their final. After this I will work one-on-one to help them choose a media to work with and trouble shoot any problems they are having.

Class $2+3$ : Students will work on their final sketch or final prototype. I will work with students one-on-one to help them choose a media to work with and trouble shoot any problems they are having.

Depending on how fast students work, I may be making copies of their prototype to make the large pattern, or be taking photos to make a digital pattern.

Class $3+4$ : Students need to finish their prototype during this class, so they will be working the majority of the class. I will be copying their work and taking photos to make a mock-wallpaper

display. If students finish during this class with enough time they will move on to the closure and summative assessment activity.

\section{Closure and Summative Assessment:}

Class 4 OR 5 30- 40 min: Students will participate in a group critique of their 3-5-min for each student to speak. Each student will display the process of their design, the final prototype, and a section of the repeat patter (we will set these up around the room). Then the class will compare the work of their peers to their own in how each student solved the problem of creating a mood with the pattern. We will also have time for positive feedback and thoughts for the future in these discussions.

Class 4 OR 5 10-20 min: Students will fill out a final reflection on the whole project (attached), and also evaluate their work using an evaluation form (attached).

\section{Accommodations for Students with Special Needs:}


In both Art 1 courses I teach there are no students with special needs or IEP plans. I will differentiate my instruction on a case-by-case basis and assess how the students understand the lesson as we are working.

Below are some examples of how I would make accommodations for this lesson in the future:

1) Visual impairment - I would give student preferential seating, and also pass around physical examples to make sure they can see everything clearly.

2) Student with behavioral needs - I would treat the needs of this student on a case-by-case basis and provide them with choices in how they wished to work on the project.

\section{Unit Connection:}

This is the final lesson in a unit on using the design process to. This is the introductory lesson to get students thinking about how they can use elements and principles of design to create mood or emotion. The sketches they create in this lesson will drive a visual research process and then the creation of a final wallpaper design that they will prototype.

Resources for Art Content and Interdisciplinary Information: (minimum of 2 quality art books $\& 2$ websites)

1. William Morris Full-Color Patterns and Designs (Dover Pictorial Archive), William Morris

2. Modern Wallpaper \& Wallcoverings: Introducing Color, Pattern \& Texture into your Living Space, Alice Whately

3. Design Sponge (Designsponge.com) - various contemporary wallpaper examples

4. Design Milk (Design-milk.com) - various contemporary wallpaper examples 


\title{
APPENDIX K: LIGHTING DESIGN LESSON
}

\section{Art Lesson Title: Lighting Design}

\author{
Art Theme: Art is about Making the Ordinary Extraordinary
}

\section{Overarching Lesson Goal(s):}

The goal of this lesson is to have students design and create a prototype for a hanging or tabletop light with one light source out of a variety of recycled material. The students will be engaged in the design process, and will learn how to problem solve and use the elements and principles of design to manipulate the way the light shines through the materials.

\section{Overview:}

Students will be introduced to lighting designs through a PowerPoint presentation and discussion. They will be exposed to multiple kinds of lighting, and asked questions about what they think is interesting or successful about the lights, how the designer manipulated the light to make an interesting sculpture, and how the designer used the elements and principles to create their design.

Then students will create at least four sketches of design ideas for lights. Once students have sketched at least four ideas they will create small models of two of their sketches out of paper (or one model and one material test). As students finish these models they will try their models on different sized lights to see how the light affects their design. I will orchestrate the people looking at their models, and try to have groups of students looking at models at the same time so that they can compare one student to the other. This will depend a bit on the pacing of the class.

Once they have decided on their final they may either go straight into building the final prototype or create a final sketch before building if they decided to change something about their design. Students will work on their final project, the light that they will display their final design on will be available in the room for students to test their light on. When all the lights are done we will have a class critique where we look at the lights with a light bulb.

After the final critique, students will individually assess and reflect on their project.

Grade Level/Class: Sculpture Grades 9-12 and why this lesson is a good match for these students: This group of students have done a number of sculptures that are relatively unplanned, and primarily more fine art type of work. This lesson will expose these students to some product design, as well as a more planned out design. Students are familiar with the elements and principles of design at this point in the semester, so they should be able to understand and use these different elements in their designs. Additionally, the project is fairly open-ended and allows for much personal and individual interpretation. Students in this age group are continuing to explore their identities, and this lesson will allow them to further explore their personal preferences and ideas.

Time Frame: 5 OR 6- 83 minute class

\section{Art Lesson Objectives:}

As a result of the instruction, students will:

Objective 1: Create a final prototype of a design for a light shade that manipulates the light using selected elements or principles of design.

RIGSE- VAD 3 (9-12) -1 B. Creating a unique solution for a visual art or design problem. 
Nat'I Visual Arts Standard - HS Accomplished VA:Cr1.2. lla: Choose from a range of materials and methods of traditional and contemporary artistic practices to plan works of art and design.

Objective 2: Investigate multiple ideas for their lighting design through sketches, models, and tests.

RIGSE VAD 1 (9-12) B. Generating, applying, revising, and evaluating strategies and techniques to address artistic problems.

VA:Cr1. 2. la Shape an artistic investigation of an aspect of present-day life using a contemporary practice of art or design.

Objective 3: Analyze their own lighting designs both through written self-assessment, and ongoing assessment throughout the project.

RIGSE - VAD 4 (9-12) -1 E. Contributing in individual or group discussions about work in which the student gives and receives constructive criticism.

Nat'I Visual Arts Standard HS Proficient - VA: Re7. 2. IIA. Evaluated the effectiveness of an image or images to influence ideas, feelings, and behaviors of specific audiences.

\section{Evaluation:}

Rubric (attached) - Rubric draws from a rubric to assess creativity by Lars Lindstrom (2006).

\section{Essential Questions:}

How did the designers manipulate the light with the elements and principles of design? (ask during PowerPoint)

How can you use sketches and models to develop your ideas?

Why do we make models?

What is good craftsmanship?

\section{Your Personal Stake}

I have include some lighting that I have personally been a part of designing. I will talk a little about my involvement in that.

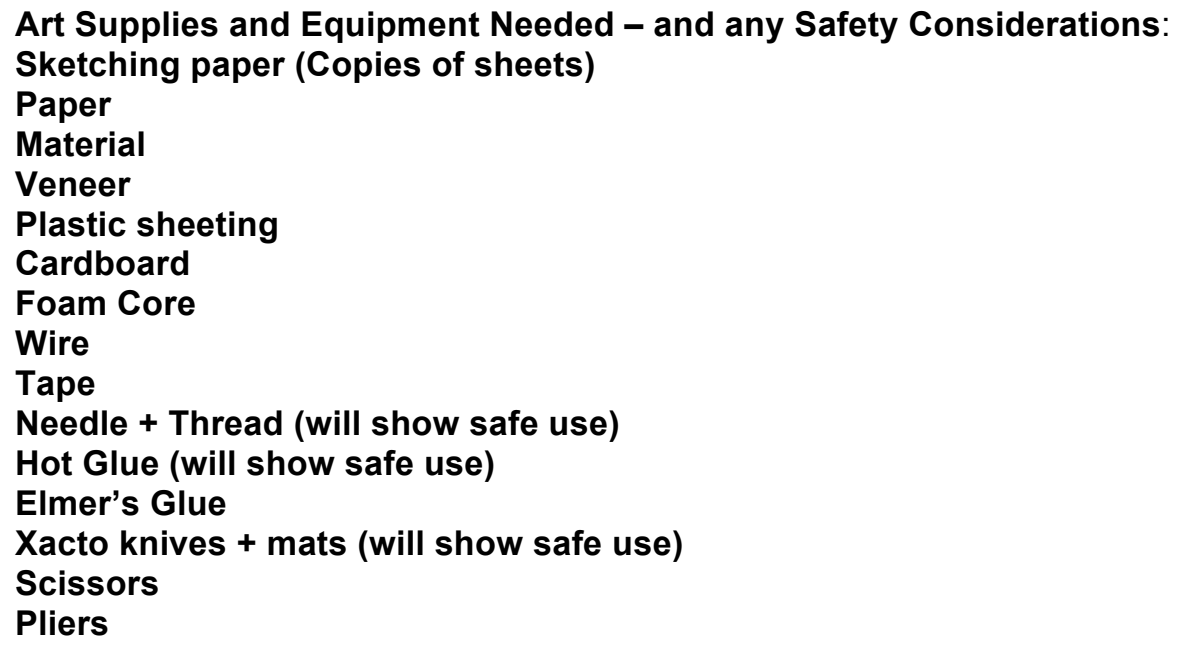


Exemplary Artworks Focused Upon and Visuals: (preferably insert thumbnails as well as noting titles!)
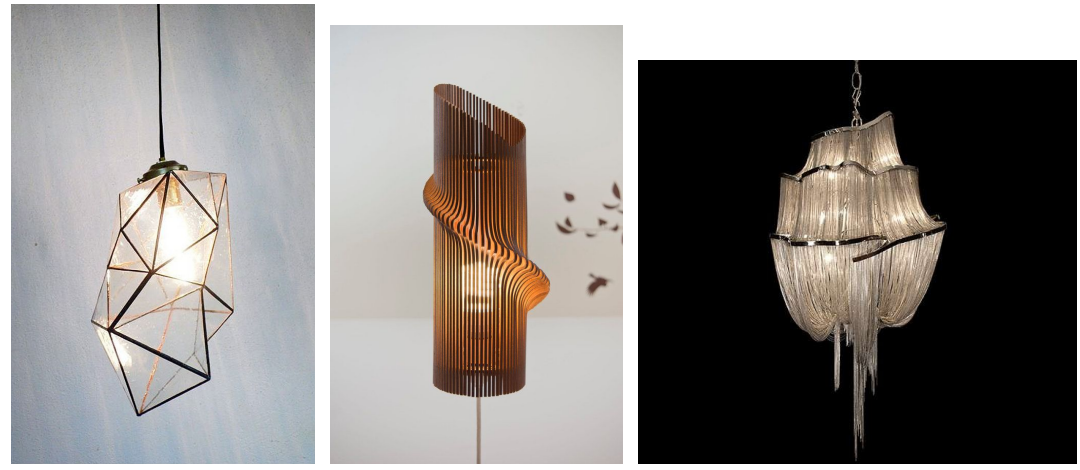

[Power point presentation developed to present additional exemplars]

Diversity of Art Content:

Designers, women and men, various cultural and racial backgrounds.

\section{Interdisciplinary Connections}

Connects with STEAM thinking, or process thinking.

\section{Art Vocabulary and Definitions:}

Model - Can be small or full scale, used to test ideas in less expensive material, or smaller amount of material. Used to see 3 dimensions of ideas.

Material Test - The trial of materials and how they will work with the making process the designer has planned. In this particular process, will be used to test how the materials work with light.

Craftsmanship - The execution of making an object or artwork. Craftsmanship is not just about being neat; it is about being intentional. This means that if the design calls for "messy" craftsmanship, it would still be considered "good" craftsmanship.

Final Prototype - A full-scale representation of your final piece, however it is not meant for sale or reproduction.

Preparation Before Teaching:

Copies of brainstorm sketch sheet.

Material Collection

Set up hanging and standing light

Test PowerPoint

Introductory Activity and any Pre-Assessment:

Class 1- 40 min: The class will look at a PowerPoint I have put together that shows different kinds of lighting design. I will question the class about how the designers manipulated the light, where they thought these lights might go (and why). The class will have a general discussion about what they see and what the lights are made out of (explaining why).

Art Lesson Activity and Formative Assessment:

Class 1-40min : Students will use brainstorm sketches as starting point at least 4 different ideas for their lighting design. I will work one-on-one with students to help them develop their ideas. 
Class 2 \& 3: I will lead a discussion on the purpose of making models. Then, students will actively test and model their light designs, and should create at least 2 models (or 1 model and one material test) before beginning their final design. Students will get to explore materials and making processes. Students will test their ideas on the lights, discuss with me and others, and finalize their final ideas.

Class 4 \& 5: I will lead a discussion about "good" craftsmanship and defining "craftsmanship." Students will execute their final prototypes, and I will work with students one-on-one with them helping and advising. They may also work together and help each other.

\section{Closure and Summative Assessment:}

Class 5 \& 6: As students finish their final prototypes they will be asked to answer the following questions in a written self-assessment:

1) How did you use the elements and principles to manipulate light, and did you do this successfully? (Explain why or why not):

2) What did you learn from making your models and tests? Did you like working in this way, making these models before making the final? (Explain why or why not):

\section{Accommodations for Students with Special Needs:}

One student has an IEP, which explains that he needs extra time on his projects. I will gauge his progress throughout the class and give him this extra time if necessary.

Another student needs help focusing because he has ADD, I will sit him in an area with less distractions, such as a table with fewer and quieter students.

Resources for Art Content and Interdisciplinary Information: (minimum of 2 quality art books \& 2 websites)

1. Lindström, L. (2006). Creativity: what is it? Can you assess it? Can it be taught? International Journal of Art and Design Education, 25(1) 53-66.

2. http://www.notcot.org/

3. https://studiodunn.com/

4. Daniel Pink (2006) A Whole New Mind 